\title{
Stepping Back Through the Looking Glass: Real Conversations with Real Disputants About Institutionalized Mediation and Its Value
}

\author{
NANCY A. WELSH* \\ TABLE OF CONTENTS
}

I. INTRODUCTION

II. SUCCESSFUL INSTITUTIONALIZATION, BUT ON THE INSTITUTIONS' TERMS.

III. SEEKING THE VOICES OF DISPUTANTS

IV. THE VOICES OF DISPUTANTS WITHIN SPECIAL EDUCATION MEDIATION
A. Research Methodology
B. The Specific Context of Special Education Mediation
C. Disputants' Expectations and Perceptions of Mediation's Value

1. Disputants' Pre-Mediation Perception 620

a. An Enhanced Opportunity to Be Heard-and to

Hear-in a Dignified, Thorough Process

b. An Enhanced Opportunity to Reach Resolution

2. Disputants' Post-Mediation Perceptions

a. Returning to the Importance of the Enhanced Opportunity to Be Heard-and to Hear-in a Dignified, Thorough Process.

b. Returning to the Importance of the Enhanced Opportunity to Reach Resolution....

3. The Value of Mediators' Facilitative Interventions.

4. The Value of Mediators' Evaluative Interventions.

5. Caucus: A Potent Tool for Enhancing or Diminishing Procedural Justice.

V. IMPLICATIONS AND PROPOSALS

A. Implications for Special Education Mediation.

B. Implications for the Broad Field of Mediation 662

VI. CONCLUSION

APPENDIX A.

APPENDIX B

APPENDIX C 678 


\section{INTRODUCTION}

A mere fifteen years ago, the term "mediation" was confused regularly with "meditation." Much has changed. ${ }^{1}$ Today, mediation is an integral part of the civil litigation system in both the state and federal courts. ${ }^{2}$ Many public agencies have also embraced the process to resolve disputes. ${ }^{3}$ In the private sector, corporations and other organizations increasingly provide for mediation in their contracts and initiate the process on an ad hoc basis. ${ }^{4}$

* Associate Professor of Law, The Dickinson School of Law of The Pennsylvania State University; B.A., magna cum laude, 1979, Allegheny College; J.D., Harvard Law School, 1982. I am tremendously grateful to Grace D'Alo for her insights, assistance, and friendship throughout this project, from inception to implementation to analysis. My thanks also go to Bob Ackerman, Lisa Bingham, Christopher Honeyman, John Lande, Bobbi McAdoo, Len Riskin, Donna Stienstra, Roselle Wissler, Andrea Schneider, and Julie Winterich for their very helpful comments and suggestions regarding earlier versions of this Article and to Donna Stienstra and Deborah Hensler for their assistance with the design of the underlying research project. I am also grateful to Jennifer Brown for her comments and the opportunity to present an early draft of the Article at the Quinnipiac-Yale Dispute Resolution Workshop. I also want to acknowledge: Geoff Sawyer, Charles Kawas, and especially Brian Ford for their research assistance, enthusiasm and diligence; the Pennsylvania Office of Dispute Resolution for its permission to conduct research regarding the special education mediation program; and The Dickinson School of Law of The Pennsylvania State University for the summer research stipend that supported this research. Finally and most importantly, I thank my husband, Eric Munck, and my sons for their support and understanding.

${ }^{1}$ But see Leonard L. Riskin, The Contemplative Lawyer: On the Potential Contributions of Mindfulness Meditation to Law Students, Lawyers, and Their Clients, 7 HARV. NEGOT. L. REV. 1 (2002) (in a somewhat ironic twist, Professor Riskin has suggested the relevance of mindfulness meditation to the practice of law and alternative dispute resolution).

2 See infra Part II.

3 These include disputes between agencies and private parties, among various agencies, and within individual agencies. See infra Part II.

${ }^{4}$ See Donald Lee Rome, Business Mediation's Orientation Focuses Detail on Printed Words, 21 Alternatives to High Cost LitiG. 21, 28-29 (2003) (advising regarding the drafting of mediation clauses); Kathleen M. Scanlon \& Adam Spiewak, Enforcement of Contract Clauses Providing for Mediation, 19 ALTERNATIVES TO HIGH COST LITIG. 1, 1-2 (2001) (summarizing case law and providing guidance regarding the drafting of enforceable mediation clauses); Robyn Mitchell et al., What Large Corporations Look for in Mediators/Arbitrators, A Panel of Corporate Professionals with Selection Capabilities at the Annual Conference of the American Bar Association Section of Dispute Resolution (Mar. 20, 2003) (describing contractual and ad hoc use of mediation at Bank of America, American Airlines, Coca-Cola Enterprises, and Shell International). 


\section{INSTITUTIONALIZED MEDLATION}

This period of successful institutionalization has given rise to demands for clarity and predictability regarding the mediation process. ${ }^{5}$ If courts, agencies, and corporations are encouraging and even requiring disputants to use mediation, then disputants should know what to expect. ${ }^{6}$ What is this process? What will the mediator do? What is the point of the process? The recently-approved Uniform Mediation Act represents one response to such demands for clarity. ${ }^{7}$ Other attempts to respond, however, have been markedly unsuccessful. Mediators have been unable to develop field-wide standards for mediator certification, a uniform mechanism for mediator evaluation or even clear ethical boundaries regarding mediators' provision of advice. ${ }^{8}$

These initiatives have been stymied by a lack of consensus regarding the goals, ${ }^{9}$ general approach, ${ }^{10}$ and mediator skills and behaviors that should

${ }^{5}$ Calls for predictability and accountability are to be expected as an innovative movement becomes institutionalized. See generally Robert Dingwall \& Kerry Kidd, After the Fall ... : Capitulating to the Routine in Professional Work, 108 PENN ST. L. REV. 67 (2003).

${ }^{6}$ See, e.g., Bobbi McAdoo, A Report to the Minnesota Supreme Court: The Impact of Rule 114 on Civil Litigation Practice in Minnesota, 25 HAMLINE L. REv. 401, 446 (2002) (recommending that the Minnesota ADR Review Board should adopt a strategy to educate clients and others about the differences between mediation and early neutral evaluation, in part because consumers "should be able to know what it is that they are choosing to use").

7 The definition of mediation was the subject of national debate, with the drafters of the Uniform Mediation Act finally reaching agreement on "a process in which a mediator facilitates communication and negotiation between parties to assist them in reaching a voluntary agreement regarding their dispute." UNIF. MEDIATION ACT $§ 2(1)$ (2001). Though this definition clarifies the goal of mediation (i.e., "voluntary agreement regarding the dispute") the procedure remains largely undefined.

${ }^{8}$ See Norma Jeanne Hill, Who Shall Mediate?, 82 JudiCATURE 70, 72 (1998) (observing that selection and evaluation of mediators is made difficult by the existence of "different possible styles and the fact that there may be many ways in which to conduct a successful mediation"); Ellen Waldman, Credentialing Approaches: The Slow Movement Toward Skills-Based Testing Continues, DISP. RESOL. MAG., Fall 2001, at 14-16, 21 (describing various organizations' performance-based testing initiatives, including their views of essential mediator skills and tasks and their competing visions of mediation, while noting basic disagreements among mediators regarding the process's goals and methods); Douglas Yarn \& Wayne Thorpe, Ethics 2000: The ABA Proposes New Ethics Rules for Lawyer-Neutrals and Attorneys in ADR, DISP. RESOL. MAG., Spring 2001, at 4 (observing that there is no consensus or even "best-practices standard in sight" regarding mediator provision of legal advice).

${ }^{9}$ See Robert A. Baruch Bush \& Joseph P. Folger, The Promise of Mediation: RESPONDING TO CONFLICT THROUGH EMPOWERMENT AND RECOGNITION 1, 106-7 (1994); DOROTHY DElla NOCE, MICROFOCUS: THE PROCESS AND PRACTICE OF TRANSFORMATIVE MEDiATION: WORKSHOP MATERIALS 14 (2002) [hereinafter Della NOCE, MiCROFOCUS]; 
characterize the mediation process. ${ }^{11}$ Most notably, mediators and academics 12 disagree over the appropriateness of "evaluative," "facilitative," and "transformative" interventions. ${ }^{13}$ Some argue that in order to help disputants reach settlement, mediators must be ready to share their own assessments regarding the application of appropriate norms and to propose appropriate settlement options. The implementation of such "evaluative" interventions, meanwhile, can range from respectfully educational to aggressively directive. Others in this debate urge that mediator evaluation is never appropriate and that mediators should rely exclusively upon "facilitative" interventions that are focused on drawing out the disputants' views and enhancing the disputants' communication and mutual understanding to enable the disputants to find their own way to a settlement. ${ }^{14}$ Advocates for the superiority of "transformative" interventions reject settlement as the goal of mediation. Instead, they believe that the mediator's role (using interventions that might also be termed "facilitative") is to change the dynamic of the disputants' interaction, through the facilitation of the disputants' "empowerment and recognition." 15

While mediators have debated the goals, approaches, skills, and behaviors that should characterize mediation, the process generally has adapted to respond to the needs, expectations, and constraints of the

Dorothy J. Della Noce, Mediation Theory and Policy: The Legacy of the Pound Conference, 17 OHIO ST. J. ON DISP. RESOL. 545, 554-55 (2002) [hereinafter Della Noce, Mediation Theory and Policy] (urging that settlement and case management were never the primary goals of mediation until the courts co-opted the process).

10 See James Alfini et al., What Happens When Mediation is Institutionalized?: To the Parties, Practitioners, and Host Institutions, 9 OHIO ST. J. ON DISP. ResOL. 307, 309 (1994) (describing "different approaches and different versions of the [mediation] process" as it has been institutionalized).

11 See id.

12 See Maria R. Volpe \& David Chandler, Resolving and Managing Conflicts in Academic Communities: The Emerging Role of the "Pracademic," 17 NEGOT. J. 245, 246 (2001) (noting the emergence of academics who are also conflict resolution practitioners).

${ }^{13}$ Leonard Riskin, whose "grid for the perplexed" is described infra, has recently reconsidered the usefulness of the terms "evaluative" and "facilitative." He now proposes that mediator interventions should be distinguished as either "directive" or "elicitive." Leonard Riskin, Decision-Making in Mediation: The New Old Grid and the New New Grid System, 79 NOTRE DAME L. REV. (forthcoming 2003).

14 See id. (observing that facilitative and evaluative interventions are not necessarily opposites, but may instead travel in tandem).

15 See infra Part III. 
environments in which it is found. ${ }^{16}$ This often has meant that the goals, approaches, skills, and behaviors that now characterize mediation have developed largely in response to the needs and expectations of the professionals who dominate these environments. In the courts, for example, the views of judges and attorneys have played a major role in the evolution of court-connected mediation. ${ }^{17}$

The irony, of course, is that mediation was conceived originally as a process that responded to the needs and expectations of the disputants, as distinct from the institutions or professionals serving those disputants. ${ }^{18}$ When mediation resurfaced ${ }^{19}$ in the 1970 s and 1980 s, it promised citizens a means to reclaim their voices and ultimate decisionmaking power ${ }^{20}$ from courts and attorneys. The process seemed to embody both a faith in the dignity and autonomy of individual citizens and a skepticism regarding the legitimacy of government authorities and professionals. ${ }^{21}$ Given this genesis

16 See generally Nancy A. Welsh, The Thinning Vision of Self-Determination in Court-Connected Mediation: The Inevitable Price of Institutionalization?, 6 HARV. NEGOT. L. REV. 1 (2001) (describing the evolution of non-family civil court-connected mediation); Nancy A. Welsh, All in the Family: Darwin and the Evolution of Mediation, DISP. RESOL. MAG., Winter 2001, at 20 (generally describing forces that trigger mediation's adaptation to environmental factors).

17 See infra Part III.

18 See Model Standards of Conduct For Mediators (1994).

19 Previously, mediation was well-established in the area of labor-management relations. See Alan Scott Rau et al., Processes of Dispute Resolution: The Role OF LAWYERS 329-30 (3d ed. 2002).

${ }^{20}$ This concept has more recently been described as "voice and choice." See JOSEPH P. Folger et al., A Benchmarking Study of Family, Civil and Citizen Dispute MEDIATION PROGRAMS IN FLORIDA 105-06 (2001) (describing the "synergistic" approach in court-connected mediation programs, which acknowledges court constraints but also works to emphasize mediation as an "alternative" process that provides "voice and choice," and describing social impacts of this approach).

${ }^{21}$ Procedural justice studies, meanwhile, have shown that if authorities treat citizens with dignity and respect, they are more likely to perceive those authorities as legitimate. See E. Allan Lind, Procedural Justice, Disputing, and Reactions to Legal Authorities, in EVER yday PRactices and Trouble CaSes 177, 188 (Austin Sarat et al. eds., 1998) (summarizing studies showing that perceptions of authorities' legitimacy correlate with procedural justice judgments); E. ALLAN LIND \& TOM R. TYLER, THE SOCIAL PSYCHOLOGY OF PROCEDURAL JUSTICE 66-70, 205, 209 (1988) (summarizing studies that have found that procedural justice judgments affect disputants' perceptions of substantive justice and their evaluation of authorities and institutions); TOM R. TYLER, WHY PEOPLE OBEY THE LAW 94-108 (1990) (finding that procedural fairness judgments influence perceptions of the legitimacy of legal authority and that this effect is particularly strong for the courts); Wayne D. Brazil, Continuing the Conversation About the Current Status and the Future of ADR: A View from the Courts, 2000 J. DISP. RESOL. 11, 24 (noting that the courts' "most precious asset is the public's trust" and such trust is grounded in the 
of the "contemporary mediation movement," 22 it seems particularly appropriate to ask two questions. First, where are individual disputants' voices regarding the place and value of mediation today? And second, how might real disputants' views influence the current debate regarding the goals and practices that ought to give mediation its meaning?

The professionals surrounding and serving disputants (including attorneys, judges, and now mediators) often claim that they can speak on behalf of disputants, that they understand disputants' needs and interests and thus can make the necessary judgments about the goals mediation should serve and the approaches that should be used. ${ }^{23}$ Indeed, researchers often have been forced to rely upon attorneys to assess litigants' reactions to courtconnected mediation. ${ }^{24}$ But disconnects arise between the perceptions of

public's belief "that the aspect of justice for which [the courts] are primarily responsible is process fairness, process integrity. It follows that the characteristic of our ADR programs about which we must be most sensitive is fairness, especially process fairness.”); Tom R. Tyler, Public Mistrust of the Law: A Political Perspective, 66 U. CIN. L. REV. 847, 863 (1998) (discussing potential political consequences of ignoring public opinion). Additionally, some very thoughtful judges have recognized the importance of procedural justice in maintaining citizens' respect for the courts. See, e.g., Wayne D. Brazil, Comparing Structures for the Delivery of ADR Services by Courts: Critical Values and Concerns, 14 OHIO ST. J. ON DISP. RESOL. 715, 727-28 (1999).

22 BUSH \& FOLGER, supra note 9, at 1.

23 See, e.g., Mark K. Schoenfield, The Hidden (Philosophical) Traps in Mediation and Arbitration, PRACT. LAW., Oct. 2000, at 14-15 (describing different mediator goals and attitudes about process and pointing out that appropriateness depends upon needs of parties); Jeffrey W. Stempel, The Inevitability of the Eclectic: Liberating ADR from Ideology, 2000 J. DISP. RESOL. 247, 264, 287 (observing that "the most highly sought mediators" provide evaluative feedback and concluding that "many disputants seem to welcome this sort of mediator activity in the apt case"); Jean R. Sternlight, $A D R$ is Here: Preliminary Reflections on Where it Fits in a System of Justice, 3 NEV. L.J. 289, 297 (2003); Zena Zumeta, A Facilitative Mediator Responds, 2000 J. DISP. RESOL. 335, 340 (acknowledging that "we really do not know what clients would choose" if they understood the differences among models of mediation but betting "that they would choose facilitative mediation").

24 See, e.g., Deborah R. Hensler, In Search of "Good" Mediation: Rhetoric, Practice and Empiricism, in HANDBOOK OF JUSTICE RESEARCH IN LAW 231, 254-55 (Joseph Sanders \& V. Lee Hamilton eds., 2001) (based on new analyses of the Rand ADR data, describing attorneys' process evaluations, as well as their assessments of how satisfactory and fair mediation was for their clients); DONNA STIENSTRA ET AL., REPORT TO THE Judicial CONFERENCE COMMTtTeE ON COURT ADMINISTRation AND CASE MANAGEMENT: A STUdy OF THE FIVE DEMONSTRATION PROGRAMS Established UndeR THE CIVIL JUSTICE REFORM ACT OF 1990 24-25 (1997) (summarizing attorneys' satisfaction with and perceptions of the fairness of ADR programs); see also Jeffrey W. Stempel, Identifying Real Dichotomies Underlying the False Dichotomy: Twenty-First Century Mediation in an Eclectic Regime, 2000 J. DISP. RESOL. 371, 389-90 (observing 


\section{INSTITUTIONALIZED MEDIATION}

professionals and their clients. ${ }^{25}$ As a result, professionals' assumptionsand particularly the occasional "imaginary conversation" with a disputant ${ }^{26}$ - cannot help but be somewhat suspect.

The primary purpose of this Article, therefore, is to describe what a group of real disputants ${ }^{27}$ perceives as most valuable about mediation before,

that "studies to date have been content to measure either attorney satisfaction as a proxy for party satisfaction or to measure satisfaction on the heels of the settlement" and that "there must be sustained examination that does not measure party attitude only in the near aftermath when there may be either disappointment or euphoria").

Research has been done, however, to investigate what disputants want when they decide to seek assistance from attorneys and courts. See, e.g., Deborah R. Hensler, The Real World of Tort Litigation, in EVERYDAY PRACTICES AND TROUBLE CASES, supra note 21 , at 155, 156-162 (based on an analysis of quantitative and qualitative data regarding tort plaintiffs in ordinary and mass tort litigation, concluding that they want to present their evidence, find out what happened, and vindicate their rights); Sally Engle Merry \& Susan S. Silbey, What Do Plaintiffs Want? Reexamining the Concept of Dispute, 9 JUST. SYS. J. 151, 153 (1984) (urging that once plaintiffs seek assistance from attorneys or courts, they want vindication).

25 See William L. F. Felstiner et al., The Emergence and Transformation of Disputes: Naming, Blaming, Claiming..., 15 LAW \& SOC'Y REV. 631, 645 (1980) (observing that professionals often define their clients' needs to match what the professionals can provide).

${ }^{26}$ Robert A. Baruch Bush \& Sally Ganong Pope, Changing the Quality of Conflict Interaction: The Principles and Practice of Transformative Mediation, 3 PEPP. DISP. RESOL. L.J. 67, 69 (2002) (describing an imaginary conversation with parties who represent a "composite" of real disputants that the authors have seen); see Robert A. Baruch Bush, "What Do We Need A Mediator For?": Mediation's "Value-Added" for Negotiators, 12 OHIO ST. J. ON DiSP. ReSOL. 1, 4, 21 (1996) (describing imaginary conversations between an ADR expert, attorneys, and parties regarding the value of mediation). Imaginary conversations have been used for a long time to illustrate and anchor philosophical and religious points. See JOHN T. NOONAN, JR., THE LUSTRE OF OUR Country: THE AMERICAN EXPERIENCE OF RELIGIOUS FREEDOM 173 (1998) (quoting Geertz as stating: "The strange idea that reality has an idiom in which it prefers to be described . . . leads on to the even stranger idea that, if literalism is lost, so is fact . . ."'); see generally Robert A. Baruch Bush, Mediation and Adjudication, Dispute Resolution and Ideology: An Imaginary Conversation, 3 J. CONTEMP. LEGAL ISSUES 1 (1989-90).

27 Commentators increasingly have called for more data regarding disputants' perspectives of different mediator models and interventions. See, e.g., ADR Vision Roundtable: Challenges for the 21st Century, 56 DISP. RESOL. J. 8, 82-84 (2001) (observing that there is a need to focus on user satisfaction in developing and implementing ADR processes and that there is no evidence that reveals users' perceptions of mediator qualifications); Frank Blechman, Ethics and Field Building: The Chicken and the Egg, 19 CONFLICT RESOL. Q. 373, 379 (2002) (noting "stunning" absence of consumer perspective in conflict resolution literature); Frank E.A. Sander, Some Concluding Thoughts, 17 OHIO ST. J. ON DISP. RESOL. 705, 706-07 (2002) (questioning why people consistently express satisfaction with mediation and find it fair); Sternlight, 
soon after, and eighteen months after they participated in the process. Further, this Article will describe how these real disputants perceive mediator interventions that could be categorized as "evaluative," "facilitative," and "transformative." This Article is based primarily upon qualitative data from in-depth interviews with parents and school officials who participated in special education mediation sessions. ${ }^{28}$ Though the specific context of these interviews is obviously important-and the specifics of that context will be considered infra Part IV-the Article will urge that these disputants and their disputes share many commonalities with disputants and disputes in other contexts and, as a result, these disputants' views have relevance for the broader field of mediation.

Based on these interviews with real disputants, this Article will suggest that both before and after disputants experience mediation, they value the process primarily for the procedural justice and the resolution that it provides. ${ }^{29}$ Individual, "one-time" 30 disputants-such as the parents involved in these mediations - seek and appreciate a process that provides them with the opportunity to express their views (often referred to as "voice" in the procedural justice literature); assurance that their views have been heard and considered by the decisionmakers (here, the school officials); and even-

supra note 23, at 296-98 (observing that "some people who opine on dispute resolution issues have a tendency to say that they or we know what disputants really want, when in fact the evidence is quite sparse" and calling for more research regarding what "disputants want from a system of justice"); Waldman, supra note 8, at 21 (calling for input from "mediation consumers" in the development of performance tests for mediators).

In the legal academy in general, there is increasing acknowledgment that legal and political dialogue and decisionmaking is and should be informed by empirical research. See generally Lee Epstein \& Gary King, The Rules of Inference, 69 U. CHI. L. REV. 1 (2002); Thomas E. Willging, Past and Potential Uses of Empirical Research in Civil Rulemaking, 77 NOTRE DAME L. REV. 1121 (2002).

28 Where appropriate, the data from the interviews also will be supplemented by clues offered by procedural justice research, as well as quantitative and qualitative research that has been conducted in other settings such as court-connected and agencyconnected mediation.

${ }^{29}$ Lisa Bingham came to a similar conclusion regarding the dual goals of mediation in her study of employees and supervisors evaluations of their mediation experience in the U.S. Postal Service REDRESS program. See Lisa B. Bingham, Mediating Employment Disputes: Perceptions of Redress at the United States Postal Service, 17 Rev. Pub. PERSONNel AdMIN. 20, 26-29 (1997).

30 See Marc Galanter, Why the "Haves" Come Out Ahead: Speculations on the Limits of Legal Change, 9 LAW \& SOC'Y REV. 95, 160 (1974) (discussing the systemic advantages of "repeat players" in the civil justice system over individuals or "one-time players"). 
handed, dignified treatment. ${ }^{31}$ Parents thus value the mediation process because they perceive it as more "procedurally just" than the unsupervised meetings that precede it. ${ }^{32}$ More sophisticated "repeat players"--such as the school officials described in this Article-also value mediation for its procedural justice. But their needs are slightly different from those of the parents. The school officials focus on their need to hear and understand the parents' concerns and for the parents to hear and understand (or at least accept) the norms that the school officials are entitled to apply. Despite their differences in emphasis, both sets of disputants seem to place great value upon mediation's ability to enhance the procedural justice of discussion and decisionmaking. This is consistent with transformative mediation's focus on "empowerment and recognition."

Just as importantly, however, the disputants value mediation's ability to deliver resolution of the disputes that gave rise to the invocation of mediation-or at least meaningful progress toward that resolution. They seek improvement upon their currently conflicted situations. Thus, the value of mediation as perceived by disputants is inconsistent with transformative mediation's rejection of resolution as a goal.

Further, the interviews with disputants suggest that if they are reassured that the mediation process and the mediators' behavior are grounded firmly in procedural justice, they also value an eclectic and apparently conflicting variety of mediator interventions designed to achieve resolution. In the postmediation interviews with disputants, they demonstrated appreciation for facilitative and transformative assistance with being heard and understood by each other. They also praised evaluative interventions that helped them to

31 See Lind, supra note 21, at 177; LIND \& TYLER, supra note 21 , at 242; see also Tom R. Tyler \& E. Allan Lind, Procedural Justice, in HANDBOOK OF JUSTICE RESEARCH IN LAW, supra note 24 , at $65,74-83$ (describing the procedural characteristics that enhance perceptions of procedural justice and the theories that explain such effects); Nancy A. Welsh, Making Deals in Court-Connected Mediation: What's Justice Got To Do With It?, 79 WASH. U. L.Q. 787, 820-26 (2001) (describing and explaining process characteristics that enhance perceptions of procedural justice).

32 It is important to recognize the profound effects of procedural justice. If disputants perceive that a process was procedurally just, they are also more likely to perceive that the substantive outcome of that process is just and that the institution providing the process is legitimate. See Lind, supra note 21, at 188; LIND \& TYLER, supra note 21 , at $66-70,205,209$ (summarizing studies that have found that procedural justice judgments affect disputants' perceptions of substantive justice and their evaluation of authorities and institutions); TYLER, supra note 21, at 94-108 (finding that procedural fairness judgments influence perceptions of the legitimacy of legal authority and that this effect is particularly strong for the courts); Tyler \& Lind, supra note 31 , at $65,84-86$ (describing the effects of perceptions of procedural justice upon authorities' legitimacy); see also Welsh, supra note 31, at 818-20 (describing and explaining the effects of perceptions of procedural justice). 
engage in a dignified, informed application of the norms that they viewed as relevant to their decisionmaking. The disputants expressed concerns about evaluative interventions, however, if they perceived that the mediators had not behaved in a manner consistent with the provision of procedural justice, or were invoking norms other than those the disputants viewed as legitimate. The post-mediation interviews seem to reveal the technique of caucus as a tool that is particularly potent and problematic in this respect. The disputants also raised concerns regarding facilitative or transformative interventions that did not appear designed to move disputes toward some form of clarification or resolution.

These reactions suggest that the mediation field's current debate over the relative superiority of evaluative, facilitative, or transformative approaches misses the point. Depending upon their implementation, evaluative, facilitative, and transformative interventions have the potential to be consistent with and enhance mediation's dual promise ${ }^{33}$ of procedural justice and resolution. ${ }^{34}$ All three types of interventions, however, also have the potential to hinder the dual achievement of procedural justice and resolution. Thus, the focus of the field should not be upon ensuring orthodoxy with any particular mediation model, but with crafting processes that use all three types of interventions in a manner that serves both procedural justice and resolution. ${ }^{35}$

33 The duality of these goals may, but need not, make implementation more difficult. See Jonathan R. Cohen, When People Are the Means: Negotiating with Respect, 14 GEO. J. LEGAL ETHICS 739, 785 n.152 (2001) (urging that more than one goal in negotiation can be important and valued).

34 Others have urged that empowerment involves the development of both internal and external resources. See, e.g., Joel F. Handler, Dependent People, the State, and the Modern/Postmodern Search for the Dialogic Community, 35 UCLA L. REV. 999, 1101 (1988). Handler describes Hasenfeld's argument:

[c]lient empowerment must be placed at the center of social work practice ... [and] requires a shift in orientation from a client-centered approach to an environmentcentered approach. The former tends to blame the clients for their problems. The structural, or environmental approach [which recognizes the ability to choose alternatives as the core of power] helps people to connect with needed resources, to Id. negotiate problematic situations, and to change existing structures.

35 See Riskin, supra note 13 (giving an example of one mediator who ranked highest as both facilitative and evaluative to show that these two approaches do not necessarily contradict each other). Professor Riskin's emphasis is upon protecting and nurturing disputants' self-determination in mediation. The research described in this Article suggests that even when disputants elect to participate in the consensual process of mediation, however, they expect procedural justice and do not focus as much on selfdetermination. See Nancy A. Welsh, Disputants' Decision Control in Court-Connected Mediation: A Hollow Promise Without Procedural Justice, 2002 J. DisP. RESOL. 179, 
The Article begins, in Part II, with an overview of the successful institutionalization of mediation, a description of the evaluative-facilitativetransformative debate, and two examples of how the goals and practices that characterize institutionalized mediation are grounded in the expectations and preferences of the institutions. Part III examines the data collected thus far from disputants regarding their expectations and perceptions of the mediation process. Part IV discusses the methodology of the research project, the legal and administrative context of special education mediation, and the themes that emerge from the interviews. Part V considers the implications of this research project regarding the goals and methods that ought to characterize mediation, both within special education and the broader field of mediation.

\section{SUCCESSFUL INSTITUTIONALIZATION, BUT ON THE INSTITUTIONS' TERMS}

Mediation, which was a procedural innovation only fifteen years ago, is now an integral part of the civil litigation system, used to resolve personal injury, contract, employment, divorce, child custody, and many other civil matters. ${ }^{36}$ A multitude of state courts mandate mediation or require attorneys to consult with their clients and advise judges regarding the appropriateness of the process. ${ }^{37}$ Congress has required all of the federal courts to institute ADR programs, ${ }^{38}$ and many of those programs feature mediation..$^{39}$ Even many appellate courts now funnel cases to mediation, with marked success. ${ }^{40}$

180-84 (describing disputants' failure to perceive more outcome control in consensual processes than in non-consensual processes and speculating regarding the reasons for this failure). Self-determination and procedural justice certainly are related conceptsperceptions of process control appear to enhance perceptions of outcome control-but they are not synonymous.

36 See, e.g., ElizABETH PLAPINGER \& DONNA STIENSTRA, ADR AND SETTLEMENT IN THE FEDERAL District COURTS: A SOURCEBOOK FOR Judges \& LAWYers 4 (1996) (describing mediation as "the primary ADR process in the federal district courts"); McAdoo, supra note 6, at 409-10 (describing Minnesota state courts' institutionalization of mediation and other ADR processes); Bobbi McAdoo \& Art Hinshaw, The Challenge of Institutionalizing Alternative Dispute Resolution: Attorney Perspectives on the Effect of Rule 17 on Civil Litigation in Missouri, 67 Mo. L. REv. 473, 476-77 (2002) (describing Missouri state courts' institutionalization of mediation and other ADR processes); Sharon Press, Institutionalization: Savior or Saboteur of Mediation?, 24 FLA. ST. U. L. REv. 903, 907 (1997) (describing Florida's court-connected dispute resolution program).

37 See RAU ET AL., supra note 19, at 547-48.

38 See 28 U.S.C. § 651(b) (1998). 
An increasing number of public agencies have also embraced the process. At the state level, departments charged with protection of the environment, human rights, farming interests, and transportation offer mediation services or regularly agree to participate in mediation processes. ${ }^{41}$ Within the federal government, the United States Postal Service (USPS) resolved over 17,000 workplace disputes in 2000-2001 through its REDRESS mediation program. ${ }^{42}$ Over the past several years, the Equal Employment Opportunity Commission (EEOC) has also experimented with mediation and, in 2001, mediated nearly 7,000 cases. ${ }^{43}$ The Department of Health and Human Services, the United States Air Force, and the Environmental Protection Agency have also made significant use of mediation to resolve disputes over contract matters, employment, and site cleanup. ${ }^{44}$ Additionally, in the 1997 reauthorization of the Individuals with Disabilities Education Act (IDEA), Congress required states receiving federal funds for special education to offer mediation as a means to resolve disputes arising between parents (or guardians) of children with special needs and the schools providing the children with assessments and services. ${ }^{45}$

It is accurate to say that a process with the name "mediation" has been institutionalized within all of these contexts, but in 1994, it became quite clear that "mediation" had many potential meanings, goals, and

39 See 28 U.S.C. $\$ 651$ (a) (1998) (allowing for mediation as a form of ADR); PLAPINGER \& STIENSTRA, supra note 36 , at 4 (describing mediation as "the primary ADR process in the federal district courts.").

40 See Carrie Menkel-Meadow, When Litigation is Not the Only Way: Consensus Building and Mediation as Public Interest Lawyering, 10 WASH. U. J. L. \& POL'Y 37, 56-57 (2002); see generally ROBERT J. NIEMIC, MEDIATION \& CONFERENCE PROGRAMS IN THE FEDERAL COURTS OF APPEALS (1997).

41 See Policy Consensus Institute, Directory of DR Programs, at http://www.policyconsensus.org/directories/statedirectories.html (last visited Nov. 23, 2003). The website provides an online list and brief description of dispute resolution programs that have been established by state courts and agencies. The list is maintained by the Policy Consensus Initiative, a nonprofit organization that helps state governments to establish and evaluate such programs.

42 United States Postal Service, REDRESS Research, at http://www.usps.com/ redress/stats.htm (last visited Nov. 23, 2003); see also Daniel Marcus \& Jeffrey M. Senger, ADR and the Federal Government: Not Such Strange Bedfellows After All, 66 Mo. L. REV. 709, 719 (2001) (describing the Post Office mediation program).

43 See Mary B. Manzo, A Guide to EEOC Mediations, 90 ILL. B. J. 607, 607 (2002).

44 See Marcus \& Senger, supra note 42, at 719-22.

45 See 20 U.S.C. $\$ 1415$ (2000); see also Individuals with Disabilities Education Act of 1997, 20 U.S.C. $\$ \S 1400-1491$ (2000). 
approaches. ${ }^{46}$ Leonard Riskin unleashed a firestorm of debate when he introduced his "Grid for the Perplexed" in that year. ${ }^{47} \mathrm{He}$ insisted that he had observed mediators who used radically different techniques, ranging from "facilitative-broad" to "evaluative-narrow" 48 and that all of these techniques could and should be categorized as part of mediation. Among the "facilitative-broad" techniques described by Professor Riskin were: "encourag[ing] the parties to discuss underlying interests in joint sessions" and "encourag[ing] and help[ing] the parties to develop their own proposals (jointly or alone) that would respond to underlying interests of both sides." 49 Mediators using these techniques assumed that the disputants could reach their own resolution and needed the mediator's assistance primarily to improve their communication and deliberation. "Evaluative-narrow" techniques, in contrast, emphasized the mediator as the expert and source of substantive information. These techniques included (from least to most aggressive): "directly assess[ing] the strengths and weaknesses of each side's case (usually in private caucuses) and perhaps try[ing] to persuade the parties to accept the mediator's analysis," "try[ing] to persuade parties to accept the mediator's assessments," "predict[ing] court (or administrative agency) dispositions," "propos[ing] position-based compromise agreements," and "urg[ing] parties to settle or to accept a particular settlement proposal or range." 50 Despite their differences, however, "facilitative-broad" and

${ }^{46}$ As early as 1983, Deborah Kolb found differences among the ranks of labormanagement mediators, describing some as "orchestrators" and others as "deal makers." Deborah M. Kolb, The Mediators 23-45 (1983). Susan Silbey and Sally Merry similarly differentiated between those community mediators who used a "therapeutic" approach and others who demonstrated a "bargaining" orientation. Susan S. Silbey \& Sally E. Merry, Mediator Settlement Strategies, 8 LAW \& POL'Y 7, 12-19 (1986). Christopher Moore has also noted that mediators could be classified as "social network mediators," "authoritative mediators," and "independent mediators," depending upon their relationship with the disputants. CHRISTOPHER W. MOORE, THE MEDIATION PROCESS: PRACTICAL STRATEGIES FOR RESOlVING CONFLICT 41 (2d ed. 1996).

${ }^{47}$ Leonard L. Riskin, Mediator Orientations, Strategies and Techniques, 12 ALTERNATIVES TO HIGH COST LITIG. 111, 111-12 (1994) [hereinafter Riskin, Mediator Orientations]; see generally Leonard L. Riskin, Understanding Mediators' Orientations, Strategies and Techniques: A Grid for the Perplexed, 1 HARV. NEGOT. L. REV. 7 (1996) (expanding upon the 1994 article) [hereinafter Riskin, Grid]. Perhaps Professor Riskin's use of a grid-a striking, easy-to-understand, and somewhat rigid visual aid-helps to explain the catalytic power of his description of mediation practice. Indeed, when Professor Riskin tested the grid in a presentation before lawyers, judges, and mediators at Hamline University School of Law, discussion centered upon the visual aid of the grid itself.

48 Riskin, Mediator Orientations, supra note 47, at 7.

49 Id. at 113; see also Riskin, Grid, supra note 47, at 32-33.

50 Riskin, Mediator Orientations, supra note 47, at 112. 
"evaluative narrow" techniques shared the same goal-assisting the disputants to reach resolution.

Also in 1994, Robert Baruch Bush and Joseph Folger published their book, The Promise of Mediation, ${ }^{51}$ which further focused and spurred the debate over the goals and practices that ought to characterize mediation. Professors Bush and Folger acknowledged the existence of different visions of mediation ("mediation stories") embodying diverging goals and methods, but they argued that the "transformative" approach to mediation most fully captured the unique and essential promise of the process. ${ }^{52}$ According to Professors Bush and Folger, mediation's focus should be upon the "empowerment and recognition" of disputants. ${ }^{53}$ They defined empowerment as the renewal of disputants' values, strengths, and capacity to handle life's complexities, and recognition as "acknowledgment and empathy for the situation and problems of others." 54 Very significantly, Professors Bush and Folger rejected settlement as the goal of mediation. ${ }^{55}$ Indeed, they criticized "problem-solving" approaches to mediation (which obviously included the evaluative and facilitative orientations and techniques that had been identified by Professor Riskin) for their underlying assumption that disputes represent problems, rather than "opportunities for moral growth and transformation." 56

Since 1994, a cacophony of voices has arisen in the debate over the goals and behaviors that ought to characterize mediation. In particular, mediators, ${ }^{57}$

51 See generally BUSH \& FOLGER, supra note 9.

52 Id. at 2.

${ }^{53} \mathrm{Id}$.

54 See id. (urging that mediation should promote empowerment and recognition of disputants); Bush, supra note 26, at 29-30 (describing empowerment as "supportingand not supplanting - the parties' own deliberation and decisionmaking processes" and describing recognition as "inviting, encouraging and supporting the parties' presentation ... and reception ... of each other's perspectives and new and altered views [to] one another....").

55 See BUSH \& FOLGER, supra note 9, at 105 ("Reaching settlement, or any particular terms of settlement, is not something that matters to the mediator, because it is not a direct objective of his or her intervention into the conflict."); Bush, supra note 26, at 36 (suggesting that the production of settlement is not what parties find most valuable about mediation and that "mediation practice need not and should not focus on settlement production...."); see also Della Noce, supra note 9, at 554-55 (claiming that settlement and case management were never the primary goals of mediation until the courts co-opted the process).

${ }^{56}$ BUSH \& FOLGER, supra note 9 , at 81.

57 Perhaps predictably, different mediators were drawn to different goals and approaches. Some supported mediation as a facilitative process. See, e.g., Gary L. GillAustern, Faithful, 2000 J. DISP. ReSOL. 343, 347 (analogizing the current discussion 
academics, ${ }^{58}$ attorneys, ${ }^{59}$ judges, ${ }^{60}$ and agency officials ${ }^{61}$ have contributed their views. Though most of the time the evaluative, facilitative, or

regarding mediation to the life work of Abraham Joshua Heschel, who "lived in the alternative to enliven the tradition, as the tradition and the present-day setting were no longer engaged in dialogue"); Zumeta, supra note 23 , at 340 (acknowledging that " $[w]$ e really do not know what clients would choose" if they understood the differences among models of mediation but betting "that they would choose facilitative mediation"). Others argued for the necessity of evaluation. See John Bickerman, Evaluative Mediator Responds, 14 ALternatives to High Cost LITIG. 70 (1996); see also Welsh, Thinning Vision, supra note 16 , at $44-45$ (describing the proponents of a proposed rule change that explicitly permitted mediators to use evaluative interventions). Still others expressed support for the transformative model of mediation. See, e.g., James R. Antes \& Judith A. Saul, What Works in Transformative Mediator Coaching: Field Test Findings, 3 PEPP. DiSP. RESOL. L.J. 97 (2002).

58 Like mediators, not all academics spoke with the same voice. Some vigorously disagreed with a definition of mediation that encompassed the very different methodsand very different underlying goals—of "facilitative-broad" mediators and aggressively "evaluative-narrow" mediators. Professors Lela Love and Kimberlee Kovach, for example, disparaged evaluative mediation as an "oxymoron." Kimberlee K. Kovach \& Lela P. Love, "Evaluative" Mediation Is an Oxymoron, 14 ALTERNATIVES TO HIGH COST LrTiG. 31, 31 (1996). They, along with others, pointed to the preservation of party selfdetermination as the fundamental goal of mediation, which could be achieved only through a predominantly facilitative understanding of the mediator's role in the process. Id. at 32; Kimberlee K. Kovach \& Lela P. Love, Mapping Mediation: The Risks of Riskin's Grid, 3 HARV. NeGOT. L. ReV. 71, 75 (1998); Lela P. Love, The Top Ten Reasons Why Mediators Should Not Evaluate, 24 FLA. ST. U. L. REV. 937, 937-38 (1997); Joseph B. Stulberg, Facilitative Versus Evaluative Mediator Orientations: Piercing the "Grid" Lock, 24 FLA. ST. U. L. REV. 985, 1001-02 (1997); see also Riskin, Grid, supra note 48, at 45, 47 (acknowledging that evaluative techniques "can interfere with the parties' coming to understand fully their own and each other's positions and interests" and "with the development of creative solutions").

Another group of academics countered by affirming the value of mediator evaluation in mediation, noting that these techniques helped to ensure that disputants' decisionmaking would be informed. See, e.g., Robert B. Moberly, Mediator Gag Rules: Is It Ethical for Mediators to Evaluate or Advise?, 38 S. TEX. L. REV. 669, 675 (1997) (arguing that "mediator evaluation can assist the parties in their self-determination efforts"); see also Jacqueline M. Nolan-Haley, Informed Consent in Mediation: A Guiding Principle for Truly Educated Decisionmaking, 74 NOTRE DAME L. REv. 775, 777 (1999) (arguing that self-determination is undermined by the absence of informed consent); Donald T. Weckstein, In Praise of Party Empowerment-and of Mediator Activism, 33 WILLAMETTE L. REV. 501, 511 (1997) ("Rather than interfering with the self-determination of parties to resolve their own dispute, activist interventions by the mediator may enhance the parties' empowerment by educating them and by aiding their realistic understanding of the alternatives to agreement."). Particularly for courtconnected cases, these academics urged that mediation outcomes should be consistent with the justice norms that the disputants had invoked by being in court. See James $\mathrm{H}$. Stark, Preliminary Reflections on the Establishment of a Mediation Clinic, 2 ClINICAL L. 
transformative template has framed these arguments, some academics and mediators have urged an "eclectic" approach,62 and Professor Riskin has even proposed recently that the terms "evaluative" and "facilitative" should be abandoned and replaced with "directive" and "elicitive." 63

Meanwhile, a growing body of research has focused on examining the actual implementation or "look" of mediation as it has been institutionalized,

REV. 457, 487 (1996); Jeffrey W. Stempel, Beyond Formalism and False Dichotomies: The Need for Institutionalizing a Flexible Concept of the Mediator's Role, 24 FLA. ST. U. L. REV. 949, 966 (1997) (arguing that "the formalist 'facilitative' model of mediation" should not be elevated "above the practical needs of disputants and the faimess concerns that must animate decision-making in any government-sponsored proceeding"). Another set of academics has argued for the primacy of the transformative model of mediation. See BUSH \& Folger, supra note 9, at 95; Della Noce, Mediation Theory and Policy, supra note 9 , at 557-58.

59 See Schoenfield, supra note 23, at 14-15 (describing different mediator goals and attitudes about process and pointing out that appropriateness depends upon needs of parties); see also Welsh, Thinning Vision, supra note 16, at 42-49, 54-56 (describing the written responses of attorneys, mediators, and academics to proposed ethical rules regarding mediator evaluation).

60 See, e.g., Wayne D. Brazil, Court ADR 25 Years After Pound: Have We Found a Better Way?, 18 OHIO ST. J. ON DISP. RESOL. 93, 98 n.12 (2002) (federal magistrate judge describing possible place of facilitative and transformative mediation in civil litigation).

61 See, e.g., Cynthia J. Hallberlin, Transforming Workplace Culture Through Mediation: Lessons Learned from Swimming Upstream, 18 HOFSTRA LAB. \& EMP. L.J. 375, 381 (2001) (former general counsel of the U.S. Postal Service describing experience with transformative mediation); Manzo, supra note 43, at 611 (ADR coordinator of EEOC's Chicago office describing mediator "reality-checking" as a part of the mediation process).

62 See John Lande, Toward More Sophisticated Mediation Theory, 2000 J. DisP. RESOL. 321, 327 (calling for pluralism in the field of mediation, or recognition of the place of various approaches); Stempel, supra note 23, at 247. Other mediators and academics have even introduced new models of mediation that are not framed by the terms of the evaluative, facilitative, or transformative templates. For example, Professor Robert Mnookin, Gary Friedman, and Jack Himmedlstein have developed a video and teaching materials for the "understanding-based" model of mediation. See Videotape: Saving the Last Dance: Mediation Through Understanding (Harvard Program on Negotiation, Center for Negotiation and the Law 2001). John Winslade and Gerald Monk also have introduced a process termed "narrative mediation" in which the mediator elicits disputants" "stories" or "meaning" rather than "facts." JOHN WINSLADE \& GERALD MONK, NARRATIVE MEDIATION: A NEW APPROACH TO CONFLICT RESOlUTION 125-26 (2000).

63 Riskin, supra note 13. Professor Riskin observes that the distinction between "facilitative" and "evaluative" techniques fails to accomplish what he had intended, which was to capture different mediator interventions" "impact[s] on party selfdetermination, a fundamental value ... that [he] thought [was] imperiled by mediation practices around evaluation that violated party expectations or desires." 


\section{INSTITUTIONALIZED MEDIATION}

as well as the perceptions of the professionals in each of these settings. Some of the most significant research of this type has arisen out of courts' mediation programs and the USPS REDRESS program. ${ }^{64}$ In the courtconnected context, this research reveals that mediation programs have evolved largely to reflect the needs and preferences of judges and attorneys. First, because many judges perceived mediation as an effective means to resolve cases and reduce congested dockets, many courts make disputants' participation in court-connected family and non-family civil mediation mandatory. Second, court-connected mediators are unlikely to act as wholly disinterested parties who view their role as purely facilitative. In the family area, while disputants are encouraged to express their feelings and develop their own settlement agreements, the mediators become directly involved in shaping mediated outcomes ${ }^{65}$ and often are directly responsible for the quality of the agreements - particularly those terms relevant to the protection of children's best interests. Attorneys who attend family mediation sessions, meanwhile, often rely upon mediators to help the clients become more realistic and to offer assessments regarding likely outcomes. ${ }^{66}$

In non-family court-connected civil cases (e.g., personal injury, contract, employment, property damage, medical malpractice, etc.) mediators similarly facilitate communication and negotiation but also engage in significantly evaluative behaviors. Research reveals that attorneys prefer and select experienced litigators with substantive expertise to serve as the mediators. ${ }^{67}$

64 Research has also been conducted in other contexts that are not included in this brief summary. Most notable among these omissions is research regarding mediation in the labor-management area, which actually has a longer history than those described in the text. See RAU, supra note 19, at 329-30.

65 See Nancy A. Burrell et al., The Impact of Disputants' Expectations on Mediation: Testing an Interventionist Model, 17 HUM. COMM. RES. 104, 108-09 (1990) (describing research in divorce and community mediation showing that mediators using a more directive, more structured, and more control oriented model-including intervening after periods of high conflict, providing orientation information, directing topics, enforcing rules, keeping disputants focused on interests and away from past relationshiprelated concerns-achieved more cooperation between the parties and a better discussion of the issues); Jessica Pearson \& Nancy Thoennes, Divorce Mediation: Reflections on a Decade of Research, in MEDIATION RESEARCH: THE PROCESS AND EFFECTIVENESS OF THIRD-PARTY INTERVENTION 9, 17 (Kenneth Kressel et al. eds., 1989) (observing that mediators are "responsible for making most of the proposed solutions"); Nancy A. Welsh, Reconciling Self-Determination, Coercion and Settlement, in DIVORCE Mediation: Current Practices AND Applications (J. Folberg, et al,, eds.) (forthcoming 2004).

66 Welsh, supra note 65

67 McAdoo, supra note 6, at 405-06 (reporting that lawyers perceive that the most important qualifications for mediators are "substantive experience in the field of law related to case" ( $84.2 \%$ of respondents) and "being a litigator" $(66.2 \%)$ ). 
Attorneys want mediators who, like judges, have the knowledge and experience that will permit them to understand the parties' legal arguments, assess the merits of their cases, and even opine regarding settlement ranges. ${ }^{68}$ In these mediation sessions, the attorneys often dominate the process, while their clients-the disputants-play minimal roles. Little time is spent in joint session. Instead, mediators move quickly to caucuses, case evaluation, and bargaining. ${ }^{69}$ Attorneys apparently value these mediator interventions because they view mediation primarily as a settlement tool that can provide opposing counsel and their own clients with a needed "reality check."70 Few

68 See, e.g., James J. Alfini, Trashing, Bashing, and Hashing It Out: Is This the End of "Good Mediation"?, 19 FLA. ST. U. L. REv. 47, 66-71 (1991) (describing "trashers" and "bashers"); Elizabeth Ellen Gordon, Why Attorneys Support Mandatory Mediation, 82 JUDICATURE 224, 228 (1999) (noting that attorneys prefer mediators who are experienced trial lawyers); McAdoo, supra note 6, at 429-30 (reporting that the top factors motivating lawyers to choose mediation include saving expenses, making settlement more likely, and providing a reality check for opposing counsel and own client). When asked, "What mediator qualifications are important to you?," $87 \%$ of lawyers responded "Mediator knows how to value case," and 83\% responded "Mediator should be a litigator." McAdoo \& Hinshaw, supra note 36, at 524. The top factors motivating lawyers to choose mediation include saving litigation expense, speeding settlement, providing needed reality check for opposing counsel and party and own client, making settlement more likely, and helping everyone value the case. Id. Lawyers' selection of mediation is infrequently motivated by evidence that clients like mediation, increased potential for creative solutions, or preservation of relationships. Id.; see also Barbara McAdoo \& Nancy Welsh, Does ADR Really Have a Place on the Lawyer's Philosophical Map?, 18 HAMLINE J. PUB. L. \& POL'Y 376, 390 (1997) (noting that Hennepin County lawyers said that they wanted mediators to give their view of settlement ranges); Thomas Metzloff, Empirical Perspectives on Mediation and Malpractice, 60 LAW \& CONTEMP. PROBS. 107, 144-45 (1997) (reporting that almost $70 \%$ of attorneys want mediators to provide opinions on the merits of cases and that attorneys highly valued the mediator's substantive expertise); Roselle L. Wissler, An Evaluation of the Common Pleas Court Civil Pilot Mediation Project, at ix (Feb. 2000) (unpublished manuscript, on file with author) (reporting that "[a]ttorneys had more favorable assessments of the [mediation] process and mediator and analyzed mediation was more helpful in achieving case objectives if the mediator evaluated the merits of the case and suggested settlement options").

${ }^{69}$ See Welsh, supra note 31, at 801-13 (describing the evolution of court-connected civil non-family mediation, particularly regarding the reduced role of the disputants, the marginalization of joint session, and the rise of evaluative interventions). But see Julie Macfarlane, Culture Change? A Tale of Two Cities and Mandatory Court-Connected Mediation, 2002 J. DISP. RESOL. 241, 309-13 (urging that court-connected mediation has resulted in "some convergence between the structure and actions of mediation and traditional litigation").

70 McAdoo, supra note 6, at 429 (reporting that the top factors motivating lawyers to voluntarily choose mediation include saving litigation expenses (67.9\%), making settlement more likely $(57.4 \%)$, providing a needed reality check for opposing counsel or 
attorneys, it appears, choose mediation because they perceive that their clients might like it or experience greater satisfaction or control. ${ }^{71}$ Meanwhile, many courts have promulgated ethical codes for court-connected mediators that permit mediators to engage in the evaluative functions that attorneys seek. ${ }^{72}$ Ultimately, attorneys and the courts favor approaches to mediation that produce resolution-and mediator evaluation appears quite effective in reaching that goal. ${ }^{73}$

Within agencies as well, the look of the mediation process has adapted to meet the needs and culture (or desired culture) of its institutional sponsors. The USPS, for example, instituted a mediation program called Resolve Employment Disputes, Reach Equitable Solutions Swiftly (REDRESS) in 1994, as part of its settlement of a racial discrimination class action. ${ }^{74}$ REDRESS was implemented nationally in $1998 .{ }^{75}$ Though one goal of the program was to reduce the number of formal Equal Employment Opportunity

party $(52.2 \%)$, and providing a needed reality check for own client (47.7\%)); McAdoo \& Hinshaw, supra note 36 , at 512-13 (reporting that top factors motivating lawyers to choose mediation are: saving litigation expenses $(85 \%)$, speeding settlement $(76 \%)$, providing a needed reality check for opposing counsel or party $(69 \%)$, making settlement more likely (69\%), helping everyone value the case $(69 \%)$, and providing a needed reality check for own client (67\%)); see also Elizabeth Gordon, Attorneys' Negotiation Strategies in Mediation: Business as Usual?, 17 Mediation Q. 377, 387 (2000) (reporting that attorneys who are not also mediators perceive that the "mediator's primary duty is to act as referee between opposing sides or to convey offers and counteroffers"); Macfarlane, supra note 69 , at 285-86 (describing both attorneys' appreciation of mediators' evaluation and their perceptions regarding the limits of such interventions).

${ }^{71}$ McAdoo, supra note 6, at 429 (reporting that the top factors motivating lawyers to choose mediation include saving expenses, making settlement more likely, and providing a reality check for opposing counsel and own client; and lawyers' selection of mediation is rarely motivated by the increased potential for creative solutions, preservation of parties' relationships, or evidence that clients "like" mediation; and few attorneys analyzed that mediation has the effect of either "providing greater client satisfaction" or "providing greater client control").

72 See Welsh, Thinning Vision, supra note 16, at 50-52, 56-57 (describing Florida's and Minnesota's ethical rules for mediators regarding the propriety of evaluative interventions).

73 See Roselle L. Wissler, Court-Connected Mediation in General Civil Cases: What We Know from Empirical Research, 17 OHIO ST. J. ON DISP. RESOL. 641, 679-80 (2002) (reporting that cases were more likely to settle if mediators evaluated the merits of cases or assisted parties in evaluating cases' value).

74 See Lisa B. Bingham, Why Suppose? Let's Find Out: A Public Policy Research Program on Dispute Resolution, 2002 J. DISP. RESOL. 101, 112-13.

75 See James R. Antes et al., Transforming Conflict Interactions in the Workplace: Documented Effects of the USPS REDRESS (TM) Program, 18 HoFSTRA LAB. \& EMP. L.J. 429, 429 (2001) (noting program's success in reducing the overall number of EEO complaints); Bingham, supra note 74 , at 101, 112-13. 
(EEO) complaints, ${ }^{76}$ other goals included "foster[ing] better communication between employees and supervisors" and "build[ing] conflict management skills in the workforce." 77 Importantly, USPS decided to make participation in a REDRESS mediation voluntary for the employees bringing informal EEO complaints but mandatory for the respondent supervisors. ${ }^{78}$ In order to ensure that a significant number of employees elected to participate in this voluntary program, ${ }^{79}$ the USPS chose to adopt a model of mediation that specifically excluded mediator evaluation. Professor Lisa Bingham explains this choice by noting that the USPS prevails in $90-95 \%$ of all EEO complaints filed against it and that, as a result:

[I]n ninety to ninety-five percent of ... evaluative mediation sessions, the mediator would be telling employees that they have no case or that they will probably not prevail on the merits ... [and, if using] a narrow focus, he or she will steer the parties away from discussing issues unless they are directly related to a legal cause of action .... A program with this system design would probably fail.... As the mediators advised complainants they have no case, the first employees would come back to the workroom floor complaining that the mediator spent all her time explaining why management was right, and that the mediator was biased. Soon no one would bother to use the system. ${ }^{80}$

In addition, USPS officials perceived that transformative mediation would help the agency to realize a "benefit for employee relations" beyond the "ability to resolve a given dispute," 81 due to the model's emphasis upon enhanced communication and mutual understanding between the disputants. ${ }^{82}$ Mediators are directed to focus on "support[ing] and facilitat[ing] parties' efforts to shift their conflict interaction" by using "the opportunities for empowerment and recognition that arise as a conflict unfolds." 83 Achievement of "constructive conflict interaction (increased

76 See Bingham, supra note 29 , at 20-21 (describing the point at which mediation is introduced to try to reach resolution before the filing of a formal complaint); Bingham, supra note 72, at 115, 117-18 (observing that Postal Service sought "effect on dispute processing efficiency" and that formal EEO complaints have dropped significantly since implementation of REDRESS).

77 Bingham, supra note 74, at 115 .

78 Id. at 113.

79 See id. at 115 (noting that $74 \%$ of employees voluntarily chose to participate in USPS REDRESS mediation).

$80 \mathrm{Id}$. at $114-15$.

81 Bingham, supra note 29 , at 21.

82 See Bingham, supra note 74, at 114 .

${ }^{83}$ Antes et al., supra note 75, at 430-31. 
personal clarity, decision-making and, interpersonal understanding)" is the mediator's goal, while resolution is viewed "more as a by-product" of that interaction. ${ }^{84}$ Nonetheless, resolution of EEO complaints remains an important program goal, 85 and the use of transformative mediation has resulted in an $81 \%$ rate of case closure. ${ }^{86}$

At the USPS, the role of professionals (i.e., the agency's lawyers and other officials) in determining the goals and practice that would characterize REDRESS mediation is quite explicit. USPS officials specifically selected the transformative model of mediation for institutionalization in the REDRESS program. The USPS required experienced mediators to participate in free training in the transformative REDRESS model before they were permitted to mediate their first case in the program. ${ }^{87}$ The USPS also trained a special corps of ADR Specialists who were responsible for observing mediators and ensuring that their approach and techniques conformed to the theory of transformative mediation. ${ }^{88}$ The ADR Specialists observed approximately 3,000 mediators in 1999 alone and, using an evaluation tool, screened out mediators who were "unwilling or unable to use transformative practice." 89 The ADR Specialists thus reduced the national roster of REDRESS mediators to about 1,500 transformative mediators. ${ }^{90}$ The USPS also continues to monitor the REDRESS program for quality, voluntary usage rate, and settlement rate.

These two examples illustrate how institutional and professional interests currently drive the goals and techniques that characterize mediation in

84 See DELLA NOCE, MICROFOCUS, supra note 9, at 14; BUSH \& FolGER, supra note 9, at 106-07; Dorothy J. Della Noce, Mediation Theory and Policy: The Legacy of the Pound Conference, 17 OHIO ST. J. ON DISP. RESOL.. 545, 554-55 (2002) (urging that settlement and case management were never the primary goals of mediation until the courts co-opted the process).

85 See Memorandum from Lisa B. Bingham to Nancy Welsh (on file with author) ("Cindy [Hallberlin, former USPS general counsel] has always said that resolution is a good thing .... [S]ettlement should not be the mediator goal, but that does not mean it is an irrelevant program outcome.").

86 See Lisa B. Bingham \& Mikaela Cristina Novac, Mediation's Impact on Formal Discrimination Filing: Before and After the REDRESS ${ }^{T M}$ Program at the U.S. Postal Service, 21 REV. PUB. PERSONNEL ADMIN. 308, 311 (2001).

87 See Tina Nabatchi \& Lisa B. Bingham, Transformative Mediation in the USPS REDRESS ${ }^{T M}$ Program: Observations of ADR Specialists, 18 HoFSTRA LAB. \& EMP. L.J. 399, 404 (2001).
$88 \mathrm{Id}$.
${ }^{89}$ Id. at $404-05$.
90 Id. at 405 . 
different settings. ${ }^{91}$ It is no wonder that the field has faced great difficulty in attempting to develop uniform certification and evaluation standards. Both examples also highlight the need to seek out the voices of disputants themselves in order to determine what they perceive as most valuable in institutionalized mediation. This Article will now turn to mechanisms that have been used to seek out disputants' views and values.

\section{SEEKING THE VOICES OF DISPUTANTS}

The courts and agencies that have institutionalized mediation have regularly sought feedback from disputants regarding their participation in the process. ${ }^{92}$ To date however, such feedback has been derived primarily from voluntary mediation usage rates, exit surveys, and interviews of litigants that occurred when mediation was first introduced into small claims courts. We know based on voluntary usage rates, for example, that few individual disputants choose to use court-connected mediation when such usage is not mandated. This phenomenon suggests that disputants lack enthusiasm for the process. The reason that disputants "vote with their feet" as they do, however, is currently uncertain and thus the subject of speculation..$^{93}$ The

91 There are many other examples of institutionalized practice that have not been included in this brief summary. Most notable among these omissions is labormanagement mediation, which actually has a longer history than those described in the text. See RAU ET AL., supra note 19, at 329-30.

92 Indeed, in the court-connected context, it is striking that traditional litigation generally was not the subject of such evaluation.

93 There are many potential explanations for this phenomenon. Perhaps disputants are simply unaware of mediation and its advantages. See SOCIETY OF PROFESSIONALS IN DisPute Resolution, Mandated Participation and SETTlement CoERCION: Dispute RESOLUTION AS IT RELATES TO THE COURTS 11 (1991). Alternatively, they may fear that suggesting mediation will signal weakness. See RUBIN ET AL., Social Conflict: EsCALATION, StALEMATE AND SETTLEMENT 159 (2d ed. 1994) (observing that because "power equality is often very delicate" in an escalated conflict, disputants "are likely to go out of their way to avoid the appearance of having a strong interest in compromise." They fear that showing such an interest may "undermine the impression that Party is a tough and opportunistic opponent who cannot be forced into doing things against its will.") Perhaps they are uncertain whether they can trust the mediation process and the mediator. Id. at 133 (noting that available and effective "conflict limiting institutions"such as the courts or institutionalized mediation programs-can enhance community stability and reduce the likelihood of conflict escalation if such institutions are viewed as "legitimate and as either unbiased-or biased in the direction of prevailing community norms" and "giving a full hearing and careful consideration to user grievances"). Perhaps once disputants become litigants, they seek externally-imposed, normative accountability and not an opportunity for communication and compromise. See Deborah R. Hensler, Suppose It's Not True: Challenging Mediation Ideology, 2002 J. DISP. RESOL. 81, 95 
result of the phenomenon has been that many courts mandate mediation. In contrast, over $70 \%$ of all USPS EEO complainants elect to participate in that institution's mediation program, ${ }^{94}$ and the program has remained voluntary. It is unclear why there is such disparity in the levels of voluntary usage when comparing these two contexts.

In terms of satisfaction, quantitative studies reveal that both mandatory court-connected mediation programs and the voluntary REDRESS mediation program produce healthy disputant satisfaction with the process. ${ }^{95}$ Quantitative studies also have found that disputants are more likely to be satisfied if their cases settle $\mathrm{e}^{96}$ and that they view dispute resolution processes as fairer if they have the opportunity to express themselves. ${ }^{97}$ Limited quantitative studies have also yielded increased perceptions of process fairness if the mediators evaluate disputants' cases..$^{98}$ In large part, however,

(suggesting that research indicates that litigants expect "legal disputes to be resolved on the basis of public norms-that is what they [think] 'justice' [is] about"). We do not know which, if any, of these possible answers is most accurate.

94 See Bingham, supra note 74, at 115.

95 See Bingham, supra note 29, at 21,25 (reporting a $71 \%$ settlement rate as of March 31, 1996, during the pilot, facilitative phase of REDRESS, as well as high satisfaction rates); Bingham, supra note 74, at $115 \mathrm{n} .56,115-17$ (reporting that $90 \%$ or more of the employees and supervisors report they are satisfied or highly satisfied with the process and the mediator while $60-70 \%$ of the employees and supervisors report that they are satisfied or highly satisfied with the outcome); Chris Guthrie \& James Levin, $A$ "Party Satisfaction" Perspective on a Comprehensive Mediation Statute, 13 OHo ST. J. ON DISP. RESOL. 885, 890 n.10 (1998); Jennifer E. Shack, Bibliographic Summary of Cost, Pace, and Satisfaction Studies of Court-Related Mediation Programs (2003), available at http:// www.caadrs.org/studies/MedStudyBiblio.htm (last visited Nov. 23, 2003) (listing the methodologies, variables examined, and key findings of more than 50 studies of court-connected mediation).

96 Quantitative research suggests quite consistently that disputants are more likely to express satisfaction with mediation when their cases settle. See Shack, supra note 92 (listing the methodologies, variables examined, and key findings of more than 50 studies of court-connected mediation). These results do not necessarily reveal what happened in mediation sessions that made settlement more likely, but they do emphasize the value of settlement.

97 See Bingham, supra note 29, at 26-29 (reporting that in the REDRESS program, disputants' perceptions of procedural justice coupled with full or partial resolution were the strongest indicators of disputants' satisfaction with outcome); Guthrie \& Levin, supra note 92, at 891 n.19; Shack, supra note 95 (listing the methodologies, variables examined, and key findings of more than 50 studies of court-connected mediation); Welsh, supra note 31 , at 820-22.

98 See Wissler, supra note 73, at 679-80, 684-85; see generally ROSELLE WISSLER, TRapPing the Data: AN Assessment of Domestic Relations Mediation in Maine AND OHIO COURTS (1999) (reporting that disputants express more favorable assessments 
we must guess 99 why individual "one-time" disputants turn to mediation, which particular mediator interventions they seek, 100 and which interventions

of the mediation process when mediators suggest possible settlement options, evaluate the merits of the case, and advocate on behalf of the children).

99 Lacking solid data, some commentators have speculated regarding what disputants would be likely to value and why. See, e.g., Sternlight, supra note 23, at 299:

[O]nce this research [regarding disputants' preferences] has been conducted, I believe that it will ultimately show that disputants are generally looking for three benefits from a dispute resolution system: (1) a system that provides them with a substantively fair/just result; (2) a system that meets the procedural justice criteria for voice, participation, and dignity as set out above; and (3) a system that helps them to achieve other personal and emotional goals, such as reconciliation, or that at least does not leave them feeling worse, emotionally and psychologically.

See also Robert A. Baruch Bush, Substituting Mediation for Arbitration: The Growing Market for Evaluative Mediation, and What It Means for the ADR Field, 3 PEPP. DISP. RESOL. L.J. 111, 128 (2003) (suggesting that access to knowledge through the internet will allow a market to emerge "for the kind of process disputing parties themselves want from third-party interveners" and that "non-evaluative mediators may actually have an advantage"); Stempel, supra note 24, at 375 (speculating that "[m]easuring mediation by customer satisfaction may tend to favor facilitation to the extent participants will probably prefer a nonevaluative, nonadversarial experience, at least during the process because this may be less stressful than substantive decision making or directly facing areas of significant disagreement"); Stempel, supra note 23, at 264, 287 (observing that "the most highly sought mediators" provide evaluative feedback and concluding that "many disputants seem to welcome this sort of mediator activity in the apt case"); Alison Taylor, Concepts of Neutrality in Family Mediation: Contexts, Ethics, Influence, and Transformative Process, 14 MEDIATION Q. 215, 230-32 (1997) (proposing a link between clients' preferences regarding mediator actions to clients' view of humans and society as either constrained (i.e., Puritans) or unconstrained (i.e., Enlightenment)); Zumeta, supra note 23, at 340 (acknowledging that "we really do not know what clients would choose" if they understood the differences among models of mediation but betting "that they would choose facilitative mediation").

100 Researchers have conducted observations of mediation sessions to determine which interventions are used. See, e.g., David Greatbatch \& Robert Dingwall, Selective Facilitation: Some Preliminary Observations on a Strategy Used by Divorce Mediators, 23 LAW. \& Soc'y REv. 613, 617-35 (1989); Sarah Cobb \& Janet Rifkin, Practice and Paradox: Deconstructing Neutrality in Mediation, 16 LAW \& SOC. INQUIRY 35, 54-59 (1991); Craig A. McEwen \& Richard J. Maiman, Small Claims Mediation in Maine: An Empirical Assessment, 33 ME. L. REV. 237, 247 (1981) (research design involving follow-up interviews four to eight weeks after mediation sessions had occurred, as well as observation of mediation sessions, and analysis of docket book information and of state court mediation reports). These observations, however, have not been accompanied with pre-mediation and post-mediation interviews of disputants in order to determine their perceptions of the value of the particular mediator interventions they experienced. See also Grace D'Alo, Accountability in Special Education Mediation: Many a Slip 'Twixt Vision and Practice?, 8 HARV. NEGOT. L. REV. 201, 267-68 (2003) (summarizing 
are most likely to produce satisfaction or perceptions of procedural justice. ${ }^{101}$ In other words, while the expectations and preferences of institutions and professionals are increasingly clear, the same cannot yet be said regarding the expectations and preferences of most of the disputants. The survey data from disputants that is currently available-though helpful in many respects-ultimately fails to provide clear guidance regarding the models of mediation, mediation goals, or mediator interventions that disputants perceive as most valuable.

Studies based on in-depth interviews with "one-time" individual disputants, meanwhile, were conducted quite early in the institutionalization of small claims mediation ${ }^{102}$ and focused upon the issues that were most pressing at that time. Often combining questions that required answers on a rating scale and others that permitted open-ended responses, ${ }^{103}$ researchers explored the following: variables that influenced the likelihood of settlement in mediation, ${ }^{104}$ the likelihood of disputants' compliance with mediated

observations of eight special education mediation sessions that occurred along with interviews described in this Article).

${ }^{101}$ See Welsh, supra note 31, at 846-51 (speculating, based on procedural justice literature, about likely disputant perceptions of evaluative interventions); Bingham, supra note 74 , at 116 (observing that some commentators believe that the model of mediation does not influence participant satisfaction).

102 See, e.g., McEwen \& Maiman, supra note 100, at 237; Craig A. McEwen \& Richard J. Maiman, Mediation in Small Claims Court: Achieving Compliance Through Consent, 18 LAW \& SOC'Y REV. 11, 18-19 (1984) (involving a research design of followup interviews-requiring completion of 31-page interview instrument-that occurred four to eight weeks after mediation session or trial, as well as second set of postmediation interviews with a sub-sample of cases six to eighteen months after completion of case in court); Neil Vidmar, An Assessment of Mediation in a Small Claims Court, 41 J. SOC. ISSUES 127, 133-34 (1985) (discussing a research project involving interviews of plaintiffs and defendants prior to "resolution hearing" and six to twelve weeks after each case was resolved by settlement or adjudication); see also Roselle L. Wissler, Mediation and Adjudication in Small Claims Court: The Effects of Process and Case Characteristics, 29 LAW \& SOC'Y. REv. 323, 328-30 (1995) (discussing a study reported in 1995 involving telephone interviews six to twelve weeks following disputants' mediation or adjudication of their cases).

Some research was also done to investigate what litigants want when they decide to seek assistance from attorneys and courts. See, e.g., Sally Engle Merry \& Susan S. Silbey, What Do Plaintiffs Want? Reexamining the Concept of Dispute, 9 JUST. SYS. J. 151,153 (1984) (urging that once plaintiffs seek assistance from attorneys or courts, they want vindication).

103 See, e.g., Vidmar, supra note 102, at 133 (describing interviews as "consist[ing] of structured questions, some requiring answers on rating scales and others allowing open-ended responses").

104 See McEwen \& Maiman, supra note 100, at 250-52 (finding that the likelihood settlement is influenced by the nature of the case, characteristics of the parties, and 
outcomes as compared to adjudicated outcomes (as well as the variables that affected such compliance), ${ }^{105}$ disputants' fairness and satisfaction assessments of mediation as compared to adjudication and the variables influencing such assessments, ${ }^{106}$ the characteristics of mediated outcomes as

mediators' decisions to terminate session in which they perceived that defendants should win; finding that likelihood of settlement is not influenced by the existence of a continuing relationship between the parties); Vidmar, supra note 102, at 134-37 (finding that rates of settlement varied according to type of liability admission, with disputes involving no liability much more likely to go to trial than partial-liability cases); see also Wissler, supra note 102, at 332-33 (finding that disputants' goals for coming to court influenced the likelihood of reaching settlement in mediation; finding that the existence of a relationship did not influence likelihood of settlement).

105 See McEwen \& Maiman, supra note 100, at 260 (finding that disputants were more likely to comply with mediated outcomes than adjudicated outcomes and, based on interviews, finding that defendants who had participated in mediation were more likely than defendants in adjudicated cases to feel a legal or moral obligation to make payments; suggesting, therefore, that the experience of reaching and finalizing an agreement in mediation resulted in higher compliance rates); McEwen \& Maiman, supra note 102, at 42-44 (finding that defendants' compliance with outcomes was influenced by award size, characteristics of defendant, the specificity of settlement terms or payment arrangements, reciprocal obligations, the perceptions of the obligated party regarding the fairness of the outcome, the length of past relationships; suggesting, overall, that defendants are more likely to comply with mediated outcomes because "consent is a powerful adjunct to command in securing compliance... [,] enlist[ing] a sense of personal obligation and honor ... [and] more open than command to the establishment of reciprocal obligations and of detailed plans for carrying out the terms of an agreement"); Vidmar, supra note 102 , at 137-38 (finding that compliance with the outcomes in adjudicated cases was higher in partial liability than in no-liability cases, but that no such pattern could be detected for compliance with outcomes in mediated cases); see also Wissler, supra note 102 , at 348-51 (finding that "defendants were only marginally more likely to comply with the specific monetary award or agreement than were defendants" who adjudicated to resolution and that the mediation and adjudication groups did not differ "in the degree to which they felt obligated to meet the terms of the agreement or award").

106 See McEwen \& Maiman, supra note 100, at 255-57 (comparing adjudication and mediation in terms of disputants' perceptions of: their opportunity to tell their side of the story, their opportunity to explore all issues, the degree to which the third party understood the dispute, their own ability to understand the process, their degree of anger at the conclusion of the processes, and their understanding of the other party's side of the dispute; and finding that "[g]iven these consistent and expected differences between ... mediation and adjudication, it is not surprising that people whose cases were mediated expressed higher levels of satisfaction 'with their overall experience in mediation/court' than those whose cases were adjudicated"); Vidmar, supra note 102, at 138-39 (finding that disputants' satisfaction was not related to whether their case was mediated or adjudicated, but was related to their perceptions regarding the fairness of the "resolution hearing" or trial, perceptions that the other party had been reasonable and the percent or amount of the dispute won by the plaintiff); see also Jonathan F. Anderson \& Lisa Bingham, Upstream Effects from Mediation of Workplace Disputes: Some 
compared to adjudicated outcomes, 107 and disputants' perceptions of the fairness of such outcomes. ${ }^{108}$ More recently, as mediation became a more common fixture in small claims courts, researchers used interviews ${ }^{109}$ to search for dispute and disputant characteristics that increased the likelihood that disputants would choose mediation rather than adjudication, ${ }^{110}$ to probe for disputants' perceptions regarding the differences between mediation and

Preliminary Evidence from the USPS, 48 LAB. L.J. 601, 607 (1997) (reporting that employees and supervisors who participated in REDRESS mediation "overwhelmingly believed mediation to be better than the traditional EEO process"); Wissler, supra note 102 , at $341,343,345-47$ (finding that "the mediation process, regardless of whether it resulted in a settlement, was evaluated as more fair and satisfying than trial"; noting, however, that disputants whose cases did not settle in mediation were somewhat less satisfied than disputants whose cases did settle in mediation and that partial-liability defendants were more likely to evaluate the mediation process and outcome favorably than defendants in no-liability cases; also finding that disputants' goals, relationships, previous experience in small claims court and other disputant characteristics "were not related to either process or outcome evaluations" and suggesting that mediation received more favorable fairness and satisfaction evaluations than adjudication due to its higher scores on such process characteristics as thoroughness, openness, process control, and outcome control).

107 See McEwen \& Maiman, supra note 100, at 253-54 (finding that few mediation agreements involved flexible and creative settlements and that mediated outcomes, on average, involved a lower percentage of plaintiffs' claims than adjudicated outcomes, but that plaintiffs were more likely to win something in mediation than in adjudication); see also Wissler, supra note 102, at 338-41 (finding that "resolution procedure has a stronger effect than limited liability on [the likelihood of] intermediate outcomes and a relatively equal effect on binary outcomes").

108 See McEwen \& Maiman, supra note 100, at 257-60 (finding that mediation deemed their settlements fair a little more often than adjudication litigants and that disputants in mediation were less likely than disputants in adjudication to base their fairness judgments on whether they won or lost); see also Wissler, supra note 102, at 341-42 (finding that disputants' assessments of the fairness of and satisfaction with outcomes was not influenced by whether those outcomes were the result of mediation or adjudication).

${ }^{109}$ See, e.g., Wissler, supra note 102 , at 330 (reporting that the interviews involved "mostly fixed-alternative questions (rated on five-point, Likert-type scales)"); see also Anderson \& Bingham, supra note 106, at 604, 614-15 (research using open-ended questions in in-depth interviews with 29 employees and 13 supervisors who had participated in REDRESS mediation sessions).

110 Wissler, supra note 102 , at 332 (finding that disputants' choice of mediation versus adjudication was not influenced by their goals for coming to court, conflict intensity, nature and length of relationship, litigants' evaluations of the other party, precourt settlement attempts, type of dispute or demographic information; also finding that adjudicated cases differed from mediated cases in the extent of liability admitted by the defendant and the type of dispute). 
adjudication, ${ }^{111}$ and to discern mediation's long-term effects. ${ }^{112}$ These research projects, however, preceded much of the evaluative, facilitative, or transformative debate as well as awareness of the different forms that mediation can take in different settings. ${ }^{113}$ Like the quantitative studies described supra, these interviews with disputants offer tantalizing clues regarding disputants' preferences but reveal neither what disputants perceive as the primary value of mediation nor the effects of different mediator interventions. ${ }^{114}$

To compound the confusion regarding individual disputants' preferences, commentators and researchers in court-connected mediation often implicitly assume that the preferences expressed by attorneys mirror those of their clients. ${ }^{115}$ This assumption, while consistent with the unique role of attorneys, is not necessarily well-founded. Attorneys often fail to hear their

111 Id. at 334-37 (finding that disputants were able to distinguish between mediation and adjudication based on the following attributes: length of session, whether the session was hurried or unhurried, the number of solutions discussed, the degree of disputant control over presentation or opportunity to tell one's story, the thoroughness of each procedure, the degree of disputant control over outcome, the level of formality, the degree of openness, the understandability of the procedure, and the prevalence of discussion or arguments).

112 See, e.g., id. at 347-48 (finding that disputants who had reached a resolution in mediation rated the other disputant less negatively and were more likely to report that the other person had tried to understand their point of view); Anderson \& Bingham, supra note 106, at 607 (1997) (finding that 92\% of interviewed supervisors believed that mediation had affected how they handle conflict, but only $28 \%$ of employees reported similar effects).

113 But see generally Anderson \& Bingham, supra note 106 (this research project, which examined REDRESS mediation sessions, focused very much upon whether transformative mediation's "empowerment and recognition" had occurred, and whether the mediation had affected disputants' subsequent conflict interactions).

114 Researchers have sometimes observed whether mediators tended to be "directive" or to engage in "evaluative" interventions, but did not then try to determine whether different interventions produced different perceptions of mediation's value. See, e.g., McEwen \& Maiman, supra note 100, at 251, 255 (observing that some mediators evaluated cases, while others did not; also observing that "small claims mediation in Maine is quite directive and generally focused on issues relating to the amount of the claim and responsibility for it"); McEwen \& Maiman, supra note 102, at 15,42 (describing small claims mediators' use of evaluative techniques such as assessing relative merits of cases, proposing possible settlements and focusing parties' attention upon comparison of transaction costs).

115 See Stempel, supra note 24, at 390 (observing that "studies to date have been content to measure either attorney satisfaction as a proxy for party satisfaction or to measure satisfaction on the heels of the settlement" and that "there must be sustained examination that does not measure party attitude only in the near aftermath when there may be either disappointment or euphoria"). 
clients' experiences, perceptions, or objectives. ${ }^{116}$ Further, research has demonstrated that attorneys' reactions to court-connected processes can diverge dramatically from their clients' reactions. ${ }^{117}$ Attorneys' knowledge of the law and facility with legal language and procedures-while essential to the provision of competent representation-also serve to distance attorneys from the needs, expectations, and perceptions of their clients. ${ }^{118}$ Indeed, attorneys often perceive themselves as dealing with clients who expect more than is possible. ${ }^{119}$ It should not be surprising, given the

116 See Clark D. Cunningham, The Lawyer as Translator, Representation as Text: Towards an Ethnography of Legal Discourse, 77 CORNELL L. REV. 1298, 1367-85 (1992) (describing lawyers' translation of clinical client's case in which case was viewed and litigated as a "stop and frisk" case rather than a case involving racial harassment); Gay Gellhorn, Law and Language: An Empirically-Based Model for the Opening Moments of Client Interviews, 4 CLINICAL L. REV. 321, 350-53 (1998) (describing clinical law student's failure to hear client's concern regarding her mental state); Hensler, supra note 24, at 156-63 (contrasting tort plaintiffs' desire for accountability and vindication of legal rights with lawyers' monetary focus in assessing claims); Carl Hosticka, We Don't Care About What Happened, We Only Care About What is Going to Happen, 26 SOC. PROBS. 599, 600-04 (1979) (describing lawyer-client interviews in which lawyers quickly interrupted client's narrative and began pursuing legal pigeonhole for case); Jean Sternlight, Lawyers' Representation of Clients in Mediation: Using Economics and Psychology to Structure Advocacy in a Nonadversarial Setting, 14 OHIO ST. J. ON DISP. RESOL. 269, 320-31 (1999) (describing monetary, non-monetary, and psychological divergences between lawyers and clients that result in lawyers blocking settlements or causing settlements in a manner that is inconsistent with clients' selfdefined interests).

117 See, e.g., Wayne Kobbervig, Mediation of Civil Cases In Hennepin COUNTY: AN EVALUATION 23-25 (1991) (demonstrating that litigants in mediation rated it more favorably than did litigants in adjudication, while attorneys rated adjudication more highly and that attorneys were much more likely than litigants to assess adjudication as efficient).

118 See Felstiner et al., supra note 25, at 645 (invoking "evidence that lawyers often shape disputes to fit their own interests rather than those of their clients"); David L. Chambers, 25 Divorce Attorneys and 40 Clients in Two Not So Big but Not So Small Cities in Massachusetts and California: An Appreciation, 22 LAW \& SOC. INQUIRY 209, 213 (1997). Chambers notes:

[M]eaning" and "power" are the two themes that Sarat and Felstiner stress. The meaning of the failed marriage, of law itself, and of the legal process is constructed, they argue, through the conversations between client and lawyer. Clients and lawyers "negotiate" over meaning in a different shadow of the law than that which Mnookin and Kornhauser (1979) modeled for the negotiations between opposing parties. Each comes with predictable sets of perceptions and goals, and each engages in subtle tactics to induce the other to adopt their views.

Id.

119 See Chambers, supra note 118, at 211. Chambers notes that in Divorce Lawyers and Their Clients, Sarat and Felstiner: 
tensions inherent in the attorney-client relationship and the distance created by professionalization, that disputants' voices regarding the place and value of mediation might diverge from the voices of their attorneys.

One group of clients, however, has received special attention in the current discussion regarding the goals and interventions that ought to characterize mediation. Researchers have solicited the perceptions and expectations of corporate clients, in part because "if lawyers and corporations make expanded use of mediation, others will pay attention." 120 Professor John Lande, for example, conducted face-to-face and telephone interviews with business executives ${ }^{121}$ and found that the executives perceived mediation as a significant improvement over the distasteful, expensive, timeconsuming, and adversarial process of litigation. Professor Lande observed "a general thinking pattern in which respondents evaluated ADR by comparison with traditional litigation" 122 and that "executives' belief in mediation may be a function, at least in part, of their desire to avoid the problems that they generally experience with litigation." 123 Thus, in

[D]escribe the absorption of nearly all clients with their grievances against their spouses. Clients commonly attribute the breakup of their marriage and unfortunate events during the divorcing process to their spouse's flawed character. They talk about these failings in part to gain their lawyer's loyalty and in part because they seek justice. The lawyers are uninterested in the failings of their clients' spouses, because they regard them as irrelevant to a successful resolution of their client's case. Thus, they respond by listening politely and noncommittally ("mmn-uh," says the first lawyer whose words we hear). "Client and lawyer are like performer and bored, dutiful audience-the lawyer will not interrupt the aria, but she will not applaud much, either, for fear of an encore."

Id. (citing Austin Sarat \& William L. F. Felstiner, Divorce Lawyers and Their Clients: POWER AND MEANING IN THE LeGal PROCESS 37 (1995)); see also JeNNIFER Bundang et AL., Multi-Option ADR PROJECT: EVAluation REPORT MARCH 2000JANUARY 2001, SuPERIOR COURT OF CALIFORNIA, COUNTY OF SAN MATEO 18-19 (Jan. 2001) (reporting that plaintiffs' satisfaction rates were lower than those of their attorneys and that the plaintiffs' attorneys' satisfaction with neutrals was higher than those of their clients, defendants or defendants' counsel).

120 Nancy H. Rogers \& Craig A. McEwen, Employing the Law to Increase the Use of Mediation and to Encourage Direct and Early Negotiations, 13 OHIO ST. J. ON DISP. RESOL. 831, 840-42 (1998) (describing quantitative and qualitative research regarding corporate use of mediation).

121 Most of whom had experience with neither litigation nor ADR proceedings. John Lande, Getting the Faith: Why Business Lawyers and Executives Believe in Mediation, 5 HARV. NEGOT. L. REV. 137, 168-69 (2000) (reporting that 74\% of the business executives had never been a party to a lawsuit and $61 \%$ had never participated as parties in ADR proceedings).

122 Id. at 178 .

$123 \mathrm{Id}$. at 213. 
comparison with litigation, mediation offers attractive time and cost savings. ${ }^{124}$ But what inherent value does mediation offer for these disputants? The business executives interviewed by Professor Lande emphasized "bottom line" results: mediation offered a greater opportunity to preserve business relationships and a greater likelihood that the top executives would be satisfied with the outcomes. ${ }^{125}$ These research results provide insights into the goals that corporate disputants believe should characterize mediation. They turn to mediation for resolution and the ability to move forward with relationships deemed "valuable." This suggests at least a partial disconnect from the "transformative" model of mediation and its rejection of settlement as a goal. The results of this research do not, however, provide any guidance regarding the particular mediator interventions that these disputants perceive as most valuable.

It is also questionable whether the views of these corporate disputants (or other likely "repeat players") are likely to be representative of the views of individual, "one-time" disputants. Research in court-connected arbitration has demonstrated a divergence between the perceptions and expectations of corporate representatives as compared to individual litigants. ${ }^{126}$ Further,

${ }^{124}$ Craig McEwen recently concluded that in disputes involving corporate disputants, issues of "time and cost appear to be tightly interwoven with issues of quality." Craig A. McEwen, Managing Corporate Disputing: Overcoming Barriers to the Effective Use of Mediation for Reducing the Cost and Time of Litigation, 14 OHIO ST. J. ON DisP. RESOL. 1, 4 (1998).

125 Lande, supra note 121, at 211-13; see also Catherine Cronin-Harris \& Peter H. Kaskell, How ADR Finds a Home in Corporate Law Departments, 15 ALTERNATIVES To HigH COST LITIG. 158 (1997) (finding that corporate law departments viewed top benefits of mediation as costs savings, savings of lawyers and executives' time, faster results, and preservation of business relationships); David B. Lipsky \& Ronald Seeber, In Search of Control: The Corporate Embrace of ADR, 1 U. PA. J. LAB. \& EMP. L. 133, 138-39 (1998) (describing a Cornell/PERC Institute on Conflict Resolution survey of the corporate counsel of the 1,000 largest U.S.-based corporations which found that they perceived mediation as saving time and money, providing control over outcomes, offering a more satisfactory process than litigation, and resulting in more satisfactory settlement).

126 See, e.g., JANE W. AdLER ET AL., Simple JUSTICE: How LITIGANTS FARE IN THE PITTSBURgh COURT ARBITRATION PROGRAm 76, 83 (1983) (noting that, unlike "unsophisticated individual litigants," institutional litigants who made extensive use of the arbitration program "appear[ed] to care little about qualitative aspects of the hearing process .... They judge arbitration primarily on the basis of the outcomes it delivers."); David B. Wilkins, Everyday Practice Is the Troubling Case: Confronting Context in Legal Ethics, in EVERYDAY PRACTICES AND TROUBLE CASES, supra note 21, at 68, 84-86 (1998) (contrasting corporate clients with individual clients); see also Bingham, supra note 29, at 26-27 (reporting that although both employees and their supervisors expressed satisfaction with mediation, employees were less satisfied than supervisors and 
there is some suggestion that corporate clients (and other repeat players) can assume a degree of control-or self-determination ${ }^{127}$-over the model of mediation that they will use that is highly unlikely for most individual, "onetime" disputants participating in the mass processing of their cases. ${ }^{128}$

Thus it is the voices of individual disputants, responding to open-ended questions, which need to be invited into the current discussion regarding the goals and practices that ought to characterize institutionalized mediation. Such inclusion is difficult. In court-connected mediation, for example, most individual, "one-time" litigants do not interact informally or regularly with the directors of mediation programs, mediators, or judges. ${ }^{129}$ Researchers

suggesting that such divergence can be explained by differences in expectations). But see generally E. Allan Lind et al., Individual and Corporate Dispute Resolution: Using Procedural Fairness as a Decision Heuristic, 38 ADMIN. SCI. Q. 247 (1993) (reporting that researchers found that procedural justice judgments strongly influenced litigants' decisions about whether or not to accept nonbinding arbitration awards, regardless of whether litigants were individuals, small business owners, or corporate officers; only corporate employees demonstrated no link between their procedural justice judgments and their decisions to accept awards).

127 See Lisa Bingham, Self-Determination in Dispute System Design and Mandatory Commercial Arbitration, 53 LAW \& CONTEMP. PROBS. (forthcoming 2003) (on file with author) (distinguishing between "disputant self-determination in the design of the system as a whole, and disputant self-determination within a given case using a specific dispute resolution process provided by the overall system design).

128 See FOLGER ET AL., supra note 20, at 87-89, 94-95, 111-12 (observing that court-connected mediation programs' goals and practices evolve in response to the stakeholders who make their voices heard on a day-to-day and informal basis and that clients are not likely to be among these stakeholders). Bryant Garth has also written recently:

[M]y point is not that the courts are losing important cases and left with those clients who cannot afford luxury ADR. It is that the elite have a full array of alternatives, including the federal courts, which they can use for tactical and other reasons. This elite sphere is difficult to enter as a lawyer or as a neutral; the sphere is relatively small, but the impact on the rest of the system is quite strong. With justice now rationed according to the market, much of the system is allocated to this group, and those occupying lower rungs typically aspire to move up to this higher stakes, higher status, higher rewards level (and often act accordingly).

Bryant Garth, Tilting the Justice System: From ADR as Idealistic Movement to a Segmented Market in Dispute Resolution, 18 GA. ST. U. L. REV. 927, 932 (2002).

129 See FOLGER ET AL., supra note 20, at 87-89, 94-95, 111-12 (observing that court-connected mediation programs' goals and practices evolve in response to the stakeholders who make their voices heard on a day-to-day and informal basis and that clients are not likely to be among these stakeholders). 
experience great difficulty in reaching these disputants. ${ }^{130}$ Mediation program directors worry about the consequences of providing researchers with access to mediation participants, particularly due to the potential negative impact such access may have upon confidentiality. ${ }^{131}$ The inclusion of individual disputants' voices also may be threatening. One of the results of professionalism is that professionals are acknowledged as understanding more about what they do than lay persons possibly can. ${ }^{132}$ As mediators increasingly define themselves as professionals, the views of one-time disputants can be viewed as uninformed and largely irrelevant. ${ }^{133}$

Nonetheless, seeking out and listening to the voices of individual disputants should be particularly important in a democracy that proclaims the value and dignity of the individual ${ }^{134}$ and in a field that names disputants'

130 They often do not have access to the disputants' addresses or telephone numbers and, even if they do, the disputants often do not return surveys or respond to telephone calls.

131 See, e.g., Antes et al., supra note 75, at 432 (observing that "in-depth interviews with the disputants themselves were not possible because of confidentiality restrictions and difficulties in gaining access to the participants for in-depth interviews"). Such difficulties have also arisen in researchers' attempts to examine clients' perceptions of attorney-client interactions. See Chambers, supra note 118, at 215-26 (describing cases studied by Sarat and Felstiner, their sampling methods, and method of gaining access to attorneys and clients and raising questions regarding the impact of observers' presence, the representativeness of the sample, the frequency and context of various patterns observed in attorney-client interactions, and the connection between these interactions and the "meanings" that were acted upon and achieved).

132 See Julianna Birkoff et al., Points of View: Is Mediation Really a Profession?, DisP. RESOL. MAG., Fall 2001, at 10, 10-11:

[I]n our society, a group of people may claim and the public may grant them a license to provide an exclusive service. Because this is specialized work, the professionals begin to know more about what they do than the public does. Because of this exclusive knowledge, the public begins to provide privileges to each profession including the discretion and control over their own mode of work. In exchange, the public asks each profession to protect the welfare of the people it serves.

133 In a few programs, mediators may actually be threatened by attempts to reach disputants. When some court-connected mediation programs in Florida, for example, stopped using questionnaires to gamer disputants' feedback, volunteer mediators interpreted the change in procedure as a sign of confidence in their skills and acceptance by the courts. FOLGER ET AL., supra note 20, at 94.

134 See Cohen, supra note 33, at 768-89 n.88 (providing examples of attempts to link civil procedure, social order, and due process to human dignity; also noting that listening to a person's voice is central to respecting his/her dignity); Lon Fuller, Means and Ends, in THE PRINCIPLES OF SOCIAL ORDER: SELECTED ESSAYS OF LON FULLER 61 (Kennith I. Winston ed., 2001) ("[W]e are not interested merely in order-the order, say, 
self-determination ${ }^{135}$ as its fundamental underlying principle. ${ }^{136}$ Indeed, seeking out and listening to the voices of individual disputants is essential for the maintenance of the legitimacy of the various public institutions that now embrace mediation. ${ }^{137}$ This Article will now turn to those voices.

of a concentration camp-but in an order that is just, fair, workable, effective, and respectful of human dignity.").

135 See Welsh, Thinning Vision, supra note 16, at 15-21 (describing an early vision of self-determination); see also RoBERT DINGWALL \& JOHN EEKELAAR, DIVORCE MEDIATION AND THE LEGAL PROCESS, Preface (Robert Dingwall \& John Eekelaar eds., 1988) (noting that the literature written by mediation enthusiasts "rests upon specific value premises which have often gone unrecognized. American writers, for instance, reflect major themes of their national culture in their description of mediation as a step toward a utopia of self-sufficient citizens defending their private interests by negotiation unaffected by state intervention"). But see Hensler, supra note 93, at 94; Susan Silbey, The Emperor's New Clothes: Mediation Mythology and Markets, 2002 J. DISP. RESOL. 171, 177 (arguing that mediation is not the "magical process" that "mediation ideologues" advertised, that the mediation movement did not arise out of disputants" desires for conflict resolution, but that "legal elites, social scientists, access to justice and community empowerment advocates, together forged the . . movement").

136 See Carrie Menkel-Meadow, Whose Dispute Is It Anyway?: A Philosophical and Democratic Defense of Settlement (In Some Cases), 83 GEO. L.J. 2663, 2670-71 (1995):

When, in a party-initiated legal system, should party consent be "trumped" by other values-in other words, when should public, institutional, and structural needs and values override parties' desire to settle or courts' incentives to promote settlement? In short, when is the need for 'public adjudication' or as Luban suggests, 'public settlement' more important (to whom?) than what the parties may themselves desire?

137 See Lind, supra note 21, at 188 (summarizing studies showing that perceptions of authorities' legitimacy correlate with procedural justice judgments); LIND \& TYLER, supra note 21 , at $66-70,205,209$ (summarizing studies that have found that procedural justice judgments affect disputants' perceptions of substantive justice and their evaluation of authorities and institutions); Tyler, supra note 21 , at 863 (discussing potential political consequences of ignoring public opinion; TYLER, supra note 21, at 94-108 (1990) (finding that procedural faimess judgments influence perceptions of the legitimacy of legal authority and that this effect is particularly strong for the courts). Some very thoughtful judges have recognized the importance of procedural justice in maintaining citizens' respect for the courts. See, e.g., Brazil, Comparing Structures, supra note 21, at 727-28; Brazil, Continuing the Conversation, supra note 21, at 24. The courts' "most precious asset is the public's trust" and such trust is grounded in the public's belief "that the aspect of justice for which [the courts] are primarily responsible is process faimess, process integrity. It follows that the characteristic of our ADR programs about which we must be most sensitive is fairness, especially process faimess." Id. 


\section{THE VoICES OF DISPUTANTS WITHIN SPECIAL EDUCATION MEDIATION}

\section{A. Research Methodology}

What do individual disputants want and expect from the mediator and from the institutionalized mediation process itself? After the process has concluded, what do these disputants perceive as "value-added?" What parts of the process or what mediator interventions raise particular concerns?

To answer these questions, a qualitative research project was undertaken, involving intensive interviews with parents and school district officials involved in cases mediated by Pennsylvania Special Education Mediation Services (PaSEMS) ${ }^{138}$ in November and December 2000. ${ }^{139}$ Though the legitimacy of qualitative research has long been the subject of debate, this form of research, which is based in "real life," is "fundamentally well suited for locating the meanings people place on the events, processes, and structures of their lives."140 Qualitative research is also advocated as the "best strategy"141 for developing hypotheses, testing hypotheses against reallife evidence, and helping to explain, supplement, or dispute quantitative data. Even small qualitative studies and individual case studies have been instrumental in allowing the creation and testing of theories in a manner that is directly tied to evidence. ${ }^{142}$

All research projects have limitations, and this study is no exception. ${ }^{143}$ A total of seventy interviews were conducted, but the relatively small number of cases involved in this research project must be acknowledged as a limitation in assessing the validity and the generalizability of the themes that emerge. ${ }^{144}$ Ultimately, the disputants' perceptions described here are particularly significant to the extent that they mirror-or contradict-the

138 Now named the Office of Dispute Resolution, Pennsylvania Department of Education.

139 PaSEMS agreed to provide access to the disputants for a period of seven weeks.

140 Matthew B. Miles \& A. Michael Huberman, Qualitative Data Analysis: AN EXPANDED SOURCEBOOK 10 (2d ed. 1994).

141 Id.

142 See Kathleen Eisenhardt, Building Theories from Case Study Research, in THE Qualitative ResearChER's CoMPANION 5, 29 (A. Michael Huberman \& Matthew Miles eds., 2002) (describing the strengths and weakness of building theory from case studies).

143 My thanks to Julie Winterich, Assistant Professor of Women's Studies at Dickinson College, for this observation.

144 See Joseph A. Maxwell, Understanding and Validity in Qualitative Research, in THE QuAlitaTIVE RESEARCHER's COMPANION, supra note 142, at 37-55 (describing different understandings of validity and generalizability). 
assumptions held by mediators, academics, attorneys, courts, and agency officials regarding what disputants want from mediation and what interventions they view as serving them best.

The author and Grace D'Alo, who was then the Director of PaSEMS, ${ }^{145}$ conducted seventy interviews in fourteen of the seventeen cases that were scheduled to go to special education mediation during the study period. ${ }^{146}$ In

145 As is often true in "action research," Ms. D'Alo's participation in this research project was extremely valuable, both because her internal advocacy was instrumental to the project's implementation and her participation permitted an information feedback loop to the agency. See generally Preston A. Britner et al., Evaluating Juveniles' Competence to Make Abortion Decisions: How Social Science Can Inform the Law, 5 U. CH. L. SCH. ROUNDTABLE 35 (1998) (calling for action research to describe the impact of involving juveniles in decisionmaking); Paul T. Wangerin, "Alternative" Grading in Large Section Law School Classes, 6 U. FLA. J.L. \& PUB. POL'Y 53 (1993) (noting the methodological problems and value of action research).

Of the total interviews, the author conducted 61, and Ms. D'Alo conducted nine. In addition, Ms. D'Alo observed six and the author observed two of the 12 mediation sessions that occurred, using performance scales that had been developed specifically for PaSEMS' program. See D'Alo, supra note 100, at 205-6, 201, 216 (describing the development of the performance scales, analyzing the performance of the eight mediators who were observed, and suggesting the need for the development and implementation of mediator evaluation instruments that capture stakeholder goals). The author had all of the interviews transcribed, coded all of them, did all of the analysis, and wrote this Article.

146 All of the parents and school officials whose cases were scheduled to proceed to mediation during the research period were contacted initially by a PaSEMS staff member who used a prepared script to describe the research project and determine potential interviewees' willingness to participate in the project. Potential interviewees were told that their responses would be used both to improve the quality of PASEMS' services and to benefit the larger mediation field. As part of the human subjects review process, the interviewees also were promised that their identities would not be revealed. Except in one case (in which the amount of time between the scheduling and date of the mediation was short and the school official had not decided whether s/he was willing to be part of the research project), interviews were not conducted unless both the parent and the school official agreed to participate in the research project. During the seven-week research period, PaSEMS held mediation sessions in sixteen cases. Pre-mediation and postmediation interviews with both the parent and the school official were conducted in twelve of those cases; in one of the sixteen cases that actually went to mediation, interviews were conducted with only the parent; in only three of the sixteen cases that actually went to mediation, no interviews were conducted. Thus, pre-mediation and postmediation interviews were conducted with both the parent and school official in $75 \%$ of the cases that were eligible for inclusion in this study (because they proceeded to mediation during the study period); interviews were conducted with at least one of the disputants in $81 \%$ of the cases that were eligible for inclusion. Pre-mediation interviews also were conducted in one additional case in which the mediation session ultimately was cancelled.

Approximately eighteen months later, follow-up interviews were conducted in ten of the twelve cases in which both the parent and the school official had been interviewed 
twelve of the sixteen cases that actually proceeded to mediation during this period, ${ }^{147}$ the parents and school officials were interviewed three times: immediately before the mediation session to determine why they had chosen to use mediation and what assistance they hoped the process and mediators would provide; 148 immediately after the mediation session to determine what they had found helpful and important, what they had found unhelpful, their reactions to particular interventions, their levels of satisfaction with the process and outcome, and their perceptions of procedural and substantive justice; 149 and approximately eighteen months after the mediation session to determine what they considered significant at that time and their level of satisfaction with the mediation process. ${ }^{150}$ The interviews were tape

previously; in one of the two remaining cases, neither the parent nor the school official could be located and in the other the author believed the post-mediation transcripts to be lost, thus removing the case from the research project. The transcripts were later found, but long after the eighteen-month checkpoint had passed.

All of the questions listed in the interview instruments (See infra Appendices A-C) were asked during the interviews. In addition, based on the flow of an individual interview, the interviewer asked follow-up questions. The author thanks both Donna Stienstra and Deborah Hensler for their assistance with the development of the interview instruments.

147 The mediation session in one of these seventeen scheduled cases was cancelled. In that case, one pre-mediation interview, with the parent, was conducted.

148 See Pre-Mediation Interview Instrument, at Appendix A. These interviews lasted from 30 to 60 minutes.

149 See Post-Mediation Interview Instrument, at Appendix B. These interviews lasted from 45 to 60 minutes.

150 See Eighteen-Month Post-Mediation Interview Instrument, at Appendix C. These interviews lasted from 10 to 30 minutes. These interviews were not conducted in one of the 12 cases because neither the parent nor the school official could be located and in another because the author believed the post-mediation transcripts to be lost, thus removing the case from the research project. The transcripts were later found, but it was long after the 18-month checkpoint had passed. 
recorded, transcribed, and analyzed. ${ }^{151}$ The specific method of qualitative research used in this study was grounded theory. 152

The cases analyzed here involved disputes regarding a variety of special education issues including: the sufficiency of evaluations of children who had applied for gifted services; the appropriateness of educational services and placements; compensation for educational services that had been deemed insufficient; entitlement to transportation services; and the appropriateness of school decisions regarding awards for completion of course work. The cases also involved students of various ages, ranging from seven to seventeen. ${ }^{153}$ The mediation sessions occurred because both the parents and school officials agreed to participate. In most instances, the parents made the initial request for mediation. In a few instances, the school districts proposed mediation. Generally these requests for mediation were made after meetings between the parents and school officials in which the school officials presented proposals to the parents regarding children's services, placement, evaluation, or compensatory education. Both parents' and school officials' mediation requests followed parents' refusals to agree with the school officials' proposals. Sometimes, the mediation requests were accompanied by requests for due process hearings if agreements were not reached in mediation.

Only one of the parents involved in these mediation sessions had any prior experience with the process; she had participated previously as an

151 During the first step in this analysis, the author reviewed all of the transcripts and wrote case memoranda that provided overviews of the pre-mediation and post-mediation data from each case and developed tentative categories and relationships. Then, using NVivo computer software, the author coded the transcripts. In essence, coding involves assigning category labels or "units of meaning to the descriptive or inferential information compiled during a study." MILES \& HUBERMAN, supra note 140 , at 56. The codes are then used to retrieve and organize information. Coding permits transcripts to be "dissect[ed] meaningfully, while keeping the relations between the parts intact" which is, of course, "the stuff of analysis." Id. The author used displays of the coded data, as well as the case memoranda, to detect themes or patterns.

152 A grounded theory is described as theory "that was derived from data, systematically gathered and analyzed through the research process. In this method, data collection, analysis, and eventual theory stand in close relationship to one another." Indeed, the researcher "allows the theory to emerge from the data." ANSELM STRAUSS \& Juliet CoRbin, Basics of QualtTATIVE RESEARCH: TECHNIQUES AND PROCEDURES FOR DEVELOPING GROUNDED THEORY 12 (2d ed. 1998).

153 Two of the children were seven years old; five students were between the ages of 11 and 14; and four of the students were 16 to 17 years old. See Peter J. Kuriloff \& Steven S. Goldberg, Is Mediation a Fair Way to Resolve Special Education Disputes? First Empirical Findings, 2 HARV. NEGOT. L. REV. 35, 63-66 (observing that disputes involving. children who have been in special education for a long time tend to be more difficult). 
advocate. ${ }^{154}$ Most of the school officials, in contrast, had participated in special education mediation sessions before. Indeed, some of these officials had prior mediation experience with the particular mediator assigned to the case examined in this research project. ${ }^{155}$ Two of the mediation sessions involved the same school district, and the same official represented the district in both sessions. A total of eight mediators were involved in the twelve cases in which both parents and school officials were interviewed; two of these mediators mediated twice and one mediator mediated three times. Consistent with its policy, PaSEMS did not permit any attorneys to attend the mediation sessions. Advocates, however, were permitted to attend and actually accompanied the parents in two of the mediation sessions. School districts were limited to sending three representatives to participate in each session and were required to send a representative with the authority to commit resources. ${ }^{156}$

Prior to the mediation sessions, both the parents and school officials received confirmations of the timing of their sessions and the issues to be addressed. They also received a thorough description of the mediation process, their roles within it, and relevant Pennsylvania regulations and standards. These materials described the mediator as "a neutral third party in the process, [who] facilitates discussion and enables the parties to either develop a written agreement, or, in a small number of cases, agree to disagree." 157 The materials also indicated that "[m]ediators help parents and school personnel understand each other's point of view and develop a plan that they are comfortable with and can implement together. In many cases, going through the mediation process helps parents and school districts build the trust necessary to resolve future disputes." 158 Finally, mediation was described as a process that "promotes a positive relationship between the parents and the school, and focuses on mutual problem solving. It is less stressful, less expensive, and usually less time-consuming to complete than a hearing." 159

As must be evident from the description of mediation provided to the disputants, the special education mediation process exists within the context of special education law and procedures. A brief overview of this context is

154 Telephone Interview with parent (Case 12, pre-mediation) (Dec. 15, 2000).

155 Interview with school official (Case 1, post-mediation) (Nov. 9, 2000); Interview by Grace D' Alo with school official (Case 8, post-mediation) (Dec. 5, 2000).

156 See 22 PA. CODE $\$ 342.65$ (e) (2003).

157 Pennsylvania Department of Education, Your GuIDE To MEDIATION: PenNSylvania SPECIAL EduCATION MEdiation SERVICE 1 (1998), available at http://www.pattan.k12.pa.us/ODR/Med\%P\&G.htm (last visited Nov. 24, 2003).

158 Id.

159 Id. 
necessary to understand how the substantive law and procedural requirements in this area influence the expectations, ${ }^{160}$ roles, and relative degrees of power of parents and school officials in determining children's educations and allocating public resources-and thus influence parents' and school officials' perceptions of the value of mediation and particular mediator interventions.

\section{B. The Specific Context of Special Education Mediation}

Congress amended the Individuals with Disabilities Education Act (IDEA or the Act) in 1997 to mandate the use of special education mediation by all of the states. ${ }^{161}$ The Pennsylvania Department of Education, however, first institutionalized mediation to resolve special education disputes in 1988. ${ }^{162}$ Indeed, Pennsylvania was a pioneer in this area.

The IDEA (and its statutory predecessors) provides that children with disabilities are entitled to "free appropriate public education that emphasizes special education and related services designed to meet their unique needs." 163 The Act also provides that disabled children should be educated in

160 See Robert H. Mnookin \& Lewis Kornhauser, Bargaining in the Shadow of the Law: The Case of Divorce, 88 YALE L. J. 950, 959-66, 968 (1979) (discussing how the "shadow of the law" affects the negotiation of disputes); Guthrie \& Levin, supra note 95, at 888-89 (describing the impact of parties' expectations upon their satisfaction with the mediation process).

161 See 20 U.S.C. § 1415 (1997) (amended 1999); see also 20 U.S.C. §§ 1400-1491 (2000).

162 See D'Alo, supra note 100, at 206 (describing the history of Pennsylvania's special education mediation program).

16320 U.S.C. $\$ 1400$ (d) (1) (A) (2000). The Act defines a "free appropriate public education" as:

[S]pecial education and related services that (A) have been provided at public expense, under public supervision and direction, and without charge, (B) meet the standards of the State educational agency, (C) include an appropriate preschool, elementary, or secondary school education in the State involved; and (D) are provided in conformity with the individualized education program ...."

20 U.S.C. \& 1401(8) (2000).

For a concise, yet comprehensive, three-part overview of special education law, see, for example, Robert E. Rains, A Primer on Special Education Law in the United StatesPart 1: The Development of the Education for All Handicapped Children Act of 1975, Public Law 94-142, 10 EDUC. \& L. 5 (1998); Robert E. Rains, A Primer on Special Education Law in the United States-Part 2: Major Supreme Court Interpretations of Federal Special Education Law and the Evolving Statutory and Case Law, 10 EDUC. \& L. 135 (1998); Robert E. Rains, A Primer on Special Education Law in the United States--Part 3: Remedies for Misdiagnosis or Misplacement of Special Education Students, 10 EDuC. \& L. 205 (1998). 
regular classrooms with non-disabled students to the maximum extent appropriate. ${ }^{164}$

In addition to establishing substantive entitlements, the IDEA requires states to provide several procedures designed to safeguard these entitlements. Perhaps most importantly, the act entitles each child to a written "individualized education program" (IEP), and further, establishes that parents and guardians are entitled to be involved in the development of this document. The IEP meeting is supposed to include the child's parents or guardian, the child "whenever appropriate," and involved education professionals. ${ }^{165}$ Congress also requires that states provide to parents or guardians an impartial due process hearing to resolve disputes, with appeal to the state educational agency and then to a state or federal court. ${ }^{166}$

The IDEA ${ }^{167}$ has been tremendously successful in providing access to public schools for children with disabilities. ${ }^{168}$ Nonetheless, in Pennsylvania and elsewhere, parents and school districts have clashed repeatedly over the standard to be used in determining whether children's educational programs are "appropriate" and sufficiently "individualized." It is beyond the scope of this Article to detail the difficult and conflicting developments of the law in this area, 169 but in those states located within the Third Circuit (which includes Pennsylvania), children are entitled to receive from schools an educational program that provides a "meaningful educational benefit."170

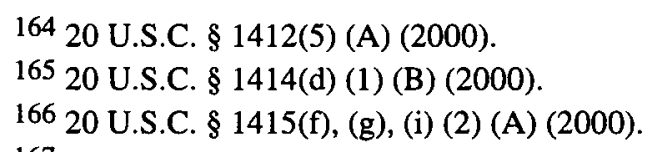

167 The name was changed from the Education of the Handicapped Act (EHA) to the Individuals with Disabilities Education Act (IDEA) in 1991.

168 See H.R. REP. NO. 105-95, at 89 (1999) (indicating that as of 1997, 5.5 million children were receiving special education through federal and state funds); Tara L. Eyer, Comment, Greater Expectations: How the 1997 IDEA Amendments Raise the Basic Floor of Opportunity for Children with Disabilities, 103 DICK L. REV. 613, 627 n.114 (1999).

169 See D.B. v. Ocean Township. Bd. of Educ., 985 F. Supp. 457, 469-70 (D.N.J. 1997) (the court provides its own table of contents for this case, which can serve as an excellent summary of special education law in the Third Circuit); Eyer, supra note 168, at 620-26 (describing the Supreme Court's rulings regarding the definition of "free appropriate public education" and subsequent interpretations by various federal circuit courts of appeal); Charlene K. Quade, A Crystal Clear Idea: The Court Confounds the Clarity of Rowley and Contorts Congressional Intent, 23 HAMLINE J. PUB. L. \& POL'Y 37, 59 (2001) (examining and critiquing the Eighth Circuit's interpretation of the entitlement to a free appropriate public education under the IDEA).

170 See Polk v. Cent. Susquehanna Intermediate Unit 16, 853 F.2d 171, 179-80 (3d Cir. 1988) (establishing the meaningful benefit standard). This case is often cited when the Third Circuit standard is discussed. See, e.g., T.R. ex rel. N.R. v. Kingwood 
The Third Circuit Court of Appeals has acknowledged that while the IDEA does not promise the "maximization" of children's potential, ${ }^{171}$ Congress did not intend that "the conferral of any benefit, no matter how small, could qualify as 'appropriate education' under" the IDEA. ${ }^{172}$ As a result, it is not sufficient for schools in the Third Circuit to provide "special education designed to confer only trivial" or "de minimus" benefits. 173

As described, the IDEA was designed to ensure that parents or guardians will be included in the development of their children's individualized educational program (IEP). There are stringent notice requirements to ensure that parents are present at IEP meetings ${ }^{174}$ and parents have the right to request such meetings at any time. ${ }^{175}$ The IDEA further provides that if the parents or guardians disagree with the IEP developed at the meeting, they have the power to challenge the proposed services or placement by demanding a pre-hearing conference with the school officials, a mediation, or a due process hearing. ${ }^{176}$

These provisions highlight the central role that parents are to play in ensuring that their children receive the free, appropriate public education to which they are entitled. ${ }^{177}$ In a landmark case interpreting the substantive and procedural rights granted by the Education of the Handicapped Act (EHA, predecessor to IDEA), the United States Supreme Court observed that it was "no exaggeration to say that Congress placed every bit as much emphasis upon compliance with procedures giving parents and guardians a large

Township Bd. of Educ., 205 F.3d 572, 577 (3d Cir. 2000); Ridgewood Bd. of Educ. v. N.E. ex rel. M.E., 172 F.3d 238, 247 (3d Cir. 1999).

171 See Bd. of Educ. of the Hendrick Hudson Cent. Sch. Dist. v. Rowley, 458 U.S. $176,189,192$ (1982) (observing that Congress did not require maximization of children's potential but did impose upon the states an educational standard that would make students' access to public schools meaningful); Polk, 853 F.2d at 180 (noting that the meaningful benefit standard is "faithful to Congressional intent and consistent with Rowley").

172 Polk, 853 F.2d at 184.

173 Id.

17420 U.S.C. $\$ 1415$ (d) (1) (B) (2000).

17520 U.S.C. $\$ 1415$ (e) (1) (2000).

17620 U.S.C. $\$ 1415(\mathrm{e})-(\mathrm{g})(2000)$. If parents do not challenge the IEP in one of these ways, the IEP will be deemed accepted. If a parent initiates any of these procedural safeguards, the child must remain in her "current educational placement" until the dispute is resolved. 20 U.S.C. $\S 1415(\mathrm{j})(2000)$. Obviously, this status quo will sometimes work to the advantage of the school and sometimes to the advantage of the parent.

177 See also Quade, supra note 169, at 53 (claiming that "the 1997 amendments strengthened [parents'] right [to accept or reject decisions regarding their children] by requiring that parents be active participants in placement decisions and in the development of the IEP"). 
measure of participation at every stage of the administrative process as it did upon the measurement of the resulting IEP against the substantive standard." 178 The Pennsylvania Department of Education describes parents as "play[ing] a key role in determining the programs and services with which their child will be provided" and "encourage[s]" parents "to participate in all aspects of the determination of the appropriateness of their child's special education."179

The IDEA, its implementing regulations, and judicial opinions, however, hint at a more limited role for parents in the determination of children's educational programs. The IDEA itself indicates that parents should provide "input" 180 to the IEP team. The regulations specifically indicate that parents should provide IEP teams with "evaluations and information" about their children to assist in the development of the IEP. ${ }^{181}$ Though the courts have found that parents are entitled to "meaningful participation" in the development of their children's IEPs, such participation does not necessarily imply that parents will be viewed as decisionmakers but instead that their input must be sought and considered, ${ }^{182}$ and that they must be given access to the documents upon which school officials rely for diagnoses and determination of appropriate services. ${ }^{183}$ As the Supreme Court has said, "The primary responsibility for formulating the education to be accorded a handicapped child, and for choosing the educational method most suitable to

$178 \mathrm{Bd}$. of Educ. of the Hendrick Hudson Cent. Sch. Dist. v. Rowley, 458 U.S. 176, 205-06 (1982).

179 From official Pennsylvania Department of Education website for parents' resources, at http://www.pde.state.pa.us/special_edu/ (last visited Nov. 24, 2003); see

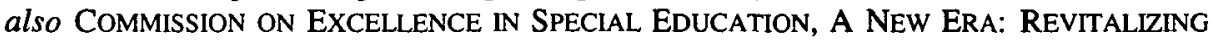
SPECIAL EDUCATION FOR CHILDREN AND THEIR FAMLIES 4 (2002) (pointing to the need to "empower every parent").

18020 U.S.C. $\$ 1414$ (c) (1) (B) (2000).

181 See 34 C.F.R. §300.533(a) (1) (i) (2003); 20 U.S.C. § 1414(c) (1), (2), (4) (2000).

182 See, e.g., W.G. v. Bd. of Trs. of Target Range Sch. Dist. No. 23, 960 F.2d 1479, 1480 (9th Cir. 1992) (holding that a school district's prior and independent development of a proposed IEP without the input and participation of the parents as well as district's subsequent failure to consider alternatives when parents raised objections at the IEP meeting violated procedural requirements of IDEA); see also Shapiro v. Paradise Valley Unified Sch. Dist. No. 69, 317 F.3d 1072, 1074 (9th Cir. 2003).

183 See, e.g., Amanda J. v. Clark County Sch. Dist., 267 F.3d 877, 892 (9th Cir. 2001) (holding that school district's failure to provide parent with child's records, particularly those evaluations indicating autism, violated procedural requirements of IDEA and observing that "[p]rocedural violations that interfere with parental participation in the IEP formulation process undermine the very essence of the IDEA"). 
the child's needs, was left by the Act to state and local educational agencies in cooperation with the parents or guardian of the child." 184

Descriptions of actual IEP meetings from parents and commentators also reflect substantial deference to the expertise and schedules of school officials. One parent interviewed for this research project said:

On the high school level, I am aware that they do an assembly line style.... [That is,] they load all the families into the cafeteria with the teacher, the special ed teachers, and the directors of special education .... [They] simply bounc[e] from table to table to table, stepping in for a matter of three seconds to sign off on the paperwork and making a presence and then moving on. That's a big breach of confidentiality, not to mention the procedural ways that IEP are to happen. ${ }^{185}$

A researcher and commentator regarding special education has observed:

The [IEP] procedures have been distorted by the exigencies of the bureaucracy ... . Both participation in the meetings and consent to the placement are usually formalities only. School districts decide the cases beforehand (called "organizing the data"). Consent forms are often signed before the placement meetings. Parents are usually presented with staff recommendations, followed by ritualistic certification. Parents are outgunned: they are strangers confronting a group of people who have worked together and struck a bargain, struggling to participate in a discussion couched in technical jargon, often with the subtle implication that the child or the parent or both are at fault. In large districts, committees spend an average of two-and-a-half minutes per decision, although this pattern varies by social class. ${ }^{186}$

These descriptions suggest that parents' involvement in the development of children's IEPs does not match the participatory and empowering vision imagined by politicians, education officials, and even the Supreme Court.

184 Bd. of Educ. of the Hendrick Hudson Cent. Sch. Dist. v. Rowley, 458 U.S. 176, 207-08 (1982) (Emphasis added). Indeed, in considering the deference that courts should show to states' administrative bodies, the Court went on to warn that "it seems highly unlikely that Congress intended courts to overturn a State's choice of appropriate educational theories .... We previously have cautioned that courts lack the 'specialized knowledge and experience' necessary to resolve 'persistent and difficult questions of educational policy."' Id. (quoting San Antonio Indep. Sch. Dist. v. Rodriguez, 411 U.S. 1,42 (1973)).

185 Telephone Interview with parent (Case 11, pre-mediation) (Dec. 15, 2000).

186 Handler, supra note 34, at 1010; see also JOEL F. HANDLER, THE CONDITIONS OF DisCRETION: AUTONOMY, COMMUNITY, BUREAUCRACY 66-67 (1986). 
This vision may hearken back to a somewhat romantic "communitarian notion of schools." 187 Reality, however, often falls short of this ideal.

Parents' use of the impartial due process hearings originally established under the Act has proved problematic as well. Parents and school districts expressed dissatisfaction with the cost, delay, and emotional disruptions caused by these hearings ${ }^{188}$ and, as a result, Congress amended the IDEA in 1997 to require states to offer mediation for the resolution of special education disputes. ${ }^{189}$ Parents who disagree with school officials' decisions regarding evaluation, services, or placement can now access mediation as an alternative to due process or as a step before proceeding to a due process hearing. Educational agencies also may initiate mediation to resolve these disputes. ${ }^{190}$

Under the federal regulations implementing the IDEA, a mediation session will be held only if both the parent and school district elect to participate. ${ }^{191}$ Thus, under the federal regulations, participation in special education mediation is wholly voluntary. ${ }^{192}$ The session must be held in a timely manner and in a location convenient to the disputants. ${ }^{193}$ The state

187 Kuriloff \& Goldberg, supra note 153 , at 41.

188 See Jonathan A. Beyer, A Modest Proposal: Mediating IDEA Disputes Without Splitting the Baby, 28 J.L. \& EDuC. 37, 44 (1999) (asserting that Congress amended the IDEA to include mediation as a means to address the "ineffectiveness, inefficiency, and unfairness associated with due process hearings..."); D'Alo, supra note 100, at 202 (describing the history and experience of both Pennsylvania's program for special education mediation and the inclusion of mediation in the IDEA's procedural safeguards); Steven Marchese, Putting Square Pegs into Round Holes: Mediation and the Rights of Children with Disabilities Under the IDEA, 53 RUTGERS L. REV. 333, 349 (2001) (suggesting that Congress inserted mediation into the IDEA as a means to reduce the use of litigation and due process and to enhance the likelihood of amicable resolution that kept children's best interests in mind); see also Kuriloff \& Goldberg, supra note 153, at $40-41$ (noting that due process "hearings have large personal and transactional costs" and that both "[p]arents and school officials find them stressful, draining, and traumatic").

18920 U.S.C. $\$ 1415$ (b) (5), (d) (2) (I), (e) (2000).

19020 U.S.C. $\$ 1415(\mathrm{e})(2000)$ (making mediation available to any dissatisfied "party," including parents, guardians, and educational agencies).

19134 C.F.R. $\S 300.506$ (b) (1) (i) (2003).

192 The Pennsylvania special education mediation program maintains this voluntary approach. Importantly, however, many states now require school districts to participate in special education mediation if the process is elected by parents or guardians. See, e.g., MinN. STAT. ANN. §§ 125A.26, 125A.43 (West 1998); see also Elizabeth R. Kosier, Mediation in Nebraska: An Innovative Past, A Spirited Present, and a Provocative Future, 31 CREIGHTON L. REV. 183, 196 (1997) (noting that Nebraska legislatures unsuccessfully attempted to make special education mediation mandatory).

19334 C.F.R. § 300.506(b) (4) (2003). 
pays for the cost of the mediation process. ${ }^{194}$ If the parties reach an agreement in mediation, they are required to formalize it in a written mediation agreement. ${ }^{195}$

The IDEA also requires states to employ "qualified and impartial" mediators who are "trained in effective mediation techniques" and "knowledgeable in laws and regulations relating to the provision of special education and related services." 196 The state may either assign mediators on a random basis from a pre-established list or may permit the parties to select their mediator through mutual agreement. ${ }^{197}$ Congress specified that mediators could not be current employees of local or state education agencies but did not define what would constitute "qualified" mediators or "effective" techniques. As Grace D'Alo has noted recently: "This leaves state educational agencies without guidance on how to determine what mediation model to follow, how to train mediators in that model, or how to evaluate mediator performance in relation to their training and to program goals." 198

At the time that these interviews were conducted, the Pennsylvania Department of Education had designated an intermediate unit to administer PaSEMS as well as the due process hearings. PaSEMS was responsible for conducting initial intake, scheduling mediation sessions, selecting mediators for particular cases, and mailing information regarding mediation to the parents and school officials who planned to attend the mediation sessions. PaSEMS was also responsible for selecting, overseeing, and training mediators in conflict resolution techniques and special education law. ${ }^{199}$ As

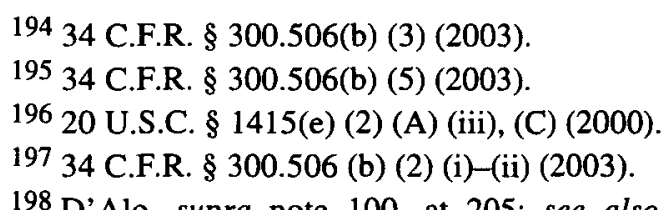

198 D'Alo, supra note 100 , at 205 ; see also Beyer, supra note 188 , at $48-51$ (describing lack of national process for definition of "qualified mediator" and speculating regarding the political reasons for the lack of clarity). But see EDWARD FEINBERG ET AL., BEYOND MEDIATION: STRATEGIES FOR APPROPRIATE EARLY DISPUTE RESOLUTION IN SPECIAL EDUCATION 10 (Oct. 2002), available at http://www.directionservice.org/cadre/ beyond_med2002.cfm\# (last visited Nov. 24, 2003) (briefing paper from The Consortium for Appropriate Dispute Resolution in Special Education) (describing goals of special education mediation as reduction of litigation, amicable resolution of differences, and decisions made with the child's best interests in mind) (quoting from S. REP. No. 105-17, at 26 (1997). Congress also will re-evaluate the special education mediation program in the near future as part of its larger inquiry into the re-authorization of the IDEA.

${ }^{199}$ D'Alo, supra note 100, at 205-06 (describing PaSEMS' role in implementing special education mediation program and in selecting, training, and evaluating mediators); Pennsylvania Department of EDUCation, Mediation Task Force REPORT TO THE BUREAU OF SPECIAL EdUCATION: FindingS AND ReCOMMENDATIONS 10 (1985) (recommending against the use of school district personnel, local advocates, 
required by the IDEA, PaSEMS did not permit any current employees of educational agencies to join its mediator panel but did view applicants' past experience in education as positive in screening applications for roster membership. Parents' advocates, meanwhile, were ineligible for service as mediators. Applicants' experience as parents of children with special needs was not credited with any particular significance. ${ }^{200}$

\section{Themes Drawn from the Interviews with the Disputants}

Despite the inevitable differences caused by the variety of personalities and situations involved in the cases included in this study, several themes emerge from the analysis of the interviews. ${ }^{201}$ First, in both their premediation and post-mediation reflections, both the parents and school officials emphasized the importance of participating in a dignified, thorough, and evenhanded process, one that provided the opportunity to speak and an assurance that they had been heard and understood. In their post-mediation comments, they also expressed particular sensitivity to the mediators' understanding and consideration of the disputants' normative framing of the issues to be resolved. The disputants' consistent valuation of these procedural elements suggests the central importance of ensuring procedural justice in mediation. Second, in both their pre-mediation and post-mediation comments, the parents and school officials emphasized the importance of progressing toward resolution in mediation. Third, in assessing the value and appropriateness of mediators' interventions, including caucus, both parents and school officials returned to the touchstones of procedural justice and

attorneys, or teachers as mediators; suggesting that mediators should be "retired individuals, college instructors, or individuals that act as mediators in other than educational capacities" and recommending that "the bureau pursue individuals with qualifications that include knowledge and experience in the education of exceptional students and in the laws, regulations and standards governing special education programs").

200 Telephone Interview with Grace D'Alo, former director of PaSEMS (Mar. 5, 2003). While the ineligibility of current employees of education agencies was based upon the IDEA regulations, PaSEMS' treatment of applicants' past educational experience and service as parent advocates was based upon the recommendations of the Mediation Task Force. See PENNSYLVANIA DEPARTMENT OF EDUCATION, supra note 157, at 10; see also D'Alo, supra note 100 , at 208 (describing the history and recommendations of the Mediation Task Force).

201 Any analysis of the themes emerging from qualitative interviews necessarily reflects both the interviewees' initial interpretations and inferences in responding to researchers' questions, as well as the interpretations and inferences of the researchers. Nonetheless, qualitative interviews offer an important opportunity to attempt to explore the subjective experience of different roles. See generally ELIZABETH MURPHY \& ROBERT Dingwall, Qualitative METhods and Health POlicy Research (2003). 
resolution-regardless of whether the interventions were facilitative, evaluative, or transformative.

The analysis of these interviews, however, also seemed to uncover provocative differences between parents' and school officials' understanding of the mediation process, their roles within it, and the sort of resolution they hoped mediation would help them achieve. These differences seem very much related to differences in the roles that parents and school officials play within the context of special education, the consequences they feel, and the power they wield outside the mediation session. This Article will return to the disputants' shared and diverging perceptions in Section V. These differences have particular significance to the extent that individual disputants seek and appreciate something in mediation that is different from that sought by the professionals who make regular use of the process.

\section{Disputants' Pre-Mediation Perceptions of Mediation's Value}

\section{a. An Enhanced Opportunity to Be Heard-and to Hear-in a Dignified and Thorough Process}

Before their mediation sessions, ${ }^{202}$ both parents and school officials emphasized the importance of being heard in a dignified and thorough process, but for different reasons. Most of the parents explained their decision to use mediation ${ }^{203}$ by focusing on their desire to ensure that the representatives of the school district would listen to them and acknowledge the unique needs and potential of their children. One parent explained that during mediation she wanted "some financial compensation paid to me for having to send my son away, but also we really want it on the record how horrible our middle school experience was," and she hoped to "speak on my son's behalf as being a young person with many different levels to him and not the projection or the perception from the middle school as being a psychiatric case." For this parent, "failure" in the mediation session was defined as "not being heard for the most part." 204 In another case, a parent observed, "My son may be one in ten thousand that come through the school district with this kind of a situation and they would rather turn their head and say, no we don't acknowledge this as a unique situation. Let's just go on the

202 The pre-mediation interviews with all of the disputants occurred within daysand sometimes even hours or minutes - of their scheduled mediation sessions.

203 It must also be noted that some parents explained that they had elected to use mediation at the recommendation of a trusted authority figure (e.g., attorney, school official, or state official). See, e.g., Telephone Interview with parent (Case 12, premediation) (Dec. 15, 2000).

204 Telephone Interview with parent (Case 1, pre-mediation) (Nov. 8, 2000). 


\section{INSTITUTIONALIZED MEDIATION}

way we've been. It's our policy."205 Finally, a parent described her understanding of the goals that should underlie special education: "I hope they look at this as an opportunity ... for change ... and [that they are] about education, [and desire to] help[] one more student hopefully reach their fullest potential. That's what I hope [for] out of this."206

The parents perceived that the mediation process, in contrast to the IEP meetings or the countless informal conversations between school officials and parents, would offer an enhanced opportunity to explain their child's unique needs, potential, and entitlements, as well as an enhanced opportunity for consideration by the school district. Often, parents attributed this two-fold benefit to the presence of the mediator who would make the process less emotional and hostile. ${ }^{207}$ They also anticipated that the neutral, objective mediator would be able to hear and understand what they were trying to say and could then serve as a translator:

I think it's important that the mediator understand what's led to the mediation and what's currently happening.... I think they can probably present my goals and my perspective... without the passion and the emotion that I have about it, which may make it easier for the district to understand. ${ }^{208}$

205 Telephone Interview with parent (Case 2, pre-mediation) (Nov. 13, 2000).

206 Telephone Interview with parent (Case 14, pre-mediation) (Dec. 19, 2000).

207 See, e.g., Telephone Interview with parent (Case 1, pre-mediation) (Nov. 8, 2000) (" $[\Gamma]$ sn't the mediator just someone who is going to sit there and hear me? They could probably really care less what my point is .... I mean they are just there to make sure we can speak to each other in an adult manner."). This desire for assistance in achieving civil dialogue appears consistent with procedural justice research that has been conducted. In a study comparing disputants' preferences among 12 different decisionmaking procedures, researchers found that subjects considered the presence or absence of representatives or investigators to be a meaningful characteristic for distinguishing among decisionmaking procedures, and further, they associated "pleasantness" with this characteristic. The researchers speculated that representatives or investigators might be perceived as "buffer[s] against severe interpersonal conflict because they eliminate the need for direct interaction between the disputants." See also Stephen LaTour et al., Procedure: Transnational Perspectives and Preferences, 86 YALE L.J. 258, 272-74 (1976). Disputants who elect to enter mediation may also hope that the forum itself will serve to reduce the likelihood of arousal and anger. See RUBIN ET AL., supra note 93, at 78-79 (describing "excitation transfer effect" in which individuals become particularly angry when they are "provoked in a situation that involves an additional source of arousal").

208 Telephone Interview with parent (Case 4, pre-mediation) (Nov. 15, 2000). 
Another parent offered this pithy explanation of the role she hoped the mediator would play: "Do the talking for me. In a very PC manner."209 Others went further and hoped that the mediator would become not just a translator but a sort of neutral advocate who would be convinced of the legitimacy of the parents' views and work to persuade the school officials to give serious consideration to those views:

I've said what I've said so many ways, so many times to so many people .... But somehow [the school officials'] defenses are up [so] that they have not been able to hear me. So I am so banking on this objective person to be able to come in and say, that's a very valid point. ${ }^{210}$

I think after the mediator hears the facts, ... she needs to make [the school] understand ... that they did indeed break the law. 211

These responses suggest rather powerfully that the parents focused upon mediation, and the mediator, as means to achieve more effective voice and serious consideration by the school officials. ${ }^{212}$ Many parents perceived a significant imbalance in their relationships with the public agencies responsible for educating their children. Often, the parents felt themselves treated as inferiors who did not need to be heard. One parent explained: "the people on the other side are not hearing it.... [I]t's almost like a paternal kind of thing where you don't really understand what psychologists and educators know .... I'm a professor, for twenty-five years and ... [i]t's a joke."213 Parents also expressed a sense of vulnerability in challenging the school officials' decisions or proposals:

[The school officials] could be resentful that I didn't think their opinion was maybe good enough. But I decided to take it a step further. You know, they're above reproach, that type of attitude .... "Our decisions are always

209 Telephone Interview with parent (Case 14, pre-mediation) (Dec. 19, 2000). In her post-mediation interview, this parent noted that she had hoped the mediator would be "an advocate for the child and the parent in some way without taking sides." Interview by Grace D'Alo with parent (Case 14, post-mediation) (Dec. 19, 2000).

210 Telephone Interview with parent (Case 11, pre-mediation) (Dec. 15, 2000).

211 Telephone Interview with parent (Case 10, pre-mediation) (Dec. 8, 2000).

212 In one case, however, the parent emphasized the mediator's potential value as the source of new alternatives because she did not perceive further communication with the school district as useful: "I'm viewing this [mediation] as a complete waste of my time.... [W]e've been through this ... They know my position. We have been up front. We have provided them with all the information they have. They have done no research." Telephone Interview with parent (Case 3, pre-mediation) (Nov. 15, 2000).

213 Telephone Interview with parent (Case 9, pre-mediation) (Dec. 8, 2000). 
right ...." I don't know if they are going to have that type of attitude or a willingness to have more of an open mind ... I honestly don't know. ${ }^{214}$

Strikingly, very few parents expressed the hope that mediation would enable them to hear and understand the school officials' explanations for their actions or proposals. ${ }^{215}$

The school officials-most of whom had prior experience with special education mediation-echoed the parents' pre-mediation perception of the mediation process as a mechanism that could enhance voice and consideration and improve the dignity of the discussion. They hoped that in mediation "everyone has their chance to speak, that we are uninterrupted, and that the decision that is reached at the end will be done just based on fact and not emotion." 216 In particular, school officials anticipated that parents would receive assistance with speaking and being understood. Some officials pointed to the structure of mediation as one source of assistance:

One thing has nothing to do with the mediator. It doesn't matter who would be sitting in the mediator's seat .... [T] he parent will state what is on their mind and what their issues are, because I really haven't heard... why they're saying "no." I' $m$ just ... sensing and getting the feeling that there is a lack of trust and the feeling that there is no help out there for their child, and from the school district. I want to hear whatever her position is, whatever her issues are ....217

Other school officials echoed those parents who hoped the mediators would serve as translators:

[M]aybe the mediator might help phrase things differently or help us see things better from the mother's perspective as to what she's trying to accomplish here for her son, and if we could offer that through a better program for him in school. ${ }^{218}$

214 Telephone Interview with parent (Case 14, pre-mediation) (Dec. 19, 2000).

215 Only two parents expressed this desire and one of these coupled her interest with many expressions of skepticism. Telephone Interview with parent (Case 4, premediation) (Nov. 15, 2000); Telephone Interview with parent (Case 12, pre-mediation) (Dec. 15, 2000). 2000).

216 Telephone Interview with school official (Case 11, pre-mediation) (Dec. 13,

217 Telephone Interview with school official (Case 1, pre-mediation) (Nov. 8, 2000).

218 Telephone Interview with school official (Case 14, pre-mediation) (Dec. 18, 2000). 
[B]asically the bottom line is that I would be satisfied to just get some clarification in regard to what Mom's real issues are .... Even if we can't agree, ... just give us something to work with. Give us some working knowledge so that we know what to address. I know it sounds vague, but it is vague. ${ }^{219}$

Overall, school officials seemed very aware of their obligation to try to hear and understand the information presented by the parents, particularly if that information would help them in assessing children's needs and arriving at more informed and substantively just decisions regarding the children's educational programs. They, like the parents, viewed the mediation process and the mediator as helping to improve the effectiveness of the parents' voice and school officials' consideration of what the parents had to say.

School officials were much less likely, however, to express the need for a forum in which they could be heard by the parents. ${ }^{220}$ Rather, school officials seemed to focus on the need to educate parents regarding relevant norms. ${ }^{221}$ For example, in the following quotes, two school officials suggested that parents did not understand the limits of their children's legal entitlements:

What I hope the mediator can do is to help the parents to see our side of it, in that, this isn't ... the only program and that ... there's just so much money in the pot. It's a huge outlay of money.... There may be students

\footnotetext{
219 Telephone Interview with school official (Case 12, pre-mediation) (Dec. 18, 2000).
}

220 There was one notable exception to this trend. In one case, the parent of a young child had already taken the school district to due process twice and had attracted media attention to her actions in front of her son's school. In that case, before the mediation, the school official primarily expressed a desire to understand the parent. After the mediation, however, the official expressed great satisfaction at being able to share with the parent his own reactions to the events that had occurred. Telephone Interview with school official (Case 12, pre-mediation) (Dec. 18, 2000); Telephone Interview with school official (Case 12, post-mediation) (Dec. 20, 2000).

221 The school officials" desire to educate the parents invokes the "norm-educating" model of mediation that has been identified by Professor Ellen Waldman. Ellen A. Waldman, Identifying the Role of Social Norms in Mediation: A Multiple Model Approach, 48 HASTINGS L.J. 703, 732-38, 741 (1997). Professor Waldman has noted that this model-as distinguished from the "norm-generating" and "norm-advocating" models-is used frequently in the divorce context and in corporate mediation programs designed to resolve discrimination, sexual harassment, and wrongful termination claims. Id. at 732-38. Waldman describes the "norm-educating" model as "strik[ing] a compromise between those who would bar discussions of law entirely from mediation practice and those who would outlaw mediation because it strays too far from the normative moorings of our adversary system." Id. at 741 . 


\section{INSTITUTIONALIZED MEDIATION}

that could benefit from it, but these two students that happen to be at [this school] are not the two that need it in my opinion. 222

The other thing ... I hope to accomplish is that the parent has or walks out of there with a better understanding of interpretation of the process itself ... . [T] he parent disagreed with the CER [Comprehensive Evaluation Report]; the parent wanted to go through the CER page by page and change it, ... to read as they wanted it to read and then they would agree. Well, that's not the process.... [I]f there were something that we were completely and totally in error of and it was brought to our attention, then we don't have a problem making a change with that, but if it's just ... "I want it changed because I don't like it" ... well, you know, . . . you just can't do that .... Success would be, in my eyes, coming to an agreement that is in the best interest of the child ... not based on what people want, but what the child needs. ${ }^{223}$

School officials" desire for "voice" did not seem to involve expressing their personal perceptions of the situation, explaining their own difficulties in complying with legal requirements, or responding to children's needs. ${ }^{224}$ Rather, they sought a forum that would provide parents with needed education regarding the legal and educational norms to be used in deciding children's educational programs. ${ }^{225}$

222 Telephone Interview with school official (Case 3, pre-mediation) (Nov. 15, 2000). 2000).

223 Telephone Interview with school official (Case 12, pre-mediation) (Dec. 18,

224 This difference between parents and school officials in the character of the "voice" they desired may simply reflect the fact that the school officials came to the mediation primarily in their role as professionals, not as fellow human beings. Professionals distinguish themselves by "applying somewhat abstract knowledge to particular cases." ANDREW ABBOTT, THE SYSTEM OF PROFESSIONS: AN ESSAY ON THE DIVISION OF EXPERT LABOR 8 (1988); see Susan S. Silbey, Patrick Davis: "To Bring Out the Best... To Undo a Little Pain" in Special Education Mediation, in WHEN TALK WORKS: PROFILES OF MEDIATORS 61 (Deborah Kolb \& Assocs. eds., 1994) (observing that the interviewee-mediator "insisted on that reciprocal exchange and informational intimacy that constitutes good conversation but threatens professional distance and objectivity"); see also Kuriloff \& Goldberg, supra note 153, at 65 (observing that for school officials, mediation, "though arduous and time consuming, provided a way to ensure they were being fair to parents," while "[f]or parents, it offered a way to secure what they considered vital for their children" thus highlighting "a fundamental difference in stakes").

225 It must be noted that the school officials' desire for education of parents in mediation is reminiscent of attorneys' desire for reality-testing of clients in mediation. See McAdoo, supra note 6, at 429 (reporting that the top factors motivating lawyers to 


\section{b. An Enhanced Opportunity to Resolve the Problem}

The parents repeatedly explained that they hoped to come to a favorable resolution of their disputes through mediation. But how? In the pre-mediation interviews, most of the parents appeared to hope that once they (or the mediators) finally gained the school officials' attention, those officials would recognize the insufficiency of the services or placements they had proposed and simply grant the parents' demands-in some cases as the inevitable and rightful response to children's now-understood needs, and in other cases as an acknowledgment of the school's partial responsibility for these children's current difficulties and pain. ${ }^{226}$ Only a few parents raised the possibility of finding previously unrecognized common ground and reaching new, mutually acceptable, and principled solutions. ${ }^{227}$ Indeed, few of the parents seemed prepared to offer or explore alternatives beyond what they had already proposed to the school officials, and none seemed to relish the opportunity to participate in a negotiation process to determine their children's educational programs. ${ }^{228}$ For example, when one parent was asked what mediation outcome would satisfy her, she responded, "Nothing less than success. That really sounds terrible, but I mean that.... [W] hat I had mentioned I do not feel is unrealistic." 229

The school officials also repeatedly highlighted mediation's value as a mechanism to achieve closure, either through the development of a mutually

voluntarily choose mediation include providing a needed reality check for opposing counsel or party $(52.2 \%)$ and providing a needed reality check for own client $(47.7 \%)$ ).

226 See, e.g., Telephone Interview with parent (Case 1, pre-mediation) (Nov. 8, 2000) ("I am just going through the motions to do the next step. We talked privately in his [the school official's] office and I felt like he heard us and then, but in order for the financial compensation he suggested this next step" and "I think that [acknowledgment of her son's poor educational experience] would come through financial compensation").

227 Cases $12,4,8$.

228 It must be acknowledged here that parents are less likely than educational experts to be aware of-and control access to-alternative resources or services that might meet children's identified needs. This imbalance in knowledge, expertise, and control could do much to explain why parents were much less likely than school officials to raise the possibility of problem solving in mediation. The author thanks Grace D'Alo and Bobbi McAdoo for their insights regarding this point. Interview with Grace D'Alo, former director of PaSEMS, Carlisle, Penn. (February 26, 2003); Telephone Conference with Bobbi McAdoo, Professor of Law, Hamline University School of Law (Mar. 3, 2003).

229 Telephone Interview with parent (Case 8, pre-mediation) (Dec. 4, 2000). In nearly every case, parents described a satisfactory outcome as synonymous with a successful outcome. See infra Appendix A, Outcome Questions 2 and 3. In addition, in describing "failure," most parents either pointed to failure to achieve any resolution or failure to achieve the resolution they had proposed. See, e.g., Cases 2, 10, 11, 14. 
acceptable agreement or through the parents' decisions to abandon their challenges to the officials' decisions. ${ }^{230}$ Consistent with their desire to use mediation to educate parents regarding the norms to be used in deciding children's educational programs-and perhaps as a result of their prior experience with the process-school officials often expressed a desire to use mediation to problem solve with parents, provided that the mediation structure or the mediator could facilitate a narrowed and future-oriented definition of the problem to be resolved (i.e., determining the educational services to be provided to children): 231

I hope that from past experience that the mediator will be strong enough to say, "Well, look, can't we get past that [fault-finding] and talk about some things that we really want to talk about like education," and that type of thing. ... I think we probably need an outside person to help both sides look at this, particularly the parent and the daughter to look at it. ${ }^{232}$

[W]e are hoping that another neutral party will help the parents to problem solve and understand that the label [as gifted] isn't going to get this child any more than what he is getting right now. ${ }^{233}$

While the parents perceived mediation as a tool for helping the districts understand how the status quo was not sufficiently acknowledging the

230 As expressed in the parents' failure to pursue a due process hearing.

231 School officials seemed to want mediators to "concretize" disputes, consistent with Merry and Silbey's description of mediators who used a bargaining approach. Merry \& Silbey, supra note 24 , at 151,153 . Perhaps all professionals are susceptible to this tendency. See, e.g., Carrie Menkel-Meadow, The Transformation of Disputes by Lawyers: What the Dispute Paradigm Does and Does Not Tell Us, 1985 J. DISP. RESOL. 25, 31-33 (describing how lawyers and law re-define the disputants' stories, their disputes and their demands for remediation in ways that routinize them, make them more "amenable to conventional management procedures," and "stifle a host of possible solutions").

Some might also argue that in expressing willingness to problem solve with parents, the school officials actually were making a strategic effort to appear willing to negotiate. Telephone Interview with Christopher Honeyman, President of Convenor Dispute Resolution Consulting (Mar. 4, 2003). Still others might note that qualitative interviews are "social interactions, in which all parties strive to present themselves and their behaviors to their listeners as appropriate" and that interviewees' responses might be viewed most accurately as "displays of moral and cultural norms rather than literal reports of reality." MURPHY \& DINGWALL, supra note 201.

232 Telephone Interview with school official (Case 10, pre-mediation) (Dec. 13, 2000).

233 Telephone Interview with school official (Case 9, pre-mediation) (Dec. 11, 2000). 
unique needs or potential of their children, the school officials seemed to see mediation as a means to educate the parents and move from confrontation to problem solving within the status quo. Some school officials even seemed to invite mediators' suggestions regarding resolution, provided they were responsive to this narrowed definition of the problem to be resolved. For example, one school official thought that the mediator could:

[L]isten, intently listen and try to determine what it is that we are trying to accomplish for this child and see if we can propose any compromises. I guess ... we feel we've tried but didn't meet the parent's satisfaction. So if the mediator can pull something out of the dialogue between the two sides that we didn't think of, that would be great. ${ }^{234}$

Thus, school officials' readiness to "get on the same page" 235 with parents was contingent upon parents' adoption of the school officials' framing of the dispute and the more limited goals that could and should be achieved. The mediator's role was to help reconcile the parents to this reality and help them problem solve within it. ${ }^{236}$

This Article will now turn to the results of the post-mediation interviews to examine the extent to which the disputants' pre-mediation expectations surfaced during or framed their post-mediation perceptions. The postmediation interviews also permit an examination of disputants' reactions to

234 Telephone Interview with school official (Case 14, pre-mediation) (Dec. 18, 2000).

235 Interview by Grace D'Alo with school official (Case 4, post-mediation) (Nov. $16,2000)$.

236 The school officials' perceptions of mediation's value may reflect the power of the "norm-educating" model of mediation for professionals. See Waldman, supra note 221, at 732-38 (describing "norm-educating" model of mediation and its use in divorce and employment matters); see also McAdoo, supra note 6, at 429 (reporting that the top factors motivating lawyers to voluntarily choose mediation include providing a needed reality check for opposing counsel or party $(52.2 \%)$ and providing a needed reality check for own client (47.7\%)); McAdoo \& Hinshaw, supra note 36, at 512-13 (reporting that top factors motivating lawyers to choose mediation include providing needed reality check to opposing counsel or party (69\%) and to own client (67\%)); Chambers, supra note 118 , at 213:

"[M]eaning" and "power" are the two themes that Sarat and Felstiner stress. The meaning of the failed marriage, of law itself, and of the legal process is constructed, they argue, through the conversations between client and lawyer. Clients and lawyers" "negotiate" over meaning in a different shadow of the law than that which Mnookin and Kornhauser (1979) modeled for the negotiations between opposing parties. Each comes with predictable sets of perceptions and goals, and each engages in subtle tactics to induce the other to adopt their views. 
mediators' facilitative and evaluative interventions, as well as the technique of caucus.

\section{Disputants' Post-Mediation Perceptions of Mediation's Value}

\section{a. Returning to the Importance of An Enhanced Opportunity to Be Heard-and to Hear-in a Dignified, Thorough Process}

All but one of the parents and one of the school officials expressed satisfaction with the mediation process immediately after it was concluded, even though many expressed a compromised sense of control over the outcome $^{237}$ and not all achieved resolution. In the interviews with parents that occurred immediately after the mediation sessions, the mediators suddenly loomed as a significant presence and an independent source of procedural justice. Parents noticed the opportunity for voice and consideration that they received from the mediator, often separate from the mediator's success in achieving enhanced consideration by the school officials. One parent observed that "all the parties got to speak ... and say what's on their minds." 238 A second emphasized that the mediator "talked personally, in a private caucus, with us and actually listened ... not me arguing my side, but actually listened to what I had to say."239

Consistent with their pre-mediation interviews, many parents also pointed to the ways in which mediation enhanced their ability to express themselves and the school district's ability to consider their views. For example, parents noticed that the mediators gave them uninterrupted time to express themselves:

I guess the most helpful was just being able to... speak my mind as to why ... I didn't agree ... with the what the district was proposing. ... [A]t one point the assistant principal was at the meeting.... I think he thought maybe I was being difficult.... But sitting there, numerous times he was shaking his head to the effect that, "Now I can see where you're coming from." 240

As the parents had hoped, mediators served as translators:

237 See Nancy A. Welsh, Disputants' Decision Control in Court-Connected Mediation: A Hollow Promise Without Procedural Justice, 2002 J. DisP. RESOL. 179, 182-84.

238 Telephone Interview with parent (Case 10, post-mediation) (Dec. 15, 2000).

239 Telephone Interview with parent (Case 12, post-mediation) (Dec. 29, 2000).

240 Telephone Interview with parent (Case 10, post-mediation) (Dec. 15, 2000). 
I could tell that [the mediator] understood what I was saying .... He could reference it [and] . . . present it ... [to] the district, and then I could see that they understood. ... [When] I was speaking to them, it wasn't clear, but as [the mediator] reframed it and spoke it to them, then I could see that they understood. . $^{241}$

Parents also highlighted the mediators' service as "neutral advocates:"

I think he tried to advocate a little bit for me... in the course of the conversation. And actually, that's what I was hoping for from mediation, that perhaps the mediator would also be an advocate for the child and the parent in some way without taking sides. ${ }^{242}$

He was very intent to what [the child's disability] was and was able to put my lay terms into more technical terms that were more binding than, "Could you . . . ?"243

When parents were invited to discuss any aspects of the mediation that were not helpful, they often chose to raise examples of mediator actions or omissions that hindered their ability to be heard. They noticed and disapproved when mediators occasionally failed to give them the opportunity to make initial presentations, were ineffective in helping the school district understand parents' concerns, mistranslated, or tried to move the parents toward settlement before demonstrating a full understanding of the parents' concerns. All of these actions or omissions-some of which occurred within caucus and will be discussed in greater detail in this section-were inconsistent with parents' desire for voice, consideration by both the mediator and the school district, and evenhanded, dignified treatment.

As foreshadowed by their pre-mediation perceptions, parents were much less likely to notice and express appreciation for the mediators' interventions if the latter focused on assisting the parents in their ability to hear and understand what the school officials had to say. This reaction is discussed in more detail in Section IV.3. with the analysis of disputants' perceptions of facilitative interventions.

Particularly if they had reached resolution, parents also highlighted the value of a thorough process that devoted sufficient time to crafting their children's educational programs. One parent, who experienced both

241 Interview by Grace D'Alo with parent (Case 4, post-mediation) (Nov. 16, 2000).

242 Interview by Grace D'Alo with parent (Case 14, post-mediation) (Dec. 19, 2000).

243 Telephone Interview with parent (Case 12, post-mediation) (Dec. 29, 2000). 
resolution and favorable implementation, painted the following very favorable picture of mediation as compared to IEP meetings:

[I]t was a pretty lengthy process whereas [the] IEP meetings ... might be twenty minutes. I think we were there...five hours maybe ... six ... something like that. So it was a lot of time and energy devoted specifically to my son, so I think that was one factor [explaining mediation's long-term effects]. I think it allowed myself and the district to present ideas and to brainstorm and have someone kind of develop those ideas more fully.... I think in [my son's] mind it made him feel valued. You know, that we were there, making an effort..., not only myself but the district was there making an effort to allow him to learn to his best abilities, ... I think that did kind of change his perspective. Instead of being a problem or a bother, . . I think it made him feel more accepted. ${ }^{244}$

The school officials, like the parents, also appreciated the enhanced opportunity for voice and consideration available in mediation. Every school official agreed that the mediation process should feel fair. To that end, they repeatedly pointed to evidence of the mediators' lack of bias or favoritism and the "ample opportunity" provided to both sides to "state their case"245 and be heard. Consistent with their pre-mediation perceptions of the value of the mediation process, the officials expressed particular sensitivity to the parents' need for a forum in which they could achieve effective voice and more thorough consideration. Sometimes, school officials expressed appreciation for the commitment of time and consideration required by mediation:

When they told us [that the mediation] would take three to five hours, ... I could not imagine sitting there for three to five hours. ... And, we did! I thought, oh, we'll be out of here in one hour.... [Y]ou work your way through every problem.... And I will say too that when you go to an IEP meeting... sometimes you have one hour, and you can't get through everything, and everyone leaves frustrated because there is not enough time, and I think just sitting down with that amount of time, with . . . one parent, was probably the most successful part of the mediation. ${ }^{246}$

244 Telephone Interview with parent (Case 4, 18-month) (July 22, 2002).

245 Interview by Grace D'Alo with school official (Case 8, post-mediation) (Dec. 5 , 2000).

246 Interview by Grace D'Alo with school official (Case 4, post-mediation) (Nov. $16,2000)$. 
Tellingly, however, many school officials expressed amazement and some dismay at the amount of time that had been required for the mediation, particularly the parents' initial statements:

I think the parents needed to have that time to be heard... . I mean, they did an opening statement that was well over an hour. I mean, whew! We ... needed a ... break after sitting there for a while, [but] they were definitely heard, okay? And I think they needed to have that. ${ }^{247}$

I think there should have been a timeline in terms of opening statements. I think Mom read a seven or eight page paper.... It certainly clarified her position, but it did seem to go on a bit long. I think a person should be able to say what their position is within five minutes. ${ }^{248}$

Consistent with their pre-mediation interviews, school officials rarely focused on the importance of their own presentations. Instead, most school officials praised mediation as an opportunity for both sides to achieve clarification of the disputed issues and problem solve more effectively. One school official seemed particularly aware of this contrast between her own focus on problem solving and the parents' need for recognition:

[T] here was a lot of opportunity for dialogue... . [W]here we were looking at perceptions coming to the forefront and ideas being tossed around[,] ... there was that sense [from the parent] of "I've got to convince somebody. Somebody has to hear me. They're [the school officials] not doing something right."249

School officials' reactions to mediators' facilitative efforts to enhance mutual communication and understanding will be discussed in greater detail later in this section with the analysis of interventions coded as facilitative.

\section{b. Returning to the Importance of the Enhanced Opportunity to Resolve the Problem}

The post-mediation interviews with parents revealed that they noticed and appreciated mediators' efforts to "move the ball forward" toward specific agreements during mediation sessions:

[The discussion] just wouldn't have been focused [without mediation]. We certainly wouldn't have gotten through the whole IEP. We would have got

\footnotetext{
247 Interview with school official (Case 9, post-mediation) (Dec. 11, 2000).

248 Interview with school official (Case 2, post-mediation) (Nov. 16, 2000).

${ }^{249}$ Interview with school official (Case 9, post-mediation) (Dec. 11, 2000).
} 
stuck on the contract.... Yeah, we would have just got stuck, and I don't think there would have been any agreement on that. ${ }^{250}$

It must be noted, however, that parents' descriptions of their agreements were sometimes tinged with ambivalence. One father admitted the difficulty of achieving a fair result before describing himself as "as satisfied [with the process] as I think I'm going to be."251 Another parent observed, "I am satisfied because we were able to come up with an agreeable ... service agreement. We were at least able to do that." 252 Parents' level of satisfaction, not surprisingly, appeared to depend both upon their expectations and what they viewed as possible. 253

The failure to reach resolution, however, nearly always arose as a source of frustration with the mediation process:

They just totally disregarded everything. ... The mediation session didn't amount to anything. 254

[Describing what occurred during the mediation session that was not helpful]: Basically [the school district] said "tough noogies." 255

250 Interview by Grace D'Alo with parent (Case 4, post-mediation) (Nov. 16, 2000).

${ }^{251}$ Interview with parents (Case 1, post-mediation) (Nov. 9, 2000) ("You're dealing with very emotional topics and people want to have faimess. But that's not very [easy] to achieve - try the best you can. I'm as satisfied as I think I'm going to be.").

252 Interview by Grace D'Alo with parent (Case 8, post-mediation) (Dec. 5, 2000).

253 See Robert Dingwall \& John Eekelaar, A Wider Vision?, in DivorCE MEDIATION AND THE LEGAL PROCESS, supra note 135, at 171. Dingwall and Eekelaar raise "the important question of public perception. What do clients want from divorce procedures? Satisfaction measures can only be understood with some reference to expectations, to the sheer distress of the [marital] breakdown itself, and, we would add, to what is socially possible." Id.; see also Guthrie \& Levin, supra note 95, at 888-89 (describing the impact of parties' expectations upon their satisfaction with the mediation process); Wissler, supra note 102, at 346-47 (reporting that disputants' satisfaction with outcomes was influenced primarily by outcome measures and to a lesser but significant degree, by process evaluations; noting that these results are "consistent with theories that maintain that outcome satisfaction is influenced more by one's assessment of the outcome compared with expectations or with others' outcomes than by the absolute outcome received"). 2000).

${ }^{254}$ Interview by Grace D'Alo with parent (Case 14, post-mediation) (Dec. 19,

${ }^{255}$ Interview with parent (Case 9, post-mediation) (Dec. 11, 2000). 
Indeed, the only parent who expressed immediate dissatisfaction with the mediation process was involved in a session that failed to achieve an agreement. 256

Despite their clear desire for resolution, however, the parents were less likely than "repeat player" school officials to pinpoint how the mediators had or had not managed the process to achieve this goal. ${ }^{257}$ The only exception to this is that on occasion, parents pointed to mediators' failure to force school officials to answer their questions:

I think [the mediator] was being fair, but at the same time by not [having] certain questions answered [by the principal of the school]. I don't think it helped to achieve . . . the goal: ${ }^{258}$

This concern regarding the failure to prod school officials to reveal their underlying reasons is analyzed in greater detail later in this section in the discussion of disputants' reactions to facilitative interventions.

If settlement was not reached, most parents blamed the school officials. ${ }^{259}$ They pointed to ways in which the school officials undermined the process by failing to "bring the appropriate players to the table," 260 by intimidating teachers who feared that if they spoke freely they "wouldn't have a job," 261 by discussing outcomes "ahead of time," 262 and by "really not listening." 263 The parents repeatedly concluded that the school officials had entered the mediation without any intention of either listening to the parents'

256 Telephone Interview with parent (Case 10, post-mediation) (Dec. 15, 2000).

257 This difference in the reactions of parents and school officials may be due to the parents' inexperience with mediation. All but one of the parents had never participated in the process before. In contrast, most of the school officials had previous experience with mediation.

258 Telephone Interview with parent (Case 10, post-mediation) (Dec. 15, 2000).

259 This dynamic seems to bear some similarity to the reported results of unsuccessful small claims mediation. See, e.g., Wissler, supra note 102, at 347-48 (reporting that if disputants reached resolution in mediation, their "ratings of the other party became less negative" but that "the unsuccessful mediation group's ratings became somewhat more negative" also noting, however, that those who reached resolution in mediation, those who did not, and those who adjudicated "reported a similar, significant reduction in anger toward the other person"). 2000).

260 Interview by Grace D'Alo with parent (Case 11, post-mediation) (Dec. 18,

261 Telephone Interview with parent (Case 10, post-mediation) (Dec. 15, 2000).

262 Telephone Interview with parent (Case 3, post-mediation) (Nov. 20, 2000).

263 Interview with parent (Case 9, post-mediation) (Dec. 11, 2000). 
views or abandoning earlier positions: ${ }^{264}$ "I just feel that [the school district] went in there, no matter what they had their mind made up what was gonna happen. They were just there because they had to be there." 265 Ultimately, and especially in cases that did not settle, the parents emphasized mediation's (or the mediator's) inability to offer meaningful relief from the greater power and control wielded by school officials:

It's a decision of the school district.... What mattered was their opinion, not necessarily any documentation or examples which I had to share. I think that was evidenced by some of the conversation that occurred. ${ }^{266}$

In general, the parents did not blame the mediators-or their management of the mediation process-for the failure to reach resolution. They did, however, begrudge the time and energy that they had spent on a futile process.

Eighteen months after the mediation occurred, many parents seemed even more focused on whether the mediation had produced resolution-both short-term and long-term. ${ }^{267}$ In one dramatic reversal, a father who had originally identified himself as "very satisfied" 268 with the mediation

264 Parents' tendency to attribute school officials' actions to their disposition rather than situational factors may be explained by attributional theory and biases. See Keith Allred, Anger and Retaliation in Conflict, in THE HANDBOOK OF CONFLICT RESOLUTION 238-49 (Morton Deutsch \& Peter Coleman eds., 2000) (describing attributions, their emotional and behavior implications, and implications for conflict dynamics).

265 Interview with parents (Case 2, post-mediation) (Nov. 16, 2000).

266 Interview by Grace D'Alo with parent (Case 14, post-mediation) (Dec. 19, 2000).

267 There was one notable exception to this trend. In one case, in which the mediation session ended in impasse, the parents worked with the school officials to schedule a second mediation session with a different mediator. The parents were convinced that the school district had failed to bring all the necessary parties to the table for the first mediation session. The second session included these parties. Even though this session also ended in an impasse, the parent spoke glowingly of mediation's value when she was contacted 18 months later:

I really enjoyed being a part of this .... [I]t is interesting because it is sort of a twosided story ... . I tell people ... it's well worth it ... . Go through it; at least it's an opportunity for you to voice your concerns. So I do recommend it whenever I see a family struggle because it really gives them the opportunity for the dust to settle and everything to become a little bit more clear, although it didn't necessarily resolve anything in our particular issue. I really felt that it was a [worthwhile] process.

Telephone Interview with parent (Case 11, eighteen-month) (Sept. 16, 2002).

268 Interview with parent (Case 9, post-mediation) (Dec. 11, 2000). 
process, even though it had ended in impasse, declared that he was now "very dissatisfied" 269 with the process:

I mean, [there have to be] two willing parties, and the person who was the mediator was a very nice person and kind of tried to make us feel good, but basically ... I'm not really interested in touchy-feely but I'm interested [in] actually having some sort of negotiations. And so really it was a waste of time. 270

Another parent who had reached a short-term agreement in mediation that failed to produce a lasting resolution ${ }^{271}$ described mediation as: "Talking with no results ... absolutely!"272 She went on to say:

And I know I'm going to get nothing out of the school district; nothing out of the IU [a regional educational agency responsible for providing services] and it's like they beat me! They've defeated me; I am not going to fight anymore. It's ... not worth my husband taking vacation time and sitting and talking for hours and getting nothing. ${ }^{273}$

Though a specific agreement had been reached and implemented in her case, the real problem - a lack of mutual understanding and trust-remained. Meanwhile, in another case, a parent who had originally judged the mediation process to be "somewhat fair"274 and described herself as "somewhat satisfied" 275 was transformed into a "very satisfied"276 consumer of the service, based on the school district's positive implementation of the mediation agreement.

[F]rom my personal experience it was very beneficial to my son's education, and I think it was also beneficial to the school district .... [I]t was very professional.... [It was beneficial] not only at the immediate mediation, but ... it had long term results for him .... [H]e actually had an individualized education program, which is what the whole process was

269 Telephone Interview with parent (Case 9, eighteen-month) (July 22, 2002).

270 Id.

271 The school district agreed to conduct a pilot test of a costly technology that the parent had proposed. After the completion of the test, however, the school district chose not to adopt the technology and had not (in the parent's view) put into place an effective alternative.

272 Telephone Interview with parent (Case 3, eighteen-month) (July 18, 2002).

273 Id.

274 Interview by Grace D'Alo with parent (Case 4, post-mediation) (Nov. 16, 2000).

275 Id.

276 Telephone Interview with parent (Case 4, eighteen-month) (July 22, 2002). 
about, really ... developing that individualized program. . . From my other experiences, the IEPs that he had were very general.... [B]ut I think through the mediation process it became very individualized to him and that helped support him. 277

In contrast with the parents, school officials were much more likely to be aware of the ways in which the mediators managed the process to make it a forum for issue clarification and problem solving. In nearly every postmediation interview, the school officials specifically commented on whether the mediator focused upon clarifying and resolving the issue of the services or placement to be provided to children:

Well, ... when both parties started ... getting off track..., starting to chew over some of those same issues and get side-tracked, I really thought the mediator brought us back to the issue and I thought that was very productive. $^{278}$

School officials also noticed and disapproved when mediators wavered in their commitment to resolving the issue of how to meet children's educational needs. For example, in response to the question "Of those things that the mediator did or said was there anything that was not helpful?," school officials noted:

I know that the mediator was bound to do this, but that we don't have to reach a decision .... I think that saying that gave the people this big sigh of ... relief that we really don't have to do any more. ${ }^{279}$

[The mediation] was a failure. It replicated our previous meetings. . . At all times, we've met with this parent in a very amicable manner, had some tough conversations on some topics, and then tried to redirect that to the student and focus on his needs and see how we could address them. And ... at each session, including this mediation session, we walked away agreeing to disagree without a plan to strengthen [the student's] program. ${ }^{280}$

Though school officials described more understanding and amicable relations with parents as "heartwarming" 281 and highly satisfying, ${ }^{282}$ they

277 Id.

278 Interview with school official (Case 2, post-mediation) (Nov. 16, 2000).

279 Telephone Interview with school official (Case 10, post-mediation) (Dec. 15, 2000).

280 Interview by Grace D'Alo with school official (Case 14, post-mediation) (Dec. 19, 2000).

281 Interview with school official (Case 2, post-mediation) (Nov. 16, 2000). 
also seemed to view such improved relations as a pleasant by-product of mediation. The real goal of the process was to come to an explicit agreement regarding children's educational programs. The school officials viewed everything else-concerns about tensions between the adults, emotional reactions, and the history of interactions between the parents and the district-as at best, secondhand, long-term issues and, at worst, distractions and impediments to progress:

I really do think that it could have gotten ugly if we didn't have a mediator who ... allowed me to... refocus the group after the parents spoke about their concerns. I really appreciated that she allowed me to do that and I'm very thankful that the parent agreed because it could have gotten ugly. And I didn't want it to go there because that's something that needs to happen secondhand to ... the most important priority, which was [the child]. The personalities and the tension remain. ${ }^{283}$

Several school officials placed particular emphasis upon the creation of a document that clearly defined their obligations (e.g., the timing and extent of the services to be provided) in order to prevent later misunderstandings and conflicts. ${ }^{284}$ Eighteen months after the mediation sessions occurred, school officials also were more likely to express satisfaction with mediation sessions that had produced clear results-either detailed agreements that forestalled further disputes or explicit declarations of impasse.

282 Interview with school official (Case 1, post-mediation) (Nov. 9, 2000); Interview by Grace D'Alo with school official (Case 4, post-mediation) (Nov. 16, 2000); Telephone Interview with school official (Case 4, eighteen-month) (July 31, 2002).

${ }^{283}$ Interview by Grace D'Alo with school official (Case 8, post-mediation) (Dec. 5 , 2000).

${ }^{284}$ School officials' focus upon explicit agreements is reminiscent of Western faith in the rule of law as embodied in contract language, in contrast to Eastern understanding of contracts as simply the beginning of an organic relationship. See Philip McConnaughay, Rethinking the Role of Law and Contracts in East-West Commercial Relationships, 41 VA. J. INT'L L. 427, 464-66 (2001) (discussing the possibility of a "trade-offs between traditional notions of "legal certainty" (involving a lack of discretion) and "new possibilities of commercial stability" (involving commitment to relationships and substantial discretion) and noting that the decisional standard chosen (legal vs. equitable) will affect a procedure's success in effecting accommodation); Kwok Leung \& Michael W. Morris, Justice Through the Lens of Culture and Ethnicity, in HANDBOOK OF JuSTICE RESEARCH IN LAW 343, 360 (Joseph Sanders \& V. Lee Hamilton eds., 2001). In comparing different cultures' preferences and assumptions, Leung and Morris note that restoring harmony and following legal rules represent two very different primary goals for dispute resolution processes. Id. 


\section{The Value of Mediators' Facilitative Interventions}

In light of the current debate regarding the types of mediator interventions that should characterize mediation, this Article examines disputants' reactions to mediators' actions or omissions that fall into the facilitative and evaluative categories. In most of the mediation sessions, the disputants reported that mediators had used facilitative (perhaps also characterized as transformative) interventions designed to generate opportunities for "reciprocal" voice and understanding. 285 These interventions included the management of communication to permit both parents and school officials to make uninterrupted statements, as well as mediators' restatement, clarification, and translation.

As noted previously, in pre-mediation interviews, most parents expressed great interest in being heard but little or no interest in listening to school officials' perspectives. After the mediation session, some parents held fast to this point of view. As a result, these disputants perceived little value in mediators' attempts to restate school officials' positions or rationales. One parent observed: "I'm not interested [in the mediator's articulation of the school district's point of view].... I knew where they were coming from." 286 These parents perceived that they had already heard what the school officials had to say.

A few parents, however, placed special importance upon mediator interventions aimed at facilitating parents' and school officials' reciprocal understanding. These parents, however, had arrived at the mediation session with an interest in understanding the school officials' perspectives:

I would say that overall the mediation process was very beneficial. I felt that it gave me the opportunity to actually voice my concerns and that the other parties were forced to listen and that that was reciprocal.... I really felt the opportunity for the, what I call tit-for-tat. [I appreciated that the] "he said, she said" [and] go[ing] back and forth and ... those issues stopped and were not present during the mediation process .... [That] really allowed for the real issues to come to the surface. ${ }^{287}$

[I appreciated being] allow[ed] ... to make a statement and identify ... how I saw the situation and the problem without being interrupted ... and then also being able to hear their statement.... [I]t

285 My thanks to Bobbi McAdoo for suggesting this term. Telephone Interview with Bobbi McAdoo, Professor of Law, Hamline University School of Law (Mar. 4, 2003).

286 Interview with parent (Case 1, post-mediation) (Nov. 9, 2000).

287 Telephone Interview with parent (Case 11, eighteen-month) (Sept. 16, 2002). It should be noted that in this case, the parents initiated a second mediation session and that the parent's comments may have reflected her experience in both mediation sessions. 
gave me a clearer idea [of] what their perception of the situation was and [what] my perception of it was .... [T] hat ... helped [and] clarified that for me. And I think I know [that] several times through the process [the mediator] clarified several different issues that I was not clear on, or I think the district was not clear on, and he kind of helped us both get a better picture of what the other one was talking about.... So I think he helped several times . . . in clarification. ${ }^{288}$

The value of mediator interventions designed to facilitate this reciprocal voice and consideration may also have found back-handed expression in parents' occasional criticisms of mediators who failed to require school officials to share with the parents their reasons for particular policies and decisions:

I thought [the mediator] could have been a little bit more forceful in getting [the school officials] to explain because as each time. I still don't feel that I got the answer as to what is it about this particular [third party] that is causing this problem that they cannot allow this aide to come into the union. Other districts have done it. What is the difference? And there was no answer. ${ }^{289}$

[In response to the question "Did you feel that the mediator helped you and the school district understand where each other was coming from?'] No. ... [T] hat's our big ... question. What are they doing? What is going on here? ... . Probably from the school district's perspective it's better to keep us not knowing why they make the decisions they do. So we can't plan some counterattack... . [But] I'm not attacking [them], I just want it for my kids. 290

Even though these parents had not necessarily chosen mediation in order to achieve an understanding of the school officials' underlying concerns or to engage in problem solving, they did want to know the basis for the positions taken by the officials. Without the revelation of such reasoning, the parents were at a dead end.

In contrast to parents' mixed appreciation for the achievement of mutual understanding, school officials regularly praised facilitative interventions that served the goals of clarifying the substantive issues (e.g., determining the child's educational and related needs and then determining appropriate ways to meet those needs, determining whether the school's proposed service or

288 Interview by Grace D'Alo with parent (Case 4, post-mediation) (Nov. 16, 2000). 2000).

${ }^{289}$ Interview by Grace D'Alo with parent (Case 11, post-mediation) (Dec. 18,

290 Telephone Interview with parent (Case 3, post-mediation) (Nov. 20, 2000). 
placement was inappropriate and therefore required revision, etc.) and enabling the parties to make progress in problem solving. For example, in some post-mediation interviews, school officials admitted that prior to the mediation, they did not fully understand what the parents wanted or why. They appreciated the mediators' facilitative interventions that helped to clarify for the officials what the parents' (and sometimes their children's) goals and concerns were. For example, school officials pointed to the uninterrupted initial statements that occurred at the beginning of nearly every mediation session as a means "to make sure you're on the same page with what the district's issues are and what the parents' issues are"291 (although, as noted previously, such appreciation was often coupled with complaints about the length and wide-ranging content of the parents' statements). Another official observed:

I'm always of the opinion that going into mediation, even as a participant..., I truly don't understand entirely the parent's perspective.... [S]ometimes having that opportunity to discuss their perspective with a neutral person asking other questions to help clarify their perspective might help to clarify my perspective of what is ... problematic. ... I would never disregard or I would never refuse to go into mediation because I think it's another opportunity for problemsolving and clarification of dialogue. ${ }^{292}$

School officials took notice when mediators helped both parties to achieve mutual understanding and clarification of the issues, which then aided them in reaching resolution:

They were statements that the parent would make and, sometimes, I guess, the parent doesn't always speak the same language we do.... I think because he had the background in the hearing aspect, then he was able to ... bring the two sides together. In other words, "this is what Mom is saying; this is what you folks are saying." 293

[H]aving gone through mediation other times, we've been able to resolve issues thanks to the mediator being there. And what I have seen is that there are times that the parents are on one side of the table and ... they see the school as being totally opposed to what they want, and when the mediator is

291 Interview by Grace D'Alo with school official (Case 11, post-mediation) (Dec. $18,2000)$.

292 Telephone Interview with school official (Case 9, eighteen-month) (July 31, 2002).

293 Telephone Interview with school official (Case 12, post-mediation) (Dec. 20, 2000). 
there, the parents will listen a little bit better to what the mediator says he's hearing, and the school district listens, maybe a little bit.... Emotions sort of go by the wayside. ${ }^{294}$

I think the effect [of the mediation] was that it helped the communication and the relationship.... It almost mended [the relationship].... because. . neither of us were wrong and neither of us were right. And he made us realize that we both had concerns or issues and we were able to figure it all out together. ${ }^{295}$

School officials also noticed when mediators failed to fulfill this function:

I still feel that we need more information about the student and his needs before we can really offer for the program, and I'm not clear as to why [the parent] truly believes her son needs enrichment beyond what we can provide.... Again, I don't think ... the district was... able to communicate. .. I expected [the mediator] ... to facilitate more than he did. When there was a stalemate, [I expected the mediator] to maybe direct or reflect back to get us ... back on track.... It was a revisit to [where] we have been before.... And again, we have lack of closure, we don't have a solution here. ${ }^{296}$

School officials even appreciated mediators' use of reframing and summarization to clarify that the parties were locked in conflicts over nonnegotiable issues. These facilitative interventions at least provided clarity and guidance to the officials ${ }^{297}$ regarding the next steps required to reach resolution:

I think it did [help the situation] because I think it helped the parents and the district to realize exactly where each party was standing, and we knew how far we were willing to go. 298

294 Telephone Interview with school official (Case 2, eighteen-month) (July 25, 2002).

${ }^{295}$ Telephone Interview with school official (Case 4, eighteen-month) (July 31, 2002).

${ }^{296}$ Interview by Grace D'Alo with school official (Case 14, post-mediation) (Dec. 19,2000 ).

297 Some also hoped that clarity was provided for the parents. E.g., Cases 2, 10.

298 Telephone Interview with school official (Case 2, eighteen-month) (July 25, 2002). 


\section{INSTITUTIONALIZED MEDIATION}

Thus, even though the mediators' facilitative interventions did not always help the parties achieve immediate resolution, the school officials appreciated the progress that had been made in understanding the core of the dispute and determining that a consensual resolution was not impossible.

\section{The Value of Evaluative Interventions}

Much of the debate over what form mediation ought to take has centered upon the appropriateness of mediators' use of evaluative interventions. In post-mediation interviews, parents expressed appreciation for mediators' evaluative interventions (e.g., choosing to focus the discussion upon certain issues, ${ }^{299}$ making suggestions for resolution, and providing guidance regarding the relevant law), provided that these interventions were sufficiently grounded in procedural justice. In other words, in those cases in which evaluative interventions were used, parents noticed whether the mediator first provided the parents with sufficient opportunity to express themselves and, even more importantly, also demonstrated an understanding and acceptance of the norms used by the parent to frame the dispute and its potential resolution.

Sometimes, parents perceived mediators' evaluative interventions as not grounded in procedural justice. For example, in one mediation session the mediator recommended a particular solution which became the basis for a tentative agreement. The parent complained after the session, however, that the mediator never gave her the opportunity to make an initial presentation. The parent described the mediation as "contrived" and noted that although the mediator "was a very personable man" and "didn't seem to take sides," she did not fully trust him. She stated: "[W]e maybe have ended up with what we want, but ... there seemed to have been something going on behind the scenes ahead of time.... And I don't know if that's the mediator or the process." 300

In another mediation session, the parents perceived that the mediator "was only interested in how far we had to go [till] ... the bottom line" and that the mediator's focus was on their answer to the question "'How much will you take?' It didn't come across as a 'goal' thought at all."301 As a result, these parents expressed little confidence that the mediator truly

299 Mediators' decision to highlight certain issues and not others and to focus the disputants' continuing discussion upon such issues was coded as evaluative because this function requires the mediator to judge-or evaluate-which topics are deserving of further discussion. See, e.g., Greatbatch \& Dingwall, supra note 100 (describing mediators' selective facilitation in divorce mediation sessions).

300 Telephone Interview with parent (Case 3, post-mediation) (Nov. 20, 2000).

301 Interview with parents (Case 1, post-mediation) (Nov. 9, 2000). 
understood their views. In that case, the parents also scorned the mediator's attempt to argue for the fairness of the officials' offer, particularly because she urged them to compare the school district's offer to "the norm of school districts" thus "set[ting] up the argument that this is standard procedure."302 The parents went on:

Yeah, this doesn't happen. What do you mean? So being wrong is good? I think that's the problem.... I mean that's one of the problems that we run into... So really what we're agreeing to is that we all settle for less, so if we're settling for less for our son, then why can't we just settle for less in the educational system. ... And then we settle for less and ... everybody is just going to settle for less. No one wants to take the higher plane .... [The mediator] present[ed] the ... school district offer as being gracious ... and in reality it [was] ungracious.... It's not gracious to only get away with half. . . . 303

In this case, the parents were very concerned about coming to a resolution that felt like an acknowledgment of the school district's role in their son's situation. The mediator's focus on both the bottom line and school districts' usual practice did not respond to the parents' normative framing of the dispute, and this suggested that the mediator had not truly considered their perspective.

In contrast, when they discerned that mediators understood their concerns, parents valued evaluative actions that helped the participants move toward resolution. At the gentle end of the continuum of evaluative interventions, parents noticed and appreciated how mediators provided coaching regarding the issues which could be used to focus the discussion and make agreement possible: "He [the mediator] helped to make it clear to me where I needed to focus when we did reconvene as to what types of issues to address specifically with the district in order to make progress in the mediation process." 304

When parents perceived that they had been heard and understood and were being treated in an evenhanded, dignified manner, they even reacted favorably to stronger evaluative interventions. In one case, for example, the parent perceived the mediator as quite explicit in explaining to her that the school district had the discretion to place her child in a segregated setting. This was not something that she wanted to hear. However, the parent perceived that the mediator had also listened to her, understood her,

302 Id.

303 Id.

304 Interview by Grace D'Alo with parent (Case 11, post-mediation) (Dec. 18, 2000). 
translated for her, and affirmed her son's right to receive hearing-related services. Under these circumstances, she apparently was ready to consider the evaluative "seed" that he had planted: "I believe what the mediator was able to do was remind me of having to give a little to keep him [the child] in public school, but [also] what their [the school district's] responsibilities were as the LEA [local educational agency] for providing services from the school." 305

Perhaps significantly, in cases that did not reach resolution and in which the mediators refrained from offering suggestions or evaluations, some parents expressed a desire for such interventions:

Even if [the mediator] said to me, "I think you're totally wrong and you're off the wall with what you want; this is what I'm recommending," I would have been happier, even if it wasn't what I wanted... . Because then it would have given me the opportunity to say, "Okay, maybe I'm wrong!". . . . But being left the way it was, you know, nobody gave me any reason to feel that what I'm asking for is wrong. ${ }^{306}$

School officials, like parents, also expressed appreciation for evaluative techniques when such interventions served the goals of clarifying the substantive issue as defined by the school officials (i.e., determining children's needs and identifying appropriate services to meet those needs) and enabling both parties to make progress in problem solving. For example, in one mediation session, the school official observed that "when [the mediator] saw a sort of vacuum, he allowed himself to contribute [ideas]. And I thought that was valuable. It may not be something mediators are trained to do or should do, but in this case I thought that was valuable." 307 In another case, the mediator shared his understanding of the school district's legal obligations and constraints, as well as the district's level of discretion in placing a child. The school official rated this intervention as one of the most helpful events that occurred during the mediation session, noting that the mediator - who was characterized as "very supportive"- "brought forth a point that we hadn't considered." 308 The mediator did not challenge the

305 Telephone Interview with parent (Case 12, post-mediation) (Dec. 29, 2000).

306 Telephone Interview with parent (Case 10, post-mediation) (Dec. 15, 2000).

307 Telephone Interview with school official (Case 3, post-mediation) (Nov. 22, 2000). In the same case, the school official commented on how the mediator behaved in making his suggestions: "He would like throw something out and then just kind of look at both of us .... So most of the negotiation was done right there at the table and he was just kind of reading people's body language." 2000).

308 Telephone Interview with school official (Case 12, post-mediation) (Dec. 20, 
school officials' normative framing of the dispute, but assisted the officials in applying the norms they viewed as relevant. Indeed, like the parents in those mediation sessions that did not result in settlement, and in which the mediator refrained from evaluating the merits or suggesting a resolution, the school officials sometimes said that they wished that the mediators would have contributed in that way.

Concerns arose, however, whenever a mediator began to advocate for a particular resolution or a normative framing that interfered (or had the potential to interfere) with the school official's definition of the problem to be addressed and the norms to be applied:

[The mediator] kept coming back to other mediations and other school districts .... Because of the legislation and the standards being what they are, the standards do not give a definitive methodology for testing or evaluating students. [Each] district has a certain amount of flexibility and leverage to put together a type of process that will be consistent for all students ... so that [an] element of fairness is involved. ...

What about in this particular district...? I've had psychologists or people say thus and such, and yes (she was saying that to us in caucus), but I think it was taking, not respecting what our process was, and saying, "Well our process isn't right. Well, our process might not be right for this particular parent." Of course the parent has an agenda, saying, "I want this kid to receive this label of giftedness." It doesn't mean that because the parent wants this label of giftedness that our process for all kids is wrong. So, it's like saying you need to respect what one district does as opposed to another because the demographics in that particular district is different from one ... is unique from one district to another. And you need to respect the uniqueness of a district. ${ }^{309}$

[Commenting on mediator's initial enthusiasm for a particular option] I think the role of mediator should be a little more, sort of play his cards closer to the vest, maybe not emote so much. Because then you get into a ... partisan sort of situation where... we very quickly were out of the realm of "do these children really need what we are talking about, or [are] we just going to follow our bliss here." 310

School officials also objected when mediators' evaluations had the potential of interfering with the goal of reaching a resolution. In one case, for example, the school official objected to the mediator's decision to "start up" a "technical special ed[ucation] question" because it had the potential to be a

309 Interview with school official (Case 9, post-mediation) (Dec. 11, 2000).

310 Telephone Interview with school official (Case 3, post-mediation) (Nov. 22, 2000). 
"deal killer"311 and to distract the parents from achieving the goal of reaching a consensual resolution regarding their child's educational program.

\section{Disputants' Perceptions of Caucus-A Potent Tool for Enhancing or Diminishing Procedural Justice}

In all but one of the mediation sessions examined here, the mediators used the technique of caucus (or private meetings with the mediator), and the tool emerged from the interviews as a potent device for either enhancing or diminishing disputants' perceptions of procedural justice. A striking number of disputants, particularly parents, raised the topic of the caucus with the interviewers. (The post-mediation questionnaires that served as the bases for the interviews did not even include a question regarding the disputants' perception of this technique.)

In the post-mediation interviews with disputants, some school officials revealed an appreciation for caucus that was based very much on their view of the mediator as a superior conveyor of information. One school official observed that the "most helpful thing" was that he "didn't get into a face-toface negotiation with the parent." The mediator "presented our proposal and came back and forth because that didn't put us in immediate conflict." The school official feared that the discomfort of negotiating "would have been really destructive to our relationship...."312 Because this official-like many others-did not view it as possible to mend relationships in a mediation session, he valued the way in which caucus simultaneously permitted bargaining and buffered both the parents and him from the negative emotions often triggered by distributive negotiation tactics.

The post-mediation interviews with many of the parents and some of the school officials, however, suggest that they evaluated the technique of caucus primarily for its consistency or inconsistency with their desire for a procedurally just process. First, it is important to recall just how important the issue of voice was to the parents. When they were uncertain that the mediator truly understood what they had said and could not hear the mediator's translation for themselves, they raised concerns about the accuracy of what the mediator communicated on their behalf. In one case, the parents observed:

Father: Well, I liked being with the representatives from the school district.... I like having a dialogue face-to-face. I don't like ... caucus

311 Telephone Interview with school official (Case 1, post-mediation) (Nov. 15, 2000).

312 Interview with school official (Case 1, post-mediation) (Nov. 9, 2000). 
very much ... because you can't see into the other person's eyes; you don't get the full read .... [Y] ]our understanding is stilted....

Mother: Well, I think we truly did have a break down in the conversation. And what we were talking about, you lost something in the caucuses, when parties were separated and you're going from room to room; we misunderstood what the other party was saying, so somewhere the translation it got mixed up.

Father: I think going from the group session and the general conversations that we were having to a more specific problem solving was problematic.... I think we could have solved this problem probably in fifteen minutes in a group caucus.

Mother: I believe that too. ${ }^{313}$

As suggested here, parents feared the potential effect of caucus on the quality of the substantive outcomes achieved in mediation:

I don't think each party should have the right to speak on their own without the other party present. ... I honestly feel that if you don't know what each party is saying, how can you really hash it out? ... But when you don't know what . . . transpired in these so-called private conversations, it's very hard I think to try to get a good resolution." 314

The privacy of caucus also may have encouraged some mediators to engage quickly in more aggressive evaluative actions and statements, which disputants then described as "adversarial," 315 "impatient,"316 and "going over the edge." 317 For example, when mediators used the privacy of caucus to try to persuade disputants to accept the validity of the other side's normative frame, both parents and school officials questioned the mediators' impartiality. This is demonstrated in the case described later when the mediator adopted an approach that the parents perceived as "bottom line" 318 and, in caucus, urged them to consider the "norm of school districts." Similarly, a school official reacted negatively to a mediator's evaluation:

I think the perception that she gave to us, especially during caucus, ... [was] that she just didn't understand why we couldn't do this for

313 Interview with parents (Case 1, post-mediation) (Nov. 9, 2000).

314 Telephone Interview with parent (Case 10, eighteen-month) (July 23, 2002).

315 Interview with parents (Case 1, post-mediation) (Nov. 9, 2000).

316 Id.

317 Interview with school official (Case 9, post-mediation) (Dec. 11, 2000).

318 Interview with parents (Case 1, post-mediation) (Nov. 9, 2000). 
a kid. ... I mean, ... we were entering into the realm of not playing devil's advocate, but being biased. You can tell me you're playing devil's advocate . . but yet at the same time it was going over the edge. ${ }^{319}$

Further, caucus led to doubts regarding mediators' impartiality. In one instance, the mediator's use of caucus, coupled with his failure to give the parent an opportunity to make an initial presentation or to disclose that he had worked previously with one of the school officials, led the parent to suspect that the mediator was collaborating with the school district:

I believe [mediation is] somewhat unfair in that I believe decisions were made prior to this [by] [t]he school district and the mediator, or the IU. There was definitely something going on there that we didn't pick up on, that we couldn't put our finger on.... They totally agreed with everything [the mediator] said. At least in front of us. In fact, they left the room first. When we came back after we left the room, they had already made phone calls, starting the process of looking into things with the IU."320

In another case, based on the length and timing of the mediator's caucuses with the school officials, the parent said:

I will tell you that at one point, in all honesty, while we were outside the room I wondered, "Is [the mediator] really impartial?" And that just speaks to my whole mistrust of the whole system at this point.... We can go indefinitely in caucus and talk, talk, talk, talk, talk. That [the mediator] spends so much time with the other side [is] very interesting. [When we got] back to work I started to question [the mediator] objectivity... . [The mediator] left and she was with them for so long, my suspicion was heightened. I mean, I was at the peak of everybody being suspect at that point. And I came to this trying not to but fully expecting an ambush of sorts. ${ }^{321}$

The use of caucus in special education mediation triggered parents' fears regarding exclusion from school officials' discussions, deliberation, and decisionmaking. One parent referred to herself and her husband as feeling like "the odd men out" 322 during the mediation. In another case, the parent noted:

319 Interview with school official (Case 9, post-mediation) (Dec. 11, 2000).

320 Telephone Interview with parent (Case 3, post-mediation) (Nov. 20, 2000).

${ }^{321}$ Interview by Grace D' Alo with parent (Case 8, post-mediation) (Dec. 5, 2000).

322 Telephone Interview with parent (Case 3, eighteen-month) (July 18, 2002). 
I think one of the things that probably was not very helpful was all the time in their caucus. All the time that was given to them in their caucus and then it just, it just, in all honesty, it raised my hackles a bit because I felt more mistrusting of them. Here they go again, meeting in private about my son. ${ }^{323}$

However, caucus was not always a hindrance to procedural justice. Both parents and school officials reacted positively to caucuses when mediators used the technique to provide disputants with a full opportunity to tell their stories or spent time in caucus ensuring that they understood what disputants were saying:

I liked the fact that he listened to what each person had to say. This is, when we were in our private groups, he would come in and address us. He would share with us what perhaps had just taken place with the family, and he would share something, and then he would wait and wait for each person so say something in terms of expressing opinions, whatever. ${ }^{324}$

Mediators' use of caucus also garnered positive reviews when the technique assisted the disputants in engaging in a thorough and dignified deliberative process. For example, when the mediator in one case did not challenge the disputants' selection of a normative frame in caucus, but instead assisted the disputants in a more careful examination and application of the legal norms they had invoked, both the parent and the school official accepted and valued the mediator's evaluative interventions. These disputants also appreciated how the mediator used caucus and other interventions to keep the mediation session from "get[ting] out of control." 325 Indeed, the parent observed, "The private caucuses eliminated the arguments." 326 In another case, a school official noted:

We were able to walk away, [to] take a break and caucus, and to let [the teacher] get some of her frustrations out... and think a little bit more clearly without the parents on the other side. [The] time pressure was taken away. So that's how I think mediation really works well.... [Y]ou're not pressured like you would be sitting in the school and you [don't] feel like you have to come up with some sort of solution right away. There is a mediator there. There is a process that allows you to sort of take a deep

323 Interview by Grace D'Alo with parent (Case 8, post-mediation) (Dec. 5, 2000).

${ }^{324}$ Interview with school official (Case 2, post-mediation) (Nov. 16, 2000).

325 Telephone Interview with school official (Case 12, post-mediation) (Dec. 20, 2000).

326 Telephone Interview with parent (Case 12, post-mediation) (Dec. 29, 2000). 
breath, step back, take a look, and then come back to the table. So I think that is the key. 327

These varying, but strong reactions suggest that caucus represents a potent tool, with significant power to either enhance or diminish disputants' perceptions of procedural justice.

\section{IMPLICATIONS AND PROPOSALS}

\section{A. Implications for Special Education Mediation}

The interviews analyzed here strongly suggest that the procedural justice and progress toward resolution that are offered by special education mediation are central to parents' and school officials' appreciation of the process. The opportunity to speak and to be heard in a setting that is evenhanded and dignified appears to represent, for both parents and school officials, a meaningful improvement over the interaction that they have come to expect-and perhaps dread-in their IEP meetings and informal conversations. In addition, both groups of disputants hope the process will enable them to resolve a pending problem or dispute.

These interviews also reveal differences in emphasis between parents' and school officials' appreciation of procedural justice, likely based upon differences in the roles they play, the consequences they feel, and the power they wield within the context of special education. For the parents, one of the mediators' primary functions appeared to be the enhancement of both the parents' voice and the likelihood of consideration by the school officials. Most of the parents expressed little initial interest in listening to the school officials or engaging in problem solving. Even after the mediation session, the parents continued to emphasize the mediators' assistance (or, occasionally, lack of assistance) with voice and consideration. The school officials, meanwhile, focused early and often upon the mediators' help in clarifying and solving the problem.

The school officials' utilitarian ${ }^{328}$ appreciation of the communication in mediation is consistent with the "self-interest" 329 model of procedural justice which provides that voice and consideration are important because they

327 Interview by Grace D'Alo with school official (Case 8, post-mediation) (Dec. 5, 2000).

328 See generally Jerry L. Mashaw, The Supreme Court's Due Process Calculus for Administrative Adjudication in Matthews v. Eldridge: Three Factors in Search of a Theory of Value, 44 U. CHI. L. REV. 28, 46-48 (1976) (describing the Supreme Court's "implicitly utilitarian" approach to procedural due process).

329 LIND \& TYLER, supra note 21 , at 222-23. 
influence outcomes. ${ }^{330}$ Such an instrumental appreciation of the opportunity for voice and consideration, however, does not fully capture the parents' perspectives. In their pre-mediation interviews, parents often referenced the frustration and sense of disempowerment that they felt as a result of not being heard by school officials. In addition to valuing the enhanced opportunity for voice and consideration because of its potential influence upon the outcome, parents also seemed to view these procedural elements as an affirmation of their importance as "full-fledged member[s] of society"331 who deserve to be heard. The parents' appreciation of mediation thus also invokes the "group-value" 332 model of procedural justice which highlights procedures" "symbolic and psychological implications" for "feelings of inclusion in society and for the belief that the institution using the procedure holds [them] in high regard." 333

This divergence in parents' and school officials' understanding of the "place" of mediation is provocative-and a bit troubling-because it seems to reflect and even have the potential to perpetuate the differences in their relative degrees of power in the special education context. While mediators and mediation advocates may perceive mediation as a process that is separate-a sort of detour or refuge ${ }^{334}$-from both the traditional decisionmaking process and the typical balance of power between parties, the expectations of the parents and school officials involved in this research project seem to be very much framed by their context. ${ }^{335}$ If mediators were to

330 Tyler \& Lind, supra note 31 , at 75.

331 Id.

332 LIND \& TYLER, supra note 21, at 230-31.

333 Tom R. Tyler \& E. Allen Lind, Procedural Justice, in THE HANDBOOK OF JUSTICE RESEARCH IN THE LAW, supra note 24 , at 75.

334 See Vivian Wiseman \& Jean Poitras, Mediation Within a Hierarchical Structure: How Can It Be Done Successfully?, 20 CONFLICT RESOL. Q. 51, 62 (2002) (observing that mediation can be "pursued within a frame that is distinct from the one representing the organizational structure").

335 See Owen M. Fiss, Against Settlement, 93 Yale L.J. 1073, 1080 (1984) (asserting that adjudication, unlike mediation, provides a "conceptual and normative distance" from resource disparity due its grounding in "independent procedural and substantive standards"); Nancy A. Welsh, Remembering the Role of Justice in Resolution: Insights from Procedural and Social Justice Theory, 54 J. LEGAL EduC. (forthcoming 2004) (describing social justice critiques of ADR, particularly concerns that "mediation, arbitration and the other processes do not actually deliver free, equal and public participation and thus cannot be expected to deliver socially just results"); see also Michele Herman et al., The Metrocourt Project Final RePort: A Study of the

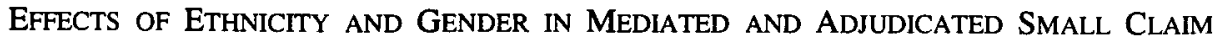
Cases at THE Metropolitan Court Mediation Center Bernalillo County, AlBUQUERQUE, NEW MEXICO viii-xii (1993) (finding that minority litigants were more 
graph the mediation process, many would likely sketch a drawing in which the mediator manages two-way communication occurring in every direction. This drawing would assume reciprocal voice and two relatively equal parties. (See Figure 1).

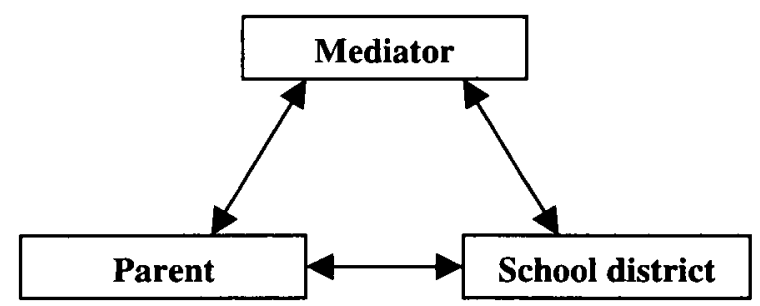

Figure 1. Mediators' Classic Picture of Mediation

Within the context of special education, however, parents' and school officials' understanding of their own roles and that of the mediator does not match this picture. The parents included in this research project viewed mediation primarily as an improvement upon-but not conceptually different from-the IEP meetings with which they were familiar: ${ }^{336}$ where it is the parents' role to present their information and views as persuasively as possible ${ }^{337}$ and the public officials' role to listen, consider, and decide. The

satisfied with mediation processes and outcomes even though mediated outcomes were not as favorable as those received in adjudication).

336 Context often defines expectations. See, e.g., ARTHUR BEST, WHEN CONSUMERS COMPLAIN (1991); LAURA NADER, Alternatives to THE AMERICAN Judicial SySTEM (Laura Nader ed., 1980); Susan S. Silbey, Who Speaks for the Consumer?, 2 AM. B. FOUND. RES. J. 429, 454 (1984):

[E]xpectations come from our experience as members of society. Consumer expectations are generated by the habits and practices of production and distribution; how we routinely buy, sell, and use goods and services establishes concepts of what constitutes adequate service or performance. As socialized beings, we learn of what the world consists, and our own role in it, by exposure and involvement; these Id. interactions come to constitute our definitions of normality.

337 It is beyond the scope of this Article to examine psychological factors that might explain the parents' and the school officials' contextualized pictures of mediation. It is intriguing to consider, however, how parents' and school officials' very different levels of involvement with the events leading up to the identification of a "dispute" could explain their different expectations of their own roles in mediation. For example, Felstiner et al. have noted that an unperceived injury must go through several transformations before it ripens into a dispute. Felstiner et al., supra note 25, at 633-36. Marc Galanter has observed that many identified injuries are never transformed into 
parents' "contextualized" picture of special education mediation appears in Figure 2.

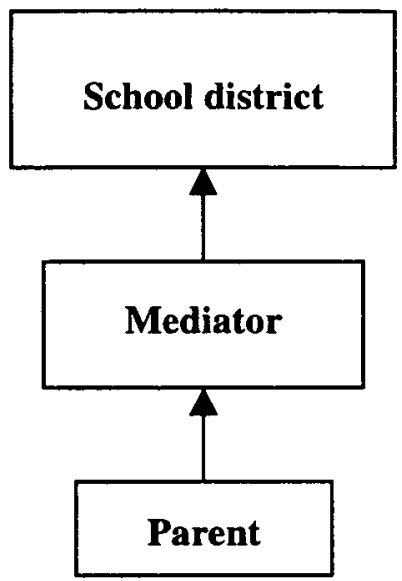

Figure 2. The Parents' “Contextualized” Picture of Mediation

In this picture of mediation, "voice" is one way, the mediator enhances the effectiveness and consideration of this "voice," and the school officials control decisionmaking. The parents do not view mediation as a means to change the power relationship with the school officials. Rather, they view mediation as a means to achieve the respect and attention that they deserve

claims and that the likelihood of such a transformation is particularly low in the area of discrimination. Marc Galanter, Reading the Landscape of Disputes: What We Know and Don't Know (and Think We Know) About Our Allegedly Contentious and Litigious Society, 31 UCLA L. REV. 4, 14 (1983). For many parents then, the very act of making a claim may represent a significant transformation in an escalating conflict. Mediation may then represent just another step in this escalating conflict, rather than an alternative to escalation. As such, mediation may be viewed as an opportunity to contend and persuade, rather than an opportunity for problem-solving. Indeed, the parent may need to be persuaded during the mediation that contention will not work, a stalemate has been reached, and problem-solving is the only remaining option to achieve any sort of resolution. See RUBIN ET AL., supra note 93, at 117-67 (describing escalation of conflict, conditions that lead to stalemate, and how de-escalation begins).

For most of the school officials, in contrast, mediation represents an opportunity to resolve a relatively mild conflict. If the parent forces the school officials to due process, then and only then will this mild conflict begin to escalate into something bigger. See Burrell et al., supra note 65 , at 134 (observing that there is a need for field studies involving disputants with "relational histories and strong commitments to a position" to examine the effect that such disputants' expectations regarding settlement have upon their compliance with mediators' structuring attempts, as well as their perceptions of mediators' control, competence and effectiveness). 
from public officials, if only temporarily. ${ }^{338}$ If Figure 2 accurately reflects most parents' understanding of mediation, it should come as no surprise that the parents valued, first and foremost, the mediators' provision of uninterrupted time for opening statements and their service as translators and even "neutral advocates" who could intercede 339 effectively" 340 on the parents' behalf. Further, it should come as no surprise that parents were sometimes less impressed by mediators' attempts to facilitate mutual understanding or problem solving. ${ }^{341}$ All but one of these parents had never experienced mediation before and had no particular reason to assume that the mediation would offer a substantially different way of interacting with school officials. Further, the concept of being part of a problem solving team may be foreign to parents, who view the school officials as the experts who possess the knowledge, expertise, and access to resources that will be required to develop and implement any educational program. Finally, even though mediators emerged as independent sources of procedural justice for parents immediately after the mediation sessions concluded, it should also come as no surprise that after the passage of eighteen months, parents were more likely to focus on the sense of justice or injustice created by the school officials. This change in emphasis makes sense as soon as one considers that the mediators, actually no more than bit players in the state educational system, disappeared from all of the parents' lives immediately after their mediation sessions concluded. The school officials, in contrast, remained.

The picture of mediation that emerges from school officials' interviews is a bit more muddled. The school officials neither seem to perceive, nor

338 Indeed, parents' anticipation that mediation will provide them with enhanced voice, consideration, and respect may be viewed as a sort of proxy for directly addressing the inequity in their relationship with school officials.

339 This image evokes various religions' practice of turning to specialized saints to intercede-peacefully yet persuasively-on believers' behalf with God. See, e.g., Donald Beschle, The Ambivalence of the Sacred, 16 J.L. \& RELIGION 843 (2001) (book review) (noting that Catholic saints are "intercessors on our behalf"); Ronald Lee, The Rom-Vlach Gypsies and the Kris-Romani, 45 AM. J. CoMP. L. 345, 353 (1997) ("The Rom who receives such a jinx, must then ask a female deity (sainte) to intercede on his behalf .....").

340 This is the case, in part, perhaps, because the mediators seemed to be respected and knowledgeable professionals.

341 Though many mediators may assume that mediation is viewed as a forum for problem-solving or transformation, many of the parents seemed to view it as another, more formalized forum for claiming or contending. See Felstiner et al., supra note 25, at 635-36 (describing claiming); RUBIN, ET AL., supra note 93, at 50-51 (describing persuasive arguments as contentious strategies). 
consciously hope to perpetuate, a power imbalance. ${ }^{342}$ Yet, in both their premediation and post-mediation interviews, the school officials joined the parents in emphasizing mediation as offering a calm setting in which they could better hear and understand the parents' views. Thus, the school officials echoed the parents' view of mediation as an opportunity for largely one-way "voice." But the school officials also paired this expectation with a desire to move from the expression of "voice," to problem solving. If anything, the school officials anticipated that mediation would offer the parents an initial opportunity for enhanced voice and consideration (consistent with Figure 2), followed by education of the parents regarding the appropriate norms to apply in order to resolve the presenting problem, culminating in problem solving that would allow the parents to join the school officials in working within same normative framework. ${ }^{343}$ It should be noted that the school officials anticipated that the appropriate normative framework, which would clarify the problem to be resolved as well as the options available for resolving it, was their framework.

What might the consistent importance of procedural justice, resolution, and the particulars of the special education context suggest regarding the value of special education mediation? Perhaps most clearly, these results

342 But those with power often are unaware of their own privilege. See Peter Coleman, Power and Conflict, in The HANDBOOK OF CONFLICT Resolution, supra note 264 , at 125 .

343 Both the transformation of disputes and the dynamics of attribution may help to explain school officials' desire to educate parents regarding the applicable norms. First, if the applicable educational or legal norms justify the decision made or action taken, the consequences to a child cannot be "named" as an injury. Fate or bad luck is responsible. See Felstiner et al., supra note 25, at 635, 643-44, 646 (observing how unperceived injuries are transformed into perceived injuries, how ideology and law can create a sense of entitlement or disentitlement, and how lawyers can arrest the development of a dispute). Second, even if the injury is named as an injury caused by the official, the parent will be less likely to blame the official if the parent is persuaded that the official's decision or action was largely determined by the situation-here the legal and educational norms that obligate and constrain school officials. See Allred, supra note 264, at 238-41 (discussing process and effects of determining whether another person's actions were intentional or due to external circumstances). The difficulty with this reasoning arises when the parent perceives the current dispute as just one incident within a larger and longer sequence of conflicts. Under these circumstances, the parent is less likely to believe that the official's actions were determined by the situation and more likely to believe that the official is simply disposed to behave in the manner that she did. See RUBIN ET AL., supra note 93, at 116-17 (describing attributional bias as source of negative attitudes and perceptions contributing to escalation of conflict). In this research project, parents frequently explained lack of settlement or lack of long-term resolution by pointing to officials' desire to maintain and exercise power, consistent with the tendency to attribute blame to the other in already-conflicted situations. 
suggest likely differences in emphasis between parents and school officials, both in their expectations and perceptions of the mediation process. It is noteworthy that many parents who elect mediation do not perceive it primarily as an opportunity for problem solving. They (and, to a lesser extent, the school officials) view mediation as an opportunity to finally be heard by the school officials in a sort of improved administrative hearing. They are likely to seek assistance in making their own voices heard and in gaining consideration from the school district. If parents cannot be accompanied by attorneys, they are likely to turn to the mediators for this assistance. The mediators need to be ready and able to serve as responsive translators and coaches, while avoiding becoming partisan advocates. ${ }^{344}$ This is a very difficult distinction of roles and, indeed, may even suggest that parents should be allowed to have attorneys speak on their behalf in special education mediation sessions. ${ }^{345}$

Second, if mediation is meant to accomplish resolution through a procedurally just process, and if the accomplishment of this goal requires the enhancement of reciprocal voice and consideration, and problem solving, ${ }^{346}$ the interviews suggest that more should be done to prepare both school officials and parents for their roles within this process. School officials should understand that they will have an obligation in mediation to listen to parents, to demonstrate that they have heard the parents, and to reveal their own underlying reasons for the positions they have taken (along with the explanations of relevant educational and legal norms that may come more naturally). Parents must be better prepared for the steps that will follow their opportunity to express themselves and the possibility that, despite the enhancement of their voice and the school officials' serious consideration,

344 See Kuriloff \& Goldberg, supra note 153, at 63-66 (suggesting that, in light of the "power imbalances inherent in the relationship [that parents have] with school officials," leveling the playing field may require "involv[ing] mediator-facilitators [in] advising each party in a special education dispute about how to work toward a satisfactory agreement" or creating a "school-based ombudsman for children with special needs").

345 See id. at 55 (finding that parents who reached settlement and were represented by attomey-advocates perceived special education mediation process as fairer than parents who were either unrepresented or represented by non-attorney advocates); see also Welsh, supra note 31 , at 843 (describing procedural justice studies that found that disputants were more likely to perceive a process as fair if they were able to select their own attorneys and perceived the attorneys as advocating on their behalf); UNIF. MEDIATION ACT $\$ 10$ (2001).

346 The following suggestions may also apply to facilitated IDEA meetings which have been proposed for inclusion in the reauthorization of the IDEA. See FEINBERG ET AL., supra note 198, at 36 (describing goals of IEP facilitation as enabling all participants to feel respected and heard-but with a future focus). 
their proposed solutions will not be accepted. How will they then define the problems to be solved? What will be the most important interests to be achieved? What will they need to learn from the school officials in order to move from their initial positions? Will they be satisfied if they can reach an agreement regarding the services to be included in their children's written IEPs, but fail develop a shared vision with the school officials?

Special education mediation programs may benefit from adopting and adapting the pre-mediation education ${ }^{347}$ provided to disputants in other areas of mediation practice. ${ }^{348}$ For example, in victim-offender mediation, the preparation of victims and offenders is considered an essential step in the mediation process. ${ }^{349}$ Meeting individually with the victim and the offender before the mediation session, ${ }^{350}$ mediators help the parties to understand the mediation process, consider whether they wish to participate, organize what they wish to say, and consider various options for resolution. ${ }^{351}$ In the REDRESS program, the USPS has conducted extensive stakeholder training in order to prepare employees and managers for their participation in

${ }^{347}$ In the labor-management mediation as well, a form of pre-mediation education takes place. There, 60 days before a collective bargaining agreement expires, each party must notify the Federal Mediation and Conciliation Service or the responsible state agency regarding the impending expiration and provide the names of contact people. Mediators then contact these people before the expiration occurs. Telephone Conference with Christopher Honeyman, President of Convenor Dispute Resolution Consulting (Mar. $3,2003)$.

348 Some states and local programs have already instituted participant and stakeholder training in negotiation, collaboration, and conflict management to aid in the resolution or prevention of special education disputes. See, e.g., FEINBERG ET AL,, supra note 198, at 26-30 (describing programs in Washington, Oklahoma, Idaho, Oregon, Iowa, Virginia, and Kentucky; also describing other strategies for prevention, resolution of disagreements, and resolution of fully-evolved conflicts), Gail Imobersteg, Evaluation Study of Special Education Dispute Resolution Issues in California: Final Report 13 (Feb. 29, 2000) (unpublished manuscript on file with author) (recommending training in "skills essential to successful mediation") (internal citations omitted). Other options include different roles for the mediator or even the use of ombudsmen.

349 See Mark Umbreit \& William Bradshaw, Victim Experience of Meeting Adult and Juvenile Offenders: A Cross National Comparison, 61 FED. PROBATION 33, 36; see also Alyssa Shenk, Victim-Offender Mediation: The Road to Repairing Hate Crime Injustice, 17 OнIо ST. J. ON DISP. RESOL. 185, 199-200 (2002) (describing a case in which a mediator spent 10 months preparing a mother to participate in a mediation session with the man who had killed her son).

350 See Umbreit \& Bradshaw, supra note 349, at 35. Some programs also conduct this preparation by telephone.

351 See Mark S. Umbreit \& Jean Greenwood, Guidelines for Victim-Sensitive Victim-OfFender Mediation: Restorative Justice Through Dialogue 11-14 (2000) (describing mediators' pre-mediation preparation of victims and offenders). 
transformative mediation sessions. ${ }^{352}$ In the court-connected mediation context, research has found that disputants are more satisfied and perceive mediation as fairer when their attorneys prepare them for the process. ${ }^{353}$

Further, if mediation is to be characterized as a forum that provides both reciprocal voice and consideration and problem-solving, individual mediators and program design can signal this more effectively. Mediators need to be more prepared to probe and even push for explanations and underlying interests from both school officials and parents. Such interventions are fully consistent with Fisher and Ury's long-ago admonishment that negotiators should dig beneath each other's positions to discover the underlying interests that can be used to forge a mutuallyagreeable solution. ${ }^{354}$ Mediators also need to be more prepared to help both school officials and parents use the process as an enhanced opportunity to listen and understand, as well as be heard.

In terms of program design, choices should be made that counteract the impression of mediation as just a kinder, gentler form of administrative decisionmaking. If mediation is meant to try to equalize the power between parents and school officials, the process should be structured to assist in this. ${ }^{355}$ Most of the mediation sessions involved in this research project took place within schools or at school districts' offices. Both parents and school

352 See Hallberlin, supra note 61 , at 381-82 (describing the importance of training over 20,000 Postal Service employees on "the tenets of transformative mediation").

${ }^{353}$ See Wissler, supra note 73, at 686-87 (noting that litigants who had received more preparation from their attorneys perceived the mediation process as fairer; also noting that attorneys who had spent more time preparing their clients and who had more prior experience with mediation also perceived the process as fairer).

354 See generally ROGER FISHER ET AL., GETTING TO YES (2d ed. 1991).

355 Others certainly have distinguished between litigation and mediation in terms of aspiring to treat litigants equally. See Fiss, supra note 335, at 1076-78 (observing that $\mathrm{ADR}$ and settlement assume equality and, in fact, accept inequality as an integral and legitimate component, while "judgment aspires to an autonomy from distributional inequalities...."); Dingwall \& Eekelaar, supra note 253, at 172. Dingwall and Eekelaar note that the formality of the courts constitute:

[A] way of framing the encounter and defining certain attributes of the parties as irrelevant to the outcome. Formal divorce procedures are part of the aspiration to treat each case on its own merits, regardless of the social or economic status of the parties involved. They may not be very effective in this but their removal eliminates whatever restraint they do constitute on the naked oppression of particular groups. The court system can always be challenged for its failure to achieve its ideal of impersonal justice: in mediation justice is by definition personal and the failure to achieve it is an individual weakness not a structural one.

Id. 
officials considered such locations convenient, familiar, and "normal."356 But these locations may not convey the message that parents and school officials will be equal participants and decisionmakers in the mediation process. In the one case that took place in a library, the parent observed: "All the hearings have been within the school building. Having a neutral site alleviated that feeling like you're walking into a war zone." 357 Another key program design cue involves the backgrounds of the mediators. At the time that this research was conducted, few, if any, Pennsylvania special education mediators were parents of children with disabilities. In contrast, experience in education was considered advantageous when applicants were screened for the roster of special education mediators. ${ }^{358}$ It is revealing that experience as an educator was considered helpful while experience as a parent was not. These selection criteria may need to change in order to enhance mediation's capacity to send a stronger signal, particularly to parents, that mediation is meant to facilitate reciprocal voice, reciprocal consideration, and joint problem solving. ${ }^{359}$

Third, these results strongly suggest that special education mediators need to be much more than mere "communication traffic cops." They should be skilled in the facilitative, transformative, and evaluative interventions that are consistent with disputants' perceptions of procedural justice and enable progress toward resolution. ${ }^{360}$ Mediators' respectful but active demonstrations of understanding - through restatement, clarification, and translation-certainly enhance procedural justice perceptions. To the extent that both parents and school officials appreciate the need for reciprocal voice and consideration, mediators' demonstrations of understanding also can facilitate a mutual understanding among the disputants that has the potential

356 See Memorandum from Grace D'Alo, former director of PaSEMS, to Nancy Welsh (Feb. 28, 2003) (on file with author).

357 Telephone Interview with parent (Case 12, post-mediation) (Dec. 29, 2000).

358 Telephone Conference with Grace D'Alo, former director of PaSEMS (Mar. 11, 2003). Consistent with federal requirements, however, none of the mediators were current employees of state or local educational agencies. See 34 C.F.R. § 303.506(c) (2003).

359 Indeed, some studies have suggested that the justice of mediation outcomes may be affected by mediators' racial or group identity. See, e.g., HERMAN ET AL., supra note 335 , at viii-xii (finding that minority litigants were more satisfied with mediation processes and outcomes even though mediated outcomes were not as favorable as those received in adjudication).

360 Other commentators have also suggested the need for a "multidimensional" model of mediation in special education. See Beyer, supra note 188, at 54-56. But see Steven S. Goldberg, Special Education Mediation: Responding to a Proposal for Reform, 30 J.L. \& EDUC. 127, 127-32 (2001) (raising concerns regarding application of evaluative mediation in special education and expressing preference for transformative model that focuses on relationship-building and healing). 
to "build that bridge" bringing disputants to "the path of agreement." 361 Transformative interventions that focus on making parents' and school officials' "recognition" of each other explicit, may even have the potential to produce a shared vision and more lasting resolution. ${ }^{362}$ Evaluative interventions-including focusing the discussion, suggesting solutions, and assessing the merits of disputants' arguments-also can enhance progress toward resolution ${ }^{363}$ and perceptions of procedural justice. Based on the interviews analyzed here, the key seems to be ensuring that mediators refrain from making evaluations until after they have provided the parents and school officials with an opportunity for voice and have demonstrated understanding. It appears that mediators also should confine themselves to helping parents and school officials consider the application of norms that the disputants perceive as relevant and legitimate.

Finally, these interviews suggest that special education mediators should use the technique of caucus sparingly and only in a manner that is consistent with the achievement of procedural justice. Parents in particular may perceive the exclusion that is an integral part of caucusing as inconsistent with their need for voice, consideration, and evenhanded treatment. They cannot observe whether mediators are translating accurately, whether school officials are giving the parents' views dignified and evenhanded consideration, and whether the mediators are behaving in a fair and openminded manner. The technique of caucus is particularly evocative in the special education context, as it replicates the very exclusion that the procedural safeguards in the IDEA were designed to redress. Finally, when caucus encourages mediators to focus on narrow deal-making within the context of a continuing and troubled relationship between parents and school officials, this technique may prove counterproductive in producing lasting resolution.

361 Interview by Grace D'Alo with school official (Case 8, post-mediation) (Dec. 5, 2000).

362 But see Nabatchi \& Bingham, supra note 87 , at 426 (noting that ADR specialists in REDRESS program tended not to observe those aspects of the mediation that "concern the conflict in the context of a long-term relationship" and suggesting the need for mediator training in this area); Dwight Golann, Is Legal Mediation a Process of Repairor Separation? An Empirical Study, and Its Implications, 7 HARV. NEGOT. L. REV. 301, 303 (2002) (regarding lack of data showing that mediation assists relationship-building).

363 The key question here is whether the resolution will be long-term. If it is not, parents' long-term satisfaction with the mediation process is likely to decline. See supra Part IV.B.4; see also Kuriloff \& Goldberg, supra note 153, at 44,60-61. If the goal of special education mediation is a long-term resolution, mediators should use their relationship with parents and school officials in mediation sessions to try to enhance the relationship between parents and school officials both inside and outside the session. 


\section{B. Implications for the Broad Field of Mediation}

Before turning to this study's implications for the broad field of mediation, the context of special education must be acknowledged. Special education disputes obviously involve parents' passionate aspirations and profound fears for their children, and these mediation sessions are likely to be characterized by volatile emotions and vulnerability. The same can be said for other contexts in which mediation is commonly used, such as medical malpractice, employment, divorce, and even certain contract disputes. Special education disputes also share other commonalities with disputes arising in other contexts. Special education disputes pit individuals who perceive that they are entitled to an important benefit against large bureaucratic organizations that control the allocation of those benefits. Many other types of mediated cases-involving issues of civil and consumer rights, employment, administrative law, and even personal injury-similarly involve the competing needs, rights, and obligations of individuals and bureaucracies, as well as issues of power imbalance. Special education cases, like most of the case types just listed, occur within relationships that may have profound and significant personal impacts, but are, at their core, socially-mandated (e.g., citizen-government) or contractual (e.g., consumercorporation or employee-employer). Like many other disputes that find their way to mediation, special education disputes also require difficult legal, medical, and psychological determinations. These cases involve children, but the evaluation of their capacities, the development of educational programs and services to meet their needs, and the delivery of such programs and services are all based on what they are legally entitled to receive under a complex analysis of relevant law and regulation.

Finally, the voices of these disputants should be included because they are especially critical at this stage in the development of the field of mediation. Because dispute resolution professionals themselves have not reached agreement regarding the goals of the process or the most appropriate methods and interventions, the norms of the institutions that have adopted mediation (e.g., the courts, agencies, and corporations) are becoming increasingly dominant ${ }^{364}$ in the mass processing of dispute resolution. Now,

364 See Lisa Bingham, The Next Step: Research on How Dispute System Design Affects Function, 18 NEGOT. J. 375, 376 (2002) (observing that "[w]e may already be witnessing the first mass extinction, as large institutional organisms move in to occupy entire habitats in the civil justice ecosystem"); Lon Fuller, The Forms and Limits of Adjudication, 92 HARV. L: REv. 353, 393 (1978); Nancy Welsh \& Peter Coleman, Institutionalized Conflict Resolution: Have We Come to Expect Too Little?, 18 NEGOT. J. $345,348-49$ (2002) (suggesting that institutionalization of conflict resolution has resulted 
as mediation increasingly adapts to respond to the administrative needs of the institutions in which it is housed, it is particularly important to turn to any and all disputants for their perspectives regarding a process that was meant originally to serve them and to aid their self-determination. ${ }^{365}$

For the broad field of mediation, the themes reported here suggest quite strongly that disputants value mediation primarily for the procedural justice it provides and its assistance in helping them achieve resolution-or at least some sort of progress toward resolution. Quantitative studies have begun to detect the effects of procedural justice and resolution. ${ }^{366}$ The interviews analyzed here affirm that procedural justice and resolution represent the dual cornerstones of mediation's value to disputants - and thus should become the cornerstones for mediator selection, training, and evaluation. ${ }^{367}$

The interviews analyzed here also intimate that the experience of procedural justice may be most important for inexperienced individual disputants who perceive themselves as largely powerless. They seem to value both the dignitary and instrumental significance of the voice, consideration and evenhanded, respectful treatment provided in mediation. The process itself sends the message that they deserve to be heard. In addition, these disputants hope that their views will affect outcomes. For more experienced, more sophisticated or more powerful disputants ${ }^{368}$ - perhaps including the

in focus that is short-term and consistent with "upholding the stability and established norms of a larger society"). The institutions that have embraced mediation are likely to view the process as a mechanism for ending a disruption in a manner that is as efficient and consistent with the institution's pre-existing norms as possible. Institutions are less likely to value mediation for its potential as "another locus in American political, social and legal life where ideas about equality are defined and redefined." Isabelle Gunning, Diversity Issues in Mediation: Controlling Negative Cultural Myths, 1995 J. DISP. RESOL. 55,86 .

365 of course, some important program design characteristics of the special education mediation program studied here must be acknowledged. The mediation sessions were voluntary, not mandatory, and attorneys did not accompany either the parents or the school officials. Obviously, these program design characteristics distinguish this mediation program from many court-connected programs.

366 See Guthrie \& Levin, supra note 95 , at $891 \mathrm{n} .19$ (listing studies showing the importance of procedural justice to disputants' satisfaction with mediation); Shack, supra note 95; Welsh, supra note 31 , at 834 (describing research that has shown that procedural justice concerns apply to mediation).

367 There may be some examples of such a focus. See, e.g., Waldman, supra note 8, at 14 (noting that Family Mediation Canada's top evaluation criterion focuses on the mediator's maintenance of a respectful, trusting relationship with the participants).

368 See Austin Sarat \& William L. F. Felstiner, Law and Social Relations: Vocabularies of Motive in Lawyer/Client Interaction, 22 LAW \& SOC'Y REV. 737, 740 (1988) (observing that while clients in their dealings with lawyers interpret events "in 
business executives interviewed by Professor Lande ${ }^{369}$ and the attorneys interviewed or surveyed by Professors McAdoo, ${ }^{370}$ Gordon, ${ }^{371}$ and Macfarlane ${ }^{372}$ - such reassurance is less important, and a procedurally just process has only an instrumental value. These disputants and representatives focus upon mediation's usefulness as a forum for clarifying and solving problems in a reasonably fair and prompt manner-and enabling the disputants to move on. ${ }^{373}$

To the extent that the views of more powerful and sophisticated users of mediation (e.g., lawyers, agency heads, and corporate officers) dominate the design and evaluation of institutionalized mediation programs, ${ }^{374}$ the understanding of mediation as a tool for efficient resolution has the potential to eclipse mediation's importance as a means to affirm individual citizens' social standing. Indeed, an exclusively outcome-oriented understanding of procedural justice is reflected in the U.S. Supreme Court's due process jurisprudence. ${ }^{375}$ Many of the cases that are mediated-personal injury, contract, employment, and special education-involve individual disputants who have never had the opportunity to tell their stories in a dignified, evenhanded setting. ${ }^{376}$ Depending upon its implementation, mediation can

terms of their impact on the self," lawyers are more likely to consider "technical rules and a problem-solving orientation... [as] more important than emotional reactions and justifications of self').

369 See Lande, supra note 121, at 161-65.

${ }^{370}$ See McAdoo, supra note 6, at 411-23; McAdoo \& Hinshaw supra note 36, at 483.

371 See Gordon, supra note 70, at 377-78; Gordon, supra note 68, at 224-26.

372 See Macfarlane, supra note 69, at 279-88 (2002) (describing Canadian attorneys' evaluations of mediation and mediators).

373 See Mitchell, et al., supra note 4 (describing her corporate employer's preference for mediators who use whatever techniques are required to bring closure); JANE W. Adler et al., Simple Justice: How Litigants Fare IN the Pittsburgh Court ARBITRATION PROGRAM 76, 83 (1983). Unlike "unsophisticated individual litigants," institutional litigants who made extensive use of the arbitration program "appear[ed] to care little about qualitative aspects of the hearing process.... They judge arbitration primarily on the basis of the outcomes it delivers." Id.

374 The views of lawyers, agency heads, and corporate officers also are likely to affect mediators' understanding of the role they need to play in order to get business. See Bush, supra note 99, at 113-16 (describing market demand for evaluative mediation); see generally Mitchell et al., supra note 4.

375 This jurisprudence focuses on ensuring the "accuracy" of decisionmaking. See Welsh, supra note 237 , at $187-90$.

376 Since most cases are resolved before trial, the only opportunities for such story telling would occur in the drafting of pleadings, the drafting of memoranda in support of 
offer them just this opportunity. In the court-connected context, mediators' and attorneys' increasing tendency to view disputants' opening statements in joint session as an inefficient distraction from resolution may evidence insensitivity to the psychological and social importance of procedural justice. ${ }^{377}$ If mediation is meant to serve all disputants, more should be done to reach out to inexperienced, individual disputants and understand their perceptions of the value of mediation and particular interventions-even if those perceptions and preferences (like the desire to have their stories "on the record" and to have mediators serve as "neutral advocates") conflict with the bottom line orientation of dispute resolution professionals or more sophisticated disputants.

Disputants' dual appreciation for the procedural justice and resolution offered by mediation also has implications for the different mediation models and interventions that have arisen in the past decade. The voices of the parents and school officials included here affirm some of the central underpinnings of the model of transformative mediation. The parents, in particular, clearly valued those aspects of mediation that enhanced their voice and increased the likelihood of gaining respectful consideration from the school officials. The disputants' appreciation of these benefits is consistent with the transformative model's emphasis upon empowerment and recognition. But imaginary conversations with imaginary disputants also have been used to support transformative mediation's claim that mediators should not have settlement as one of their goals. Conversations with real parents and school officials reveal that disputants enter mediation in order to achieve resolution and value mediators' interventions that help them achieve that goal in a procedurally just manner. Resolution in this and perhaps most contexts is the desired end of a procedurally just mediation process. Indeed, it could be argued that resolution inevitably represents a "value-added" for disputants who are currently mired in unresolved conflicts. ${ }^{378}$

motions, motion hearings, and in depositions. None of these avenues seem likely to satisfy disputants' desire for procedural justice.

377 See Welsh, supra note 31, at 809-13 (describing marginalization of joint session and bargaining research that supports this development).

378 Thus, disputants seem to value mediation's potential to improve their situation, even if such improvement is not accompanied by a personal transformation. See BUSH \& FOLGER, supra note 9, at 84 (observing that "problem-solving mediation defines the objective as improving the parties' situation from what it was before. The transformative approach instead defines the objective as improving the parties themselves from what they were before"). Perhaps these disputants' more limited goal of improving the situation reflects a Westem individualistic skepticism regarding the ability to change people's dispositions. See Leung \& Morris, supra note 284, at 354 (observing that the Chinese have greater belief than Americans in the malleability of people). It is also 
The disputants' apparent dual appreciation of mediation similarly seems to offer partial affirmation and partial critique of evaluative mediation's focus upon delivering resolution. The disputants interviewed here certainly sought resolution. In addition, however, they needed to know that mediators' evaluations were grounded in (and legitimized by) a procedurally just process. ${ }^{379}$ They needed to know that they had the opportunity to speak. They needed to know that the mediator had heard and considered what they said. They needed to perceive that the mediator was fair and respected them. ${ }^{380}$ Interestingly, the facilitative techniques of restatement and clarification appear particularly effective in assuring disputants that they have been heard and understood by the mediator-and perhaps even by each other. ${ }^{381}$ This may suggest that evaluative mediation, like transformative mediation, offers only half a loaf. Evaluative interventions will be valued if they are preceded by and based upon the understanding and respect that characterize procedurally just processes. ${ }^{382}$

possible that these disputants' more limited goal reflects a level of "identification-based distrust" which is best addressed by developing explicit agreements regarding expected behaviors. See Roy Lewicki \& Carolyn Wiethoff, Trust, Trust Development, and Trust Repair, in HANDBOOK OF CONFLICT RESOLUTION, supra note 264, at 98 (contrasting identity-based trust, calculus-based trust, identity-based distrust, and calculus-based distrust and suggesting strategies to build trust and manage distrust).

379 This is consistent with the procedural justice research that has been done, most of which has taken place within the context of adjudicative processes. See Welsh, supra note 31 , at 817-38 (describing procedural justice research and its application to mediation).

380 Indeed, evaluation can be part of a normative or moral dialogue. See Robert P. Burns, Some Ethical Issues Surrounding Mediation, 70 FORDHAM L. REV. 691, 708-99 n.62 (2001) (discussing evaluation's potential to be consistent with and even to enhance "moral dialogue" if it is done in a manner that treats the other as rational and autonomous).

381 See Pearson \& Thoennes, supra note 65, at 17 (observing that the production of an agreement in divorce mediation was more likely in those cases in which "mediators spent more time discussing possible solutions and brainstorming options; for their part, spouses spent more time exhibiting empathetic understanding of the other points of view").

382 The reactions of the parents and school officials to mediators' evaluative interventions seem to mirror research that has shown that in the attorney-client relationship, client satisfaction is heightened when attorneys' counseling is grounded in their referent power (power emerging from a positive relationship with the client) rather than their legitimate power (power based on attorney's social role as authority) or expert power (power based upon attorney's knowledge or expertise). See ROBERT COCHRAN ET AL., THE COUNSElor-AT-LAW: A COLlaborative APPROACH TO CliENT INTERVIEWING AND COUNSELING 114-16 (1999) ("The more referent power counselors gain, the more likely their clients will listen to their counselors, be satisfied with the advice, and comply 
Further, these interviews affirm that mediation, like any other process, reflects and perpetuates certain norms. Such norms are particularly salient in evaluative interventions, as the mediator begins to reveal his own framing and assessment of the parties' dispute. The voices of these real disputants suggest that the often-ignored dimension on Professor Riskin's original grid-how the mediator identifies the issues to be resolved in mediation ${ }^{383}$ is critical, particularly as mediators begin to use evaluative interventions.

Of course, a normative choice is being made whenever a particular frame is adopted to define the "problem" to be addressed by a mediation session. In the interviews described here, parents and school officials used two different, yet equally legitimate, normative frames. The parents often identified the underlying dynamic that brought them to mediation in terms of power imbalance. For them, the dispute was grounded in two related problems: the bureaucracy's inability or unwillingness to understand and accommodate the unique needs and potential of children and the school officials' inability or unwillingness to hear parents' voices and treat them as meaningful participants in designing children's educational services. The language of the IDEA provides some basis for this normative framing by the parents. The IDEA promises "individualized" education that will meet children's

with the chosen course of action."); see generally Michael Watkins, Principles of Persuasion, 17 NEGOT. J. 115 (2001) (describing overlap between those qualities and behaviors that enhance perception of fair process and leader's ability to persuade).

Others have also suggested that the value of evaluative interventions depends upon its grounding in procedural justice. See Dwight Golann, How Mediators Can Help with Relationship Repairs, 19 ALTERNATIVES TO HIGH COSTS LITIG. 193-97. Golann speculates that even though the reconciliation of relationships rarely occurred in cases studied:

[t]he most likely source of disputants' satisfaction . . . is that mediation provides a fundamentally different kind of settlement process [because] it allows adversaries to bargain more rationally and civilly; to tell their story directly to the other side, express painful emotions and perhaps receive an acknowledgment; and to reconcile themselves gradually to outcomes short of victory. Indeed, it can be argued that a process which helps ease disputants' path to an amicable 'divorce' is just as valuable to them as one that enabled troubled relationships to continue.

Id.; see also Zumeta, supra note 23, at 340 (reporting that she "received constant complaints from clients who had participated in evaluative mediation and were quite offended by the process [because] [ $t$ ] hey felt they were not really heard, and that they did not have any influence on the outcome"); see also Julie Macfarlane, Why Do People Settle?, 46 MCGILL L.J. 663, 668-69 (2001) (arguing that settlement depends more upon the disputants themselves and their experience of conflict than upon rational risk assessment).

383 Riskin, Grid, supra note 47 , at 18-23. 
needs, ${ }^{384}$ and the Third Circuit has made it clear that Pennsylvania school districts' educational policies will not be allowed to stand in the way of appropriate individualization of educational services. 385 "Individualization" requires an understanding of a child's unique needs. Further, as the Supreme Court observed, ${ }^{386}$ Congress took pains in the procedural safeguards of the IDEA to make parents meaningful participants in the decisionmaking regarding their children's education. These legislative and judicial pronouncements (as well as the Pennsylvania Department of Education's description of parents' role in mediation) ${ }^{387}$ could indeed be understood as dictating that special education mediation should have as its primary goal the development of real partnerships between parents and school officials so that they can truly develop and implement "individualized" educational programs. 388

But the language of the IDEA and the decisions of the Supreme Court and federal circuits also provide school officials with justification for their normative framing of mediation's purpose. They are ultimately responsible for providing a "meaningful educational benefit" to children served under the IDEA. They are not required to maximize these children's potential but to provide "appropriate" educational services within the context of their states' educational policies for all children. ${ }^{389}$ The courts have proclaimed the need to defer to local and state educational agencies, not parents, as society's designees to decide educational policies. Ultimately, the school officials are not held accountable for the health of their partnerships with parents or their

384 See 20 U.S.C. \$ 1414(d).

385 Polk v. Central Susquehanna Intermediate Unit 16, 853 F.2d 171, 172 (3d Cir. 1988) (stating that blanket rules denying particular services violate IDEA because the are, by definition, not individualized).

$386 \mathrm{Bd}$. of Educ. of Hendrick Hudson Central School Dist. v. Rowley, 458 U.S. 176, 205 (1982).

387 The Pennsylvania Department of Education describes mediation a process in which parents play an essential role and are actively involved the development of their children's educational plans. See http://www.pde.state.pa.us/special_edu/.

388 See D'Alo supra note 100, at 210 (describing importance of building relationships to genesis of Pennsylvania special education mediation program); Goldberg, supra note 360, at 131 (urging that special education mediation should become a process "that genuinely builds relationships and is a true healing process that brings people together for its original purpose: to develop a program, while saving time, money, and emotion"); Imobersteg, supra note 348, at 49 (reporting that while survey results showed that the majority of parent and school representatives thought that mediation had helped the parent-school relationship, a majority of the parents perceived mediation as hurting the relationship while school officials were almost evenly divided).

${ }^{389}$ Rowley, 458 U.S. at 181. 
facility in customizing educational services. ${ }^{390}$ The partnerships are merely the means to an end, and customization can only go so far before it begins to impede the ability of the system to sufficiently meet all children's needs. It is little wonder, then, that school officials value mediation to the extent that it helps them fulfill their responsibilities and exercise their discretion responsibly. It also should not be surprising that the school officials appreciate those mediation sessions that focus on providing them first with clarity-clarity regarding the problem, clarity regarding children's needs, clarity regarding the services that will appropriately meet those needs, and clarity regarding their obligations under the final agreement-followed by education of the parents regarding the appropriate norms to be applied and finally, if possible, an improved relationship with the parents.

At the moment, it is not clear which of these two legitimate frames defines the purpose of special education mediation. ${ }^{391}$ What is clear from the interviews with disputants described here is that when mediators use evaluative interventions, disputants care about the answers to the following norm-related questions: Did the mediator adapt to the disputants' definition of the issue(s) to be addressed in the process and the norms to be applied to its (their) resolution, or did the mediator impose her own definition of the issues and norms? When there were conflicts between the disputants' definitions of the issues to be addressed in the mediation sessions or the norms to be applied to its (their) resolution, whose definition (or normative framing) was embraced by the mediator and thereafter served as her focus for the mediation sessions? And, as mediation is institutionalized, it may even be appropriate to consider the answer to a third question: If the mediation session is court-connected or agency-connected or corporation-connected, must the mediator's definition of the issues to be addressed and the norms to be applied be consistent with the mission of the sponsoring institution? ? $^{392}$

These interviews also suggest that the technique of caucus, which has become increasingly dominant in increasingly evaluative court-connected mediation, deserves much more attention from researchers, mediators,

390 But see Handler, supra note 34 , at 1010-12 (describing a Madison, Wisconsin program that made parents "part of the solution to special education rather than the problem").

391 Congress certainly did not provide any such guidance in IDEA. Rather Congress appeared to value special education mediation primarily for what it was not-a timeconsuming, expensive, and adversarial due process hearing.

392 See Deborah Hensler, Suppose It's Not True: Challenging Mediation Ideology, 2002 J. DISP. RESOL. 81, 97-98 (arguing that courts should provide fact- and law-based dispute resolution and that courts should not incorporate either pure interest-based mediation or transformative mediation). 
trainers, and policy makers. ${ }^{393}$ This technique, more than any other, has the potential to bring mediation's dual goals of procedural justice and resolution into conflict. Sequential caucusing has been described as "uniquely mediative" 394 and invaluable for overcoming strategic barriers and avoiding the communication of harmful, higher order information. ${ }^{395}$ Like many very helpful drugs, however, caucus can be toxic if it is used without restraint. Disputants perceived caucus as a helpful and important part of the mediation process when mediators used the technique to ensure that the disputants had a full opportunity to express themselves or that the mediators sufficiently understood the disputants' perspectives. Similarly, disputants valued caucus when the mediators used their individual meetings with the disputants to assist them with the application of the norms they viewed as relevant or to coach them regarding how they might communicate or frame their demands/offers more effectively once they returned to joint session. Indeed, used in this way, caucus could be conceptualized as serving procedural justice by enhancing the dignity of-as well as the opportunity for voice and consideration in-the joint session in mediation. ${ }^{396}$ On the other hand, when the use of caucus dominated the mediation session or the mediator used the privacy of caucus to advocate for the appropriateness of a particular perspective or a particular bargain, disputants voiced a variety of objections. Some perceived that the caucus had prevented the airing and joint consideration of relevant information. ${ }^{397}$ Some began to question the impartiality and open-mindedness of the mediator. Others perceived themselves as excluded from the group that was making the real decisions within the mediation session. Ultimately, these observations suggest that the

393 This is particularly true for those types of mediation that frequently involve oneshot players. Some researchers have begun to notice the impact of caucus. See, e.g., Nabatchi \& Bingham, supra note 87, at 426 (observing that several mediator behaviors, such as caucusing "were noted to both foster and interfere with empowerment and recognition" and raising the question: "[W]hen are these behaviors consistent with the transformative model and when are they not?").

394 Jennifer Brown \& Ian Ayres, Economic Rationales for Mediation, 80 VA. L. REV. 323, 325-26 (1994).

395 Ian Ayres \& Barry J. Nalebuff, Common Knowledge as a Barrier to Negotiation, 44 UCLA L. REV. 1631, 1633-34 (1996-97).

396 Conceived in this way, caucus would serve in much the same way that pre-trial conferences with judges originally focused on improving the quality of the impending trial.

397 See also Nabatchi \& Bingham, supra note 87, at 413, 418 (in evaluating the performance of transformative mediators, ADR specialists also raised concerns about caucus and its potential interference with empowerment and recognition). 
increasingly dominant use of caucus as a bargaining tool, 398 despite its effectiveness in producing settlements, has the potential to endanger the goal of offering an experience of justice in mediation. Caucus should be viewed as a supplement to the joint session, not as its surrogate. 399

The voices of these disputants finally suggest that rigid distinctions between transformative, facilitative, and evaluative interventions are much less important than the answers to the following questions: Were the mediators' interventions preceded by and grounded in a procedurally just process? Did the mediators' interventions assist the disputants in making progress toward resolution of the issues they had identified and using norms they perceived as legitimate? The voices of these disputants may even be understood to suggest that "quality" mediation requires the use of appropriate facilitative and transformative and evaluative interventions that serve procedural justice and resolution, rather than the development of niches for mediators with different "orientations." 400

\section{CONCLUSION}

When Alice stepped through the looking glass, she eagerly anticipated seeing "such beautiful things" 401 that would be "as different as possible" 402 from the rather tedious reality of her drawing room. And, indeed, she saw just what she had dreamed she would. Like Alice, we mediation advocates

398 See Welsh, supra note 31 , at $809-13$; JOHN W. COOLEY, THE MEDIATOR's Handbook: Advanced Practice Guide for Civil Litigation 177 (2000) ("Besides listening, the caucus is your most important tool for achieving settlements.").

399 See Christopher Moore, The Mediation Process 318 (2d ed. 1996) (describing the need to determine how to return to joint session from caucus).

400 This inference would affirm the choice made by PaSEMS not to exclude any type of mediation practice. But this inference also would compel PaSEMS and other institutionalized mediation programs to ensure that their mediators are skilled in all types of interventions. See also Nancy Welsh \& Barbara Gray, Searching for a Sense of Control: The Challenge Presented by Community Conflicts Over Concentrated Animal Feeding Operations, 10 PENN ST. ENV. L. REV. 295, 313-14 (2002) (reporting that stakeholders in CAFO-related disputes sought third parties who would engage in both facilitative and evaluative interventions); Nancy A. Welsh \& Debra Lewis, Adaptations to the Civil Mediation Model: Suggestions from Research into the Approaches to Conflict Resolution Used in the Twin Cities' Cambodian Community, 15 MEDIATION Q. 345, 352 (1998) (observing that respondents preferred third parties who were fair, nonjudgmental, and understanding but also would engage in evaluative interventions).

401 Lewis Carroll, Alice IN Wonderland and Through the Looking Glass 161 (1923).

402 Id. at 162. 
are also likely to see what we hope to see, influenced by our own professional experiences and aspirations. Some of us have been drawn to the magical, sometimes almost mystical ${ }^{403}$ differences to be found between mediation and the "quite common and uninteresting" 404 variations of adjudication. ${ }^{405}$ But in a field devoted to the self-determination of disputants, we need to focus on-and work to discover-what the disputants see. Ultimately, the voices of real disputants may call us to step back through our own looking glass, and there we may discover that mediation (regardless of the particular model) and adjudication are more alike than they are different. Both should respond to the same yearning-for procedural justice and resolution, which are not such "common and uninteresting" goals after all.

${ }^{403}$ See Gary Gill-Austern, supra note 57, at 348 n.16

I am reminded of Judaism's understanding of four levels of textual interpretation. The levels are: Peshat-literal meaning; Remez-allegorical meaning; Derashmoral or homiletic meaning; and Sod-mystical meaning. Not all students reach Sod or Derash or even Remez. A pedagogy, however, that teaches Peshat without an awareness of the other three levels is empty, for it is the awareness of partiality that precludes the Peshat student from thinking that she knows the secrets of the tradition. It teaches the student humility. Thus, if for the uninitiated mediator we must speak of openings, collecting information, defining issues, generating and exploring options for settlement, and so on, it is only for the purpose of anchoring the novice and setting her or him on course.

404 Carroll, supra note 401, at 161; see Gary Gill-Austern, supra note 57, at 347-48 (arguing that "what is at stake in the present discussion regarding mediation is the living and being of the alternative as a way to enliven and transform the tradition" with each "in dialectical tension with the other").

405 See Della Noce, supra note 9, at 552-53 (describing mediation as a "unique social process" that is independent of litigation). 


\section{Pre-Mediation Interview Instrument}

\section{Background Questions}

1. [If not available from written record] How did this dispute originate and what steps have been taken so far?

2. What has your experience been in trying to communicate or negotiate with the other person about this so far?

3. Why do you think that this dispute has not already been resolved?

4. Why did you decide to go to mediation?

5. Would you tell me what you expect the mediation process to be like?

\section{Outcome Questions}

1. Can you tell me what you hope to achieve in mediation?

2. What would success be? What would failure be?

3. What would satisfy you?

4. If you reach a resolution in the mediation, how do you think that you ought to feel about the resolution?

5. [If no mention of fairness] Is it important to you that the resolution feel fair?

6. How will you decide whether the resolution was fair or unfair?

7. How important is it that if mediation is not successful in helping you resolve your dispute, that you know you can go to a due process hearing?

\section{Process Questions}

1. What do you hope to be able to do or say in the mediation session? Why?

2. To whom do you want to be able to do or say this? (e.g., self, advocate, another representative)

3. Who do you want to be sure hears what you say? (e.g., other person, mediator)

4. What assistance do you want from the mediator? What do you think that the mediator could do or say that would be most helpful in the mediation? Why would this be most helpful? 
5. What do you want from the other side? What can they do or say that would be most helpful in the mediation? Why would this be most helpful?

6. How do you think that the mediation should feel? What do you think that the mediator could do or say to help it feel that way? What can you do? What could the other side do?

7. [If no mention of fairness] Is it important to you that the mediation process feel fair?

8. How will you decide whether the mediation process was fair or unfair?

\section{Demographic information}

1. Relationship between interviewee and child (e.g., mother, father, guardian)

2. Age of child

3. Grade

4. Length of time since child was diagnosed as having special education needs

5. Length of time that child has been in this school

6. Length of time that child is likely to continue in this school

7. Description of relationship between interviewee and other participant in mediation

8. Prior experience, if any, with mediation or due process 


\section{Post-Mediation Interview Instrument}

\section{Background Question}

- Was the mediation what you expected it to be?

\section{Outcome Questions}

1. Did you achieve what you wanted to achieve through the mediation process?

2. Was the mediation a success or a failure? Why?

3. [If a resolution was reached] How do you feel about the resolution? Why? What about the resolution makes it feel this way?

4. [If no mention of fairness] How fair would you say the resolution was: very fair, somewhat fair, neither fair nor unfair, somewhat unfair, or very unfair?

5. [If no resolution was reached] Why do you think mediation did not result in a resolution of your dispute?

6. Did you feel you had control over the outcome? Why or why not?

\section{Process Questions}

1. What happened in the mediation session that was helpful?

2. What happened in the mediation session that was not helpful?

3. Were you able to do or say what you wanted to do or say in the mediation? Why or why not?

4. How would you describe the mediator? Which of the mediator's characteristics do you think were most important in this mediation?

5. What did the mediator do or say (or how did the mediator behave) in this session that you felt was important? Why was this important?

6. Of those things that the mediator did or said, what was helpful? [If more than one] Which were most helpful? Why?

7. Of those things that the mediator did or said, what was not helpful? [If more than one] Which were least helpful? Why? 
8. [If responses to 1-7 do not result in responses that relate to procedural justice or negotiation] Did the mediator [see a-f below]? Was that: helpful, neither helpful nor unhelpful, or not helpful? How did the mediator do that?
a. Allow you to tell your story?
b. Treat you in a respectful and dignified way?
c. Understand what you said?
d. Consider what you said?
e. Help you to negotiate?
f. Help the other side to negotiate?

9. [If responses to $1-7$ do not result in responses that relate to facilitative-evaluative-transformative debate] Did the mediator [see a-l below]? Was that: helpful, neither helpful nor unhelpful, or not helpful? Why?

a. Help you clarify your goals?

b. Help you communicate with the other person?

c. Structure the process so that you had a good chance to tell your side of the story?

d. Encourage you to talk about your concerns and goals?

e. Encourage you to talk about how you felt?

f. Help you and the other person understand where each other was coming from?

g. Summarize the important things that you and the other person said?

h. Ask you what would happen if this case went to due process?

i. Explain to you what would happen if this case went to due process?

j. Help you and the other person to work together to come up with ideas for how to resolve this dispute?

k. Suggest ways to resolve this dispute?

1. Recommend a resolution that the mediator thought would be fair? 
10. Did the mediator apply too much pressure or was the mediator not forceful enough?

11. Was the mediator fair to all sides or biased toward one side? What do you base your conclusion on?

12. Did you trust the mediator? Why or why not?

13. We've talked about the things the mediator did and didn't do or say here. Which were most helpful to you? Why?

14. How did the mediation process feel to you? Why?

15. What about the process made it feel this way to you?

16. What did the mediator do or say that made it feel this way to you?

17. [If no mention of fairness] All in all, how fair would you say the process was: very fair, somewhat fair, neither fair nor unfair, somewhat unfair, or very unfair? Why?

18. How much control did you feel that you had in the mediation process: substantial control, somewhat control, neither one way or other, little control, no control? What made you feel that way?

19. How important do you feel that you were in this process? Did this matter to you? What made you feel the way that you do?

20. All in all, how satisfied are you with the mediation: very satisfied, somewhat satisfied, neither satisfied nor dissatisfied, somewhat dissatisfied, or very dissatisfied?

21. What about the process made you feel this way?

22. What did the mediator do or say that made you feel this way?

23. What, if anything, did the other side say or do that made you feel this way?

24. What, if anything, did you do that made you feel this way?

25. Would you use mediation again? Why or why not?

26. Is there anything else that is important for me to know about the mediation process or the mediator?

27. Can I pass your comments [or particular information] along to the mediator of your case? 


\section{8-Month Post-Mediation Interview Instrument}

1. What would you like to tell me, if anything, about the mediation process that took place in November-December 2000 ?

2. Did the mediation process have any effects? (On relationships? Services provided?)

3. (If an agreement was reached) Did the mediated agreement last? Why or why not?

4. Do you think the mediation process helped the situation? Why or why not?

5. At this point, how satisfied are you with the mediation that took place in 2000: very satisfied, somewhat satisfied, neither satisfied nor dissatisfied, somewhat dissatisfied, or very dissatisfied? Why?

6. Anything else you would like to tell me? 